\title{
The impact of exposure to violent music on undergraduate college males' state anger, affective, physiological, and aggressive behavioral action responses
}

\author{
Kristee Hamm Treadwell \\ West Virginia University
}

Follow this and additional works at: https://researchrepository.wvu.edu/etd

\section{Recommended Citation}

Treadwell, Kristee Hamm, "The impact of exposure to violent music on undergraduate college males' state anger, affective, physiological, and aggressive behavioral action responses" (2006). Graduate Theses, Dissertations, and Problem Reports. 2499.

https://researchrepository.wvu.edu/etd/2499

This Dissertation is protected by copyright and/or related rights. It has been brought to you by the The Research Repository @ WVU with permission from the rights-holder(s). You are free to use this Dissertation in any way that is permitted by the copyright and related rights legislation that applies to your use. For other uses you must obtain permission from the rights-holder(s) directly, unless additional rights are indicated by a Creative Commons license in the record and/ or on the work itself. This Dissertation has been accepted for inclusion in WVU Graduate Theses, Dissertations, and Problem Reports collection by an authorized administrator of The Research Repository @ WVU.

For more information, please contact researchrepository@mail.wvu.edu. 
The Impact of Exposure to Violent Music on Undergraduate College Males' State Anger, Affective, Physiological, and Aggressive Behavioral Action Responses

Kristee Hamm Treadwell

\author{
Dissertation submitted to the \\ College of Human Resources and Education \\ at West Virginia University \\ in partial fulfillment of the requirements \\ for the degree of
}

\author{
Doctor of Philosophy \\ in \\ Counseling Psychology
}
Department of Counseling, Rehabilitation Counseling, and Counseling Psychology

\author{
Morgantown, West Virginia \\ 2006
}

Keywords: violent music, state anger, positive and negative affect, physiological responses, aggressive behavioral action responses

Copyright 2006 Kristee H. Treadwell 


\begin{abstract}
The Impact of Exposure to Violent Music on Undergraduate College males' State Anger, Affective, Physiological and Aggressive Behavioral Action Responses
\end{abstract}

Kristee H. Treadwell

The current study addresses the potential negative impact of exposure to violent lyrical music on West Virginia University undergraduate college males' state anger, affective, physiological and aggressive behavioral action responses. In addition, relationships between the following variables were also examined: (a) level of trait anger and aggressive behavioral action responses, (b) level of trait anger control and aggressive behavioral action responses, (c) level of trait anger expression and aggressive behavioral action responses, (d) overall anger expression index and aggressive behavioral action responses, (e) daily music listening and aggressive behavioral action responses, and (f) prior music exposure and aggressive behavioral action responses. Music preference influence on aggressive behavioral action responses was also explored. Parametric and nonparametric procedures were utilized to test the research questions. The results of the study revealed that college males exposed to violent lyrical music and subsequently provoked report more aggressive behavioral action responses compared to no music (control) participants. No significant difference in number of aggressive behavioral action responses were found between the violent lyrical and non-violent lyrical groups. Exposure to both violent lyrical and non-violent lyrical music did not impact participants level of state anger or positive and negative affective responses. A significant positive correlation between total number of aggressive behavioral action responses and trait anger was indicated for the violent lyrical participants. No significant between group differences in systolic (SBP) and diastolic blood pressure (DBP) and heart rate (HR) responses were found among the violent lyrical, non-violent lyrical and no music participants. Yet, upon comparing baseline SBP and post-music SBP, within group differences were revealed among both violent lyrical and non-violent lyrical participants. Clinical implications and limitations are discussed as well as suggestions for future research. 


\section{Dedication}

For my husband, John, who with his unfailing love and support makes all things possible. 


\section{Acknowledgements}

The culmination of the pages that follow would not have been possible without the support and guidance of many individuals. First, the chair of my committee, Margaret Glenn, Ed.D., who was always willing to go the extra mile in helping me accomplish this feat and who made me believe in myself that such an endeavor was possible. I cannot express enough thanks to her for her guidance and support during this endeavor. Next to acknowledge is my committee: Bob Marinelli, Ed.D.; Roy Tunick, Ed.D., Kevin Larkin, Ph.D. and Deborah Hendricks, Ed.D. who offered essential guidance and feedback that enabled me to offer the scholarly product that is before you. I would especially like to thank Kevin Larkin, Ph.D. who graciously offered the facilities necessary to make this research possible and who was always willing to lend a helping hand when needed. A special thanks is also in order for Dr. Hendricks, better known as "DJ," for her patience and guidance in helping me to understand at times that which seemed incomprehensible. I am truly grateful to these individuals for their willingness to invest their time and energy into facilitating my growth and development as a writer and research scholar.

In addition to Dr. Larkin's assistance, this research could not have taken place without Benjamin Parker's and Ryan McPeak’s unrelenting willingness to help out as my study confederates. I cannot thank each of them enough for taking a significant amount of time out of their own schedules and lives in general to help make this research possible.

I would also like to acknowledge the staff at WVU's Carruth Center for their continuous support during the completion of this document. I cannot express enough gratitude to these individuals for their encouragement that helped me to keep my chin up during times in which completion of the task at hand seemed questionable. I especially want to thank Cathy Yura, Ed.D. for her understanding and compassionate words of encouragement that helped me to press on until completion.

Thank you also to my family and friends who never ceased to encourage me with their kind words.

Finally and foremost, I want to acknowledge my husband, John, who was willing to put his life and needs on hold, yet cheered me on every step of the way. Thank you for believing in me and helping me to believe in myself and for always reminding me that I could do this especially during times of doubt. Words cannot express how much I appreciate all of your support and assurance. This accomplishment is yours too! 
Table of Contents

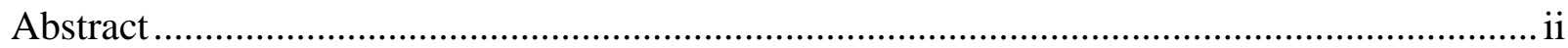

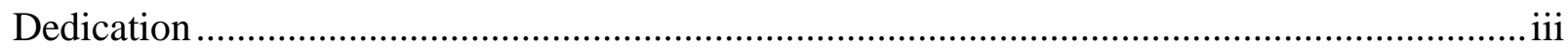

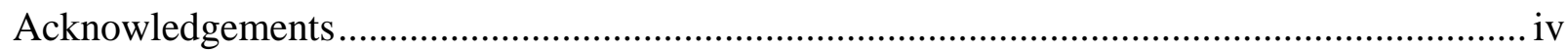

Table of Contents .....................................................................................................

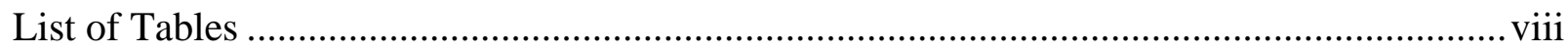

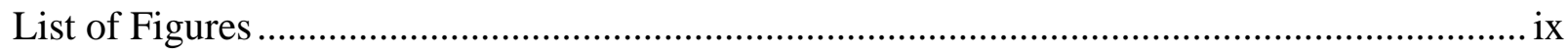

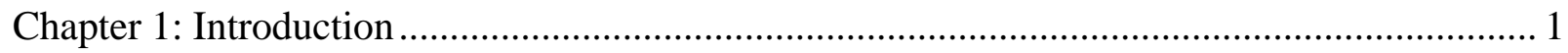

Violent Television Programming and Related Impact............................................ 1

Violent Movies and Related Impact ............................................................... 3

Violent Video Games and Related Impact........................................................... 3

Music Video Violence and Related Impact ....................................................... 5

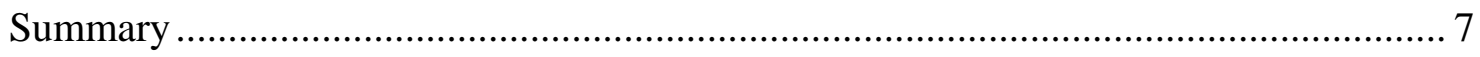

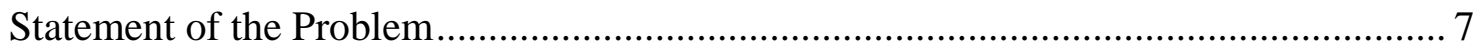

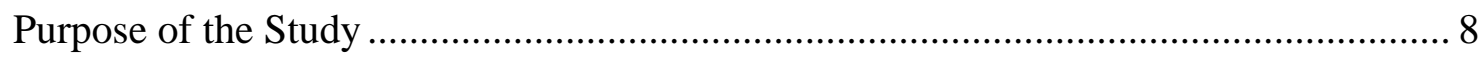

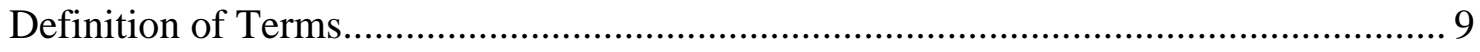

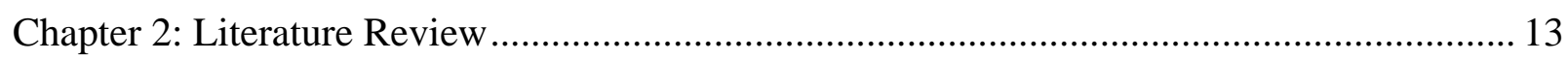

Music Preferences and Related Responses ......................................................... 13

Violent/Aggressive Audio Music and Exposure Effects ....................................... 14

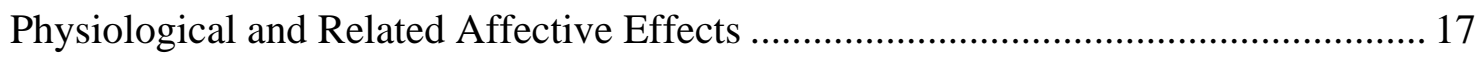

Cognitive and Related Affective Effects ........................................................... 20

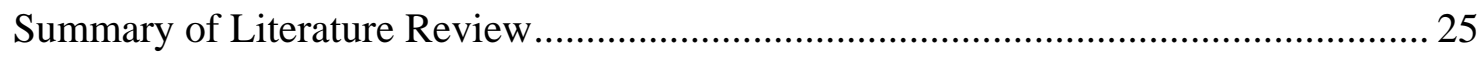

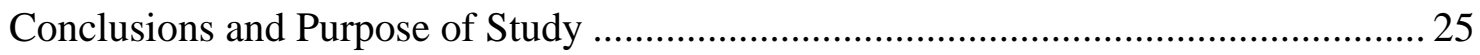




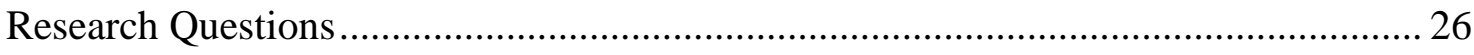

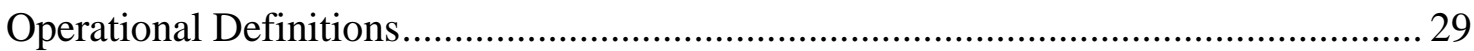

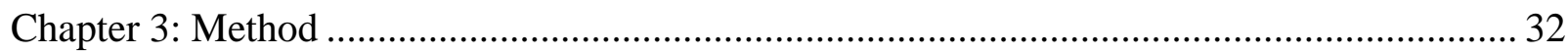

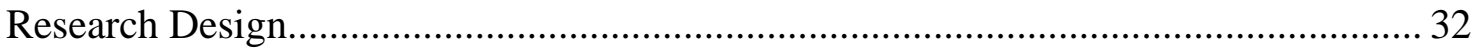

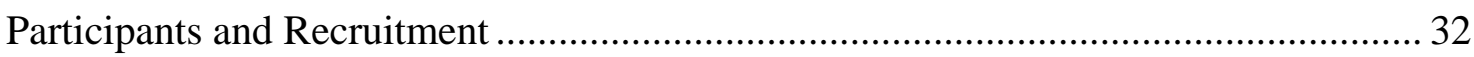

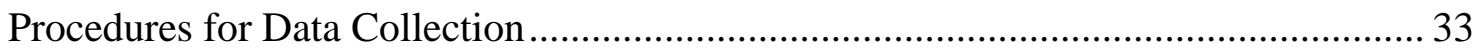

Independent and Dependent Variables ........................................................................ 37

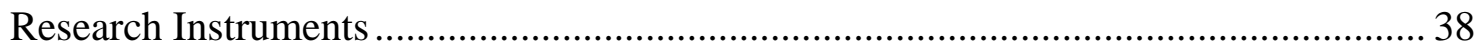

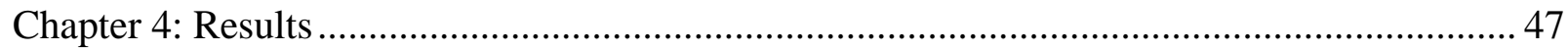

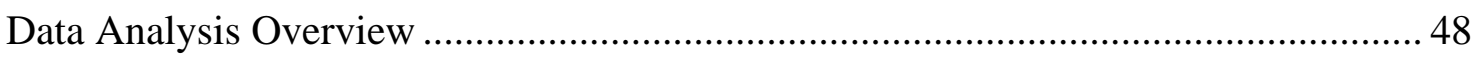

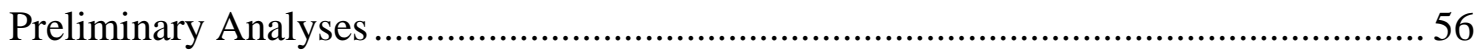

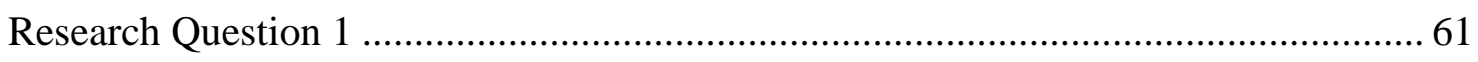

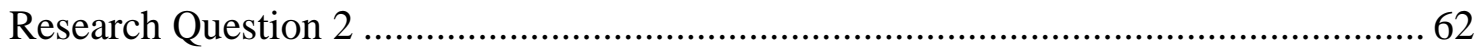

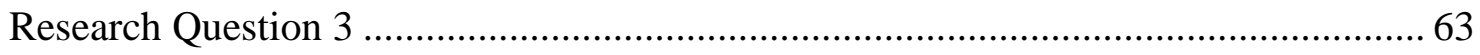

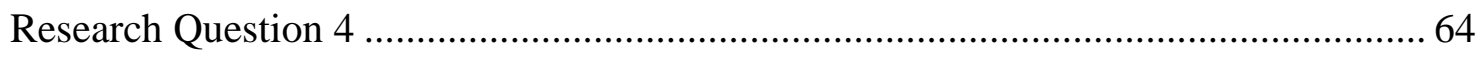

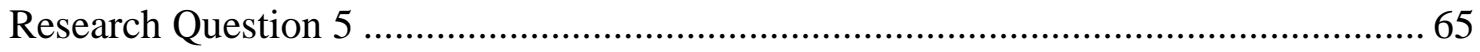

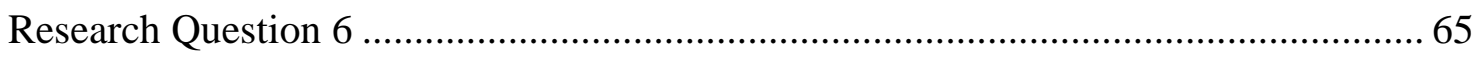

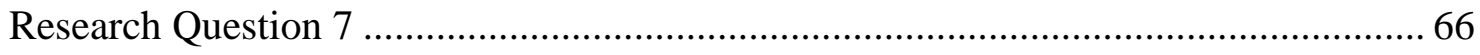

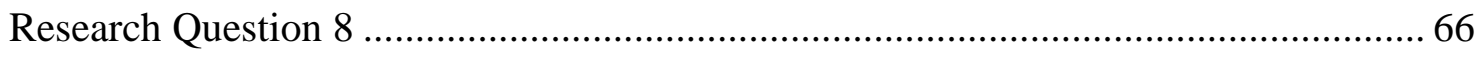

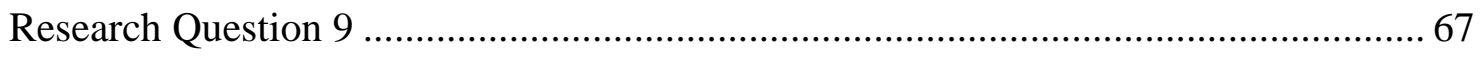

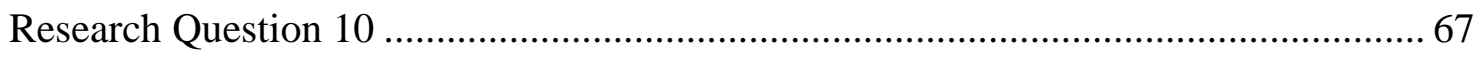

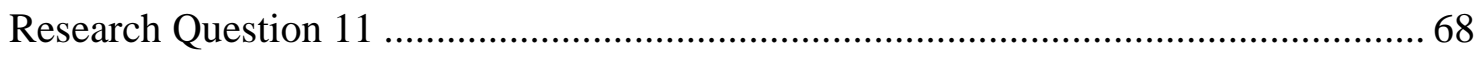

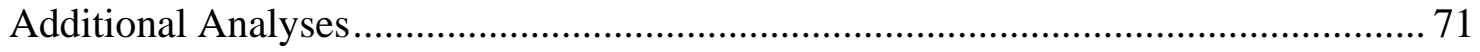




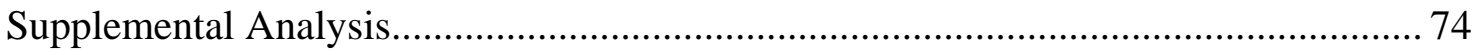

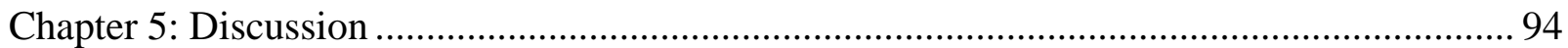

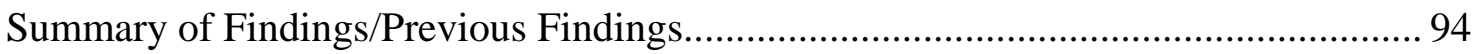

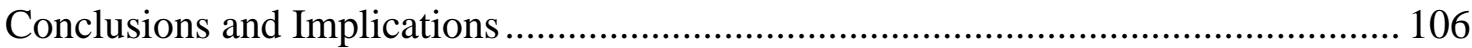

Limitations of Study ................................................................................. 108

Future Research Recommendations................................................................. 109

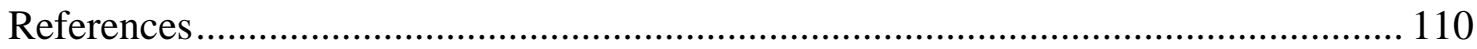

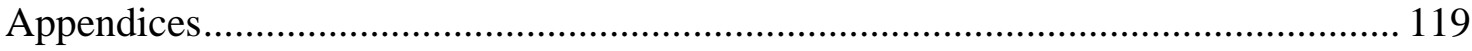

Appendix A: Recruitment Flyer.................................................................... 120

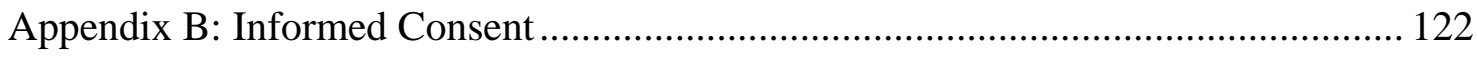

Appendix C: Demographics Questionnaire ....................................................... 126

Appendix D: State-Trait Anger Expression Inventory-2 .................................... 128

Appendix E: Positive and Negative Affect Schedule ............................................. 129

Appendix F: Cook-Medley Hostility Scale........................................................ 130

Appendix G: Aggressive Provocation Questionnaire (Modified ............................... 131

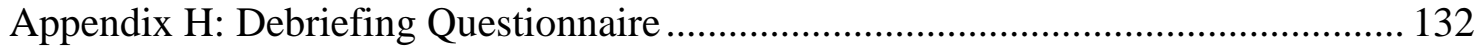

Appendix I: Summary Tables for Physiological Analyses ..................................... 134 


\section{List of Tables}

Table 1. Procedural Timeline with Measures ................................................................. 36

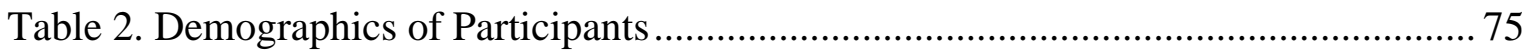

Table 3. Music Preferences of Participants.................................................................. 77

Table 4. Research Question 1: Summary of Significant Findings................................... 78

Table 5. Means and Standard Deviations for Research Question 1................................. 79

Table 6. Means and Standard Deviations for Research Question 2............................... 80

Table 7. Means and Standard Deviations for Research Question 3................................ 81

Table 8. Means, Standard Deviations and Correlations for Violent Lyrical Group ........... 82

Table 9. Means, Standard Deviations and Correlations for Non-Violent Lyrical Group ... 83

Table 10. Means, Standard Deviations and Correlations for No Music Group................. 84

Table 11. Means and Standard Deviations for Research Question 9............................... 85

Table 12. Means, Standard Deviations and Correlations for Trait Hostility ..................... 86

Table 13. Means, Standard Deviations and Correlations for Lyrical Understanding......... 87

Table 14. Level of Lyrical Understanding and Representation ................................... 74 


\section{List of Figures}

Figure 1. Mean State Anger Across Phase and Group.................................................. 88

Figure 2. Mean Negative Affect Across Phase and Group.......................................... 89

Figure 3. Mean Systolic Blood Pressure Across Phase and Group ................................ 90

Figure 4. Mean Diastolic Blood Pressure Across Phase and Group................................. 91

Figure 5. Mean Heart Rate Across Phase and Group .................................................. 92 


\section{CHAPTER 1}

Introduction

Since the late 1940s, scientists, policy makers, and the American public have become increasingly concerned about the potential harmful effects of exposure to media violence. During the last four decades, there has been a significant amount of scientific inquiry focused on the relationship between violent media exposure and subsequent acts of violence (Huesmann, Moise, \& Podolski, 1997).

There appears to be one specific finding that has consistently emerged in media violence studies: Exposure to the mass media has been associated with both aggressive behavior as well as aggressive attitudes among exposed individuals (Huesmann, Moise, \& Podolski, 1997). More specifically, media depictions of violence (e.g., television, movie, video game, print advertising, rock music and music videos) have been suggested to influence both the attitudes and behavior of youth including their rate of engagement in at-risk and violent behavior as well as their overall adjustment (Hoberman, 1990; Strasburger, 1995). The authors of these studies maintain the need for the development of media portrayals that stigmatize or punish actors who engage in violent behavior and the need for education of adults in exercising appropriate critical viewing skills to better assist adolescents' television viewing discretion.

\section{Types of Violent Media}

Violent television programming and related impact. Much attention has been given to exploring the presence of violence in television programming since its advent in the early 1950 s. A review of television programming in the late 1970 s found that $15 \%$ of all nationally viewed programs were categorized as having intensive violent content (Huesmann \& Eron, 1986). A subsequent study reported a finding of between five and six acts of violence per hour during 
prime time television programs and between 20 and 25 violent acts during Saturday morning children's programs (Gerbner \& Signorelli, 1990). Other findings have indicated the presence of violent content in $57 \%$ of all television programs, and $33 \%$ of these programs were found to have very violent content resulting in an overall 19\% rate of very violent television programming (Mediascope, 1996). In addition, results of a 1992 study indicate that approximately 9.5 violent acts occurred per hour during prime time television programs, while thirty-two acts of violence occurred per hour during Saturday morning children’s programs (Goldstein, 1994).

A number of studies have examined the negative effects of violent television programming on television viewers' individual responses. Two such studies found significant effects in those who were exposed to violence in this format. Josephson (1987) investigated the relationship between exposure to television violence and aggression among male students in grades 2 and 3. They found an increased rate of aggressive responses among male students exposed to a violent television condition compared to a nonviolent television condition. Drabman and Thomas (1974) examined the influence of aggressive televised film on 22 male and 22 female third and fourth grade students' tolerance for real-life aggression. The participants were randomly assigned to one of two conditions: (a) exposure to an aggressive cowboy televised film clip or (b) exposure to no televised film. The participants were then asked to watch two small children via a video monitor. The results indicate that children exposed to the aggressive televised film clip exhibited a longer response latency period prior to seeking adult help when the children whom they were viewing progressively became abusive toward one another. The televised film group participants were tolerant of behavior up to the point of physical aggression and destruction before they sought help for the children on the video monitor. 
Violent movies and related impact. Research studies have explored the behavioral impact of exposure to violent movies among participants from various age groups. Adolescents $\left(4^{\text {th }}\right.$ and $5^{\text {th }}$ graders) participating in research that replicated Drabman and Thomas's study (1974) exhibited higher tolerance for aggressive behaviors when first exposed to a violent movie clip (Molitar \& Hirsch, 1994). This substantiated the findings from the 1974 study while using a more time appropriate media in an experiment to determine differences among participants viewing a violent movie clip or an Olympic competition movie clip.

Analysis of emotional arousal when viewing violence supplements research regarding behavioral impact. Frost and Stauffer (1987) examined the effects of media film, or movie, violence on the emotional arousal of participants who represented differences related to gender and income levels. Participants completed the Eysenck Personality Questionnaire and were exposed to two minutes of nonviolent material and movie depictions of 10 forms of violence. Participants' skin conductance and blood pulse volume were measured to determine degree of arousal following exposure to the violent film media. The results indicated that neither gender nor personality measures were related to arousal, but arousal did vary with type of film violence exposure.

Violent video games and related impact. The advent of the video game introduced a previously unseen form of visually interactive entertainment and was viewed as a technological advancement. It is also another form of media that can influence the user/viewer. It has the potential for serving as a negative influence because they are frequently found to contain violent elements. For example, the very first video games included violent fantasy with the goal of the games being to terminate other characters (Anderson \& Bushman, 2001; Worchel, Cooper, 
Goethals, \& Olson, 2000). Video games have since evolved into more high tech, graphic representations with more realistic characters killing or being killed in violent ways.

More and more individuals are reportedly engaging in the play of video games and are, thus, being influenced by such violent video games. A survey of seventh and eighth grade middle-class American students revealed that approximately $67 \%$ of the girls reported playing video games between one and two hours in their home, while approximately $20 \%$ reported playing video games at arcades. Ninety percent of the boys reported playing video games in their home while $50 \%$ reported playing video games in arcades (Funk, 1993). The percentage of participants engaging in significant play can be considered substantial. Violent games, among the boys, were preferred over those with an educational intent (50\% versus 2\%) (Funk, 1993). In addition, a subsequent study conducted in 1999 found that $14.8 \%$ of freshman college males played 6 hours of video games each week while $2.5 \%$ played more that 20 hours per week (Cooperative Institutional Research Program, 1999).

The influence of these video games on different age groups has been reported in separate research projects. They reported significant changes in behavior, attitudes and physiological responses. Silvern and Williamson (1987) compared the effects of exposure to a violent video game among children between the ages of 4 and $6(\mathrm{~N}=28)$ and found that both the violent cartoon and video game increased the level of aggressive free play among the children exposed to the violent media. A year earlier, Cooper and Mackie (1986) examined the effects of violent video games on the behavior of 10 and 11 year-old children and found that the violent video game increased the exhibition of aggressive behavior among the child players. Later, Ballard and Wiest (1996) investigated the impact of violent video games on the physiological and attitudinal responses of male college students. The results of the study suggested that playing 
violent video games can contribute to an increase in physiological arousal and hostile attitudes among male college students.

Music video violence and related impact. Another recent source of concern has been the influence of music videos. The introduction of an all-music video channel, MTV, in 1981 brought notoriety to the music video industry (Huesmann, Moise, and Podolski, 1997). An initial study indicates that music videos are predominantly viewed by individuals 12 to 34 years of age. In addition, the reported average viewing time is one hour each weekday and approximately an hour and a half on the weekend (Hansen \& Hansen, 1990). A later study indicated that music videos are viewed in over 55 million homes and that music videos are considered to be the most popular form of media influence (Strouse, Buerkel-Rothfuss, \& Long, 1995). A subsequent study also indicated that music videos are often characterized as having violent content (Huesmann, Moise, \& Podolski, 1997). Another study reported that 50\% of music videos include one or more violent action scenes (Huston et al., 1992).

Researchers have made an effort to determine the impact of exposure to violent music videos on individuals' responses. There appears to be a correlation between viewing and resultant behavior. One study investigated the effects of a hospital administration's ban on viewing MTV on the aggressive behavior of 222 forensic patients over a 55 week period (Waite, Hillbrand, \& Foster, 1992). The results suggested that the elimination of music video viewing was associated with a statistically and clinically significant decrease in the frequency of the patients' overt aggressive behavioral displays. Another related study examined the effects of rock video exposure on college students' thoughts and attitudes about suicide $(\mathrm{N}=133$, mean age $=19.1)($ Rustad, Small, \& Jobes, 2003). Participants were first exposed to either a suicide music video or a neutral video. The researchers assessed impact on mood, priming of suicide 
related thoughts, perceptions of personal risk, sensitivity to suicidality in others, and attitudes and beliefs about suicide. The results suggest that exposure to a music video having suicidal content appeared to significantly increase the occurrence of suicide-related cognitions among normal young adults (Rustad, Small, \& Jobes, 2003).

Another resultant behavior investigated by researchers relates to perceptions of dating violence. Significant interactions between gender and video exposure were found in a study limited to African American participants 11 to 16 years of age (Johnson, Adams, Ashburn \& Reed, 1995). Participants were assigned to one of the following conditions: (a) nonviolent rap video exposure depicting images of women in sexually subordinate roles or (b) no video exposure. Subsequent to the exposure, participants were asked to read a vignette that involved teen dating violence perpetrated by a male. The results suggested that males acceptance of dating violence was not impacted by exposure to the videos. However, female participants who were exposed to the rap video exhibited a greater acceptance of dating violence compared to the female participants who did not view the video. A second study chose to investigate the impact of exposure of violent rap, nonviolent rap, or no music video exposure on a similar population. The results indicated that participants exposed to the violent rap music video condition exhibited greater acceptance of the use of violence and expressed a higher probability that they would themselves engage in violent behavior compared to participants in the nonviolent rap and control groups (Johnson, Jackson \& Gatto, 1995). These studies cannot be generalized to the larger population of adolescents because of the limitations in ethnic representation among the participants. 


\section{Summary}

The majority of the studies to date related to the impact of violent media exposure have examined visual modes of media influence, including television and film and their effect on behavior. The findings of such research has shown that violent messages both auditory and visual in nature can be found in the media across its various forms including television, movie, video game, print advertising, music, and music videos. Such violent representations appear to have negative effects on its viewing or listening audience, which often includes children, adolescents and college students. The negative effects are varied and include increased aggressive behavioral and attitudinal responses, increased acceptance of and tolerance for violence, and increased negative affective and physiological responses. More attention in research is warranted to further clarify the potential for harm associated with exposure to violent media in its various forms.

\section{Statement of the Problem}

The effects of exposure to violent music in audio form has been an area that has received significantly less attention compared to violent music videos. As a result, more attention has been given to the potential negative effects of being exposed to violent audio music within the last decade. Yet, more carefully controlled experimental examination of the effects of music violence on behavioral responses warrants further investigation. Also, more attention needs to be given to this area of research in an effort to clarify the actual impact of violent audio music exposure given that previous studies have produce mixed findings regarding actual impact of violent music exposure. In addition, while previous studies have researched similar constructs, some studies described the music to which individuals were exposed to be negative or explicit while others described their exposure music to be violent. There appears to be confusion 
regarding whether or not both types of music will affect individuals in the same way. Thus, the current study will clearly define the exposure music as being violent in an effort to specifically delineate the effects of exposure to violent lyrical music.

More specifically, violent music exposure among college students is an area of concern. The results of a 1982 survey of college students regarding popular music and its influence on social values found that $48 \%$ of college students indicated a belief that music influences values while $82 \%$ reported a belief that music lyrics may have the potential to influence values subconsciously (Toohey, 1982). A portion of these college students sampled (28\%) reported that they listened to music five or more hours per day. Given that college students report a significant amount of their time each day listening to music in audio form, more attention to investigating potential negative effects of exposure to violent audio music among today's college students is necessary.

Previous studies have also consistently indicated higher levels of both physical and verbal aggression among males compared to females (Archer, Kilpatrick, \& Bramwell, 1995; Buss \& Perry, 1992). Undergraduate college males may be particularly vulnerable to potential negative effects on their aggressive behavioral action responses upon exposure to violent music media, and therefore, this population should be examined in more detail.

\section{Purpose of the Proposed Study}

While a number of studies have examined various variables that may be negatively affected upon exposure to aggressive or violent music, much less attention has been given to uncovering the effects of such exposure on individuals' behavioral responses and, therefore, the behavioral component associated with such exposure warrants additional examination. Further, according to Anderson, Carnagey, and Eubanks (2003), additional research regarding the 
potential negative effects on individuals' behavioral responses following exposure to violent music is now more imperative given research evidence which clearly demonstrates that violent music increases aggressive thoughts and feelings among exposed individuals.

The current study will address the potential negative impact of exposure to violent lyrical music on undergraduate college males' aggressive behavioral action responses. In addition, the degree to which exposure to violent music affects undergraduate college males' state anger, anger and related feelings, affective (positive and negative), and physiological (heart rate and blood pressure) responses will be the subject of the current investigation as well.

\section{Definition of Terms}

\section{State Anger Response}

State anger refers to the current intensity of one's angry feelings as measured by the State Anger scale of the State-Trait Anger Expression Inventory-2 (STAXI-2; Spielberger, 1999).

\section{Trait Anger Response}

According to the STAXI-2 (Spielberger, 1999), trait anger is defined as one's general predisposition to experience anger. More specifically, trait anger reflects the degree of one's anger temperament, or the disposition to experience anger without being provoked, and the degree of one's anger reaction, or frequency to experience angry feelings upon being provoked. Anger Expression-Out Response

Anger expression-out refers to how often one expresses anger outwardly (Spielberger, 1999).

\section{Anger Expression-In Response}

Anger expression-in refers to how often one experiences anger but does not express it, instead suppressing anger (Spielberger, 1999). 


\section{Anger Control-Out Response}

Anger control-out is defined according to the STAXI-2 (Spielberger, 1999) to be the extent to which one outwardly exerts control over anger.

\section{Anger Control-In Response}

Anger control-in is defined according to the STAXI-2 (Spielberger, 1999) to be the extent to which one makes an effort to inwardly control anger through calming or cooling off oneself.

\section{Anger Expression Index}

The anger expression index is described as the overall measure of one's anger expression and control tendencies (Spielberger, 1999).

\section{Trait Hostility}

Trait hostility indicates an individual's degree of character "dislike for and distrust of others" (Cook \& Medley, 1954).

\section{Affective Responses}

Affective responses refer to different positive and negative emotions that one is experiencing in the present moment as defined by the Positive and Negative Affect Schedule (PANAS; Watson, Clark, \& Tellegen, 1988). Examples of positive affective experiences include feeling attentive, interested, alert, excited, or enthusiastic, while examples of negative affective experiences include feeling distressed, angry, fearful, guilty, or jittery.

\section{Aggressive Behavioral Action Responses}

According to the authors of the Aggressive Provocation Questionnaire (APQ; O'Connor, Archer, \& Wu, 2001), aggressive behavioral action responses are defined as being one's tendency to behave aggressively upon being presented with various hypothetical provoking 
situations. More specifically, aggressive behavioral responses involve a behavioral response categorized as being aggressive in nature and involving direct verbal or physical aggression. Physiological Responses

For the purposes of the proposed study, physiological responses are defined as being measures of heart rate and blood pressure (systolic and diastolic) using electrocardiography (ECG).

\section{Violent Music Clip}

The violent music clip in the proposed study is defined as being a song with violent lyrical content. More specifically, the violent music clip used in the current study is the song "Jerk-Off" from the album "Opiate" composed by the hard rock group Tool in 1992. The song is approximately four minutes in length. The selection of this particular song is based on the fact that it was previously piloted and used in a recent study investigating violent song lyrics and their impact on aggressive thoughts and feelings (Anderson, Carnagey, \& Eubanks, 2003). In addition, the selection of this specific song for the current study was made in an effort to expose participants to a novel stimulus and to control for potential habituation effects that may be associated with repetitive exposure to more contemporary music given that repeat exposure has been shown to impact individual response patterns (Iwanaga \& Moroki, 1999; Landreth \& Landreth, 1974).

Non-Violent Music Clip

The non-violent music clip in the proposed study is defined as being a song with nonviolent lyrical content. More specifically, the non-violent music clip used in the current study is the song "Four Degrees" from the album "Undertow" composed by the hard rock group Tool in 1993. The song is approximately four minutes in length. The selection of this particular song is 
based on the fact that it was previously piloted and used in a recent study investigating violent song lyrics and their impact on aggressive thoughts and feelings (Anderson, Carnagey, \& Eubanks, 2003). In addition, the selection of this specific particular song for the current study was made in an effort to expose participants to a novel stimulus and to control for potential habituation effects that may be associated with repetitive exposure to more contemporary music given that repeat exposure has been shown to impact individual response patterns (Iwanaga \& Moroki, 1999; Landreth \& Landreth, 1974). 


\section{CHAPTER 2}

\section{Literature Review}

Studies conducted to date that have investigated the negative impact of exposure to aggressive or violent music in audio form can be divided into two broad categories. The first category consists of those studies that examined the relationship between music preferences and various other response variables including aggression, attitudes toward women and trust/distrust, anger, self-esteem, sensation seeking, academic performance, and impact on behavioral responses. The second category consists of those studies that researched the potential negative effects on individuals' response patterns (e.g., attitudes, anger, aggressiveness, and mood) following actual exposure to aggressive or violent music in audio form.

\section{Music Preferences and Related Responses}

Questions regarding the degree of influence music preferences have on individuals' response patterns have stimulated a number of research inquiries, especially given that music preferences are believed to be of significant importance to individuals and to reflect information about one's personal qualities and personality (Rentfrow \& Gosling, 2003). For example, a recent study examined the influence of music preferences and listening frequency on subsequent attitudes, including aggression, attitudes toward women, and trust/distrust, among college-aged individuals (Rubin, West, \& Mitchell, 2001). Anger and self-esteem were analyzed as covariates. Significant differences in attitude were found among participants according to stated music preferences. Participants who preferred heavy-metal music exhibited higher levels of aggression and less regard for women, while participants who preferred rap music displayed more aggression and distrust. An earlier related study investigated relationships among resting arousal, music preference, and sensation seeking behavior among college students (Ballard, 
1999). The results indicated a negative relationship between preference for arousing music and arousal at rest. A positive relationship was found between a preference for arousing music and engagement in sensation seeking and antisocial behaviors for the sampled male college students. However, among female college students, a positive relationship was found between preference for arousing music and resting arousal. In addition, a former study indicated that rap and heavymetal music preferences are associated with below-average school performance, behavioral problems at school, use of drugs, arrests, and involvement in sexual activities among adolescents (Ballard, Took, \& Weiss, 1994).

The findings of such studies suggest that more attention should be given to college students' music preferences given previously identified relationships between one's music preferences and negative attitudinal and behavioral responses. The current study will seek to identify additional relationships between stated music preferences and other response variables within the college student population. More specifically, further investigation will be conducted on the link between one's music preferences and subsequent state anger, affective (positive and negative), physiological, and aggressive behavioral action responses upon exposure to violent audio music compared to non-violent and no music exposure. The intent will be to place emphasis on better understanding such relationships as they occur among the college male population in an effort to expand upon previous research findings.

\section{Violent/Aggressive Audio Music and Exposure Effects}

Behavioral effects. The impact of in vivo exposure to aggressive or violent music on individuals' subsequent responses has increasingly been the topic of inquiry for a number of research investigations within the last decade. For example, one study examined the impact of alcohol consumption and exposure to violent lyrical music on aggressiveness among college- 
aged males (Smith, 1995). The results indicated that individuals who were given a low dose of alcohol and subsequently exposed to heavy-metal music having violent lyric content aggressed more severely against an imagined confederate delivering shocks of longer duration and of increasing intensities across trials. These findings suggested that non-visual media may also influence aggressive responses among college-aged males. Because this study included another variable in addition to violent lyrical music, additional inquiry is needed to further determine violent music exposure effects without the confounding influence of an additional variable in an effort to further establish proof of the negative influence of exposure to violent music alone.

A related study investigated the effects of lyrical content and music type on male undergraduates' mood, anger experience and expression, levels of depression, self-esteem, stateand trait-anxiety, and current suicidal ideation (Ballard \& Coates, 1995). The results of the study revealed that undergraduate males who were exposed to rap music exhibited more angry responses compared to undergraduate males who were exposed to heavy metal music. However, no immediate effects of lyrical content or music content on suicidal ideation or state anxiety were found. In addition, male undergraduates exposed to nonviolent rap songs exhibited depression scores that were more elevated compared to exposure to violent rap songs. Because there appears to be mixed findings regarding the impact of lyrical content on subsequent response patterns among college males, additional clarification regarding the negative effects of exposure to violent music is in order and will be addressed in the current study.

A subsequent study examined the impact of rap music on the aggressive responses of elementary school males in grades 3 through 5 (Litman, 1997). Participants were exposed to one of the following three conditions: (a) lyrical rap music condition involving exposure to both music and lyrics, (b) non-lyrical rap music condition involving exposure to only rap music, and 
(c) no music control condition involving exposure to no music. The results suggested a minimal effect on participants' short-term aggressive behavioral responses following exposure to rap music for a brief period of time. In addition, the study found that the dyads exposed to both music conditions exhibited higher rates of nonverbal aggressive behavior compared to dyads not exposed to rap music. Participants assigned to the lyrical rap music condition exhibited a marginally higher rate of nonverbal aggression compared to the participants assigned to the nonlyrical rap music condition. However, given that the sample was elementary school male students, further investigation of music exposure effects on other populations is warranted to determine the degree of generalization across differing populations. More specifically, because the study found evidence of aggressive behavioral effects following music exposure, additional inquiry is needed to determine whether or not exposure to violent lyrical music has similar effects on the aggressive behavioral responses of other populations including that of college-aged males.

A study conducted earlier examined the impact of exposure to misogynous rap music with lyrics reflecting cognitively distorted attitudes toward women on male college students' sexually aggressive behavior (Barongan \& Hall, 1995). The students were assigned to either a misogynous or neutral rap music condition and were subsequently asked to select either a neutral, sexual-violent, or assaultive film vignette to a female confederate. The findings suggested that males who were first exposed to cognitively distorted misogynous rap music were more likely to show an assaultive vignette $(30 \%)$ to the female confederate compared to males assigned to a neutral rap music condition $(7 \%$ selected the sexual-violent or assaultive vignette to show). Such findings indicate that misogynous rap music may serve to increase sexually aggressive behavior among males who are exposed to such a condition and suggest that cognitive 
distortions are related to subsequent engagement in sexually aggressive behavior (Barongan \& Hall, 1995). The study utilized music with misogynistic content so additional inquiry is warranted to determine whether or not other types of lyrical music have similar negative implications on subsequent behavioral response patterns among college male students.

More recently, a survey study involving 2,300 adolescents ages 13 to 15 discovered a relationship between listening to violent music and verbal aggression among the adolescents who were sampled (Atkin, Smith, Roberto, Fediuk, \& Wagner, 2002). Given that this was a survey study and that the analyses were correlational in nature, additional research that is experimental in design would be beneficial in an effort to determine the existence of actual cause-and-effect patterns related to behavioral responses following actual exposure to violent lyrical music. Experimental research would serve to validate in vivo the study's purported relationship between reported exposure to violent music and subsequent aggressive responses. In addition, experimental research involving additional populations would also serve to strengthen and generalize the study's proposed findings.

Physiological and related affective effects. Other studies have examined the impact of exposure to various music types on individuals' emotional and psychophysiological responses. For example, an exploratory study examined the emotional and psychophysiological impact of exposure to music representing either sad, fear, or happy emotions among college students (Krumhansl, 1997). The study suggested that following exposure to music clips representing each of the three emotions participants reported having experienced changes in their respective emotional responses. In addition, physiological measures indicated that exposure to music representing either sad, fear, or happy emotions had a significant effect on participants' physiological responses with fear music clips yielding the most pronounced increase in blood 
transit time and amplitude, while sad music gave rise to a larger decrease in heart rate, increase in blood pressure (systolic and diastolic), decrease in skin conductance, and decrease temperature relative to the other types of music. Both fear and happy music resulted in significant increases in respiration rates. In effect, the study provided evidence of a relationship between type of music exposure and changes in both emotional and physiological responses (Krumhansl, 1997). Sloboda (1991) also found that music elicits strong physical responses among listeners including tears, spine shivers and heart racing. Another study suggested that music is associated with increased autonomic nervous system responses (Davis \& Thaut, 1989). In contrast, Guzzetta (1989) found lower heart rates following music exposure. A number of other studies as outlined by Hodges (1980) have also found contradictory findings related to heart rate with some studies suggesting increases in heart rate during exposure to excitative rather than sedating music pieces while others have found increases during sedative music or no change at all during music exposure (e.g., DeJong, van Mourik, \& Schellekens, 1973; Ellis \& Brighouse, 1952; Zimny \& Weidenfeller, 1963). Landreth and Landreth (1974) found that musical pieces characterized as having "driving and insistent rhythm, mounting sequential interplay, and progressive dynamic intensity" contributed to increased heart rate while musical pieces having "eminent changes in rhythm, texture and dynamics" were associated with decrease heart rate among listeners (p. 11). More recently, Iwanaga and Moroki (1999) found that increases in heart rate, blood pressure and respiration were more pronounced during exposure to excitative versus sedative music. In addition, they found that sedative music was associated with relaxation feelings while excitative music was associated with feelings of vigor and tension. However, in an earlier study, no changes in heart rate were evidenced during repeated exposure to excitative music (Iwanaga, Ikeda, \& Iwaki, 1996). Vanderark and Ely (1994) also found no significant changes in heart rate 
as well as no changes in blood pressure during exposure to music. A later study supported Vanderark and Ely's findings of no changes in systolic and diastolic specifically among a sample of female high school students using classical and pop music samples (Bassagaoglu, Kalkan, and Sari (2004). Washco (1933) found that individual's heart rate and blood pressure increased or decreased depending upon the type of music to which they were exposed. Therefore, findings regarding the impact of music on individual's physiological responses of heart rate and blood pressure are inconsistent and warrant further investigation.

Goldstein (1980) examined the intensity of emotional responses and related stimuli and found that music was indicated as most often causing intense emotional responses. In addition, Pansepp (1995) found that more intense emotional responses were reported among music listeners and were more often associated with music pieces categorized as being sad rather than happy. Another investigation examined the impact of exposure to happy or sad music or lyrics on college students' mood and memory (Sousou, 1997). Undergraduate college students were exposed to one of five conditions: (a) happy lyrics, (b) sad lyrics, (c) no music, (d) happy music, or (e) sad music. Following exposure to one of the five conditions, their mood and memory were measured. The results indicated that the participants' mood was impacted by the music rather than the lyrics to which he or she was exposed. The no music condition yielded the highest memory recall score (Sousou, 1997). While the study failed to indicate a significant relationship between change in mood and exposure to happy or sad lyrics, the study did not investigate the impact of exposure to both lyrics and music simultaneously. However, a prior study conducted earlier found that college students who were exposed to sad music accompanied with sad lyrics, rather than sad music alone, reported an increase in depression and a decrease in positive affect (Stratton \& Zalanowski, 1994). Because of the inconsistencies in the results of these studies' 
findings regarding the impact of lyrical content, more attention needs to be given to exploring potential effects of the lyrical content of music.

Additional research is also needed to determine the degree of influence lyrics in combination with music has on one's subsequent physiological and affective responses given the limited number of studies pertaining to physiological and affective effects of music exposure. Specific investigation that uses additional types of lyrics and music would be beneficial to determine whether or not findings similar to that of previous studies occur following exposure to other lyric and music types. In addition, given that a number of the studies utilized musical pieces having no lyrics, additional research involving music with lyrics is warranted to further understand the impact of different types of lyrics on physiological response. More specifically, given that violent lyrical music and its impact on physiological responses have not been given sufficient attention in the literature, additional research is needed to further understand how it influences individual's physiological response patterns. Further heart rate and blood pressure (systolic and diastolic) exploration is especially warranted given the paucity of available research and current mixed findings for that which is available. In addition, there is a lack of information regarding the impact of music on blood pressure in general, and more specially, there exists gaps in the literature regarding the influence of violent lyrical audio music on individual's heart rate and blood pressure responses collectively speaking.

Cognitive and related affective effects. Researchers have increasingly provided evidence of cognitive and related affective effects following exposure to violent audio music. For example, one study investigated the effects of exposure to sexually violent rock music on male college students' attitudes toward women and violence against women (St. Lawrence \& Jackson, 1991). The results of the study indicated that heavy-metal rock music served to increase college 
male students' engagement in sex-role stereotyping and to engender more negative attitudes toward women. A follow-up study examined the effects of exposure to sexually violent rap music on male college students' attitudes toward women (Wester, Crown, Quatman, \& Heesacker,1997). Participants were assigned to one of four conditions: (a) sexually violent rap music, (b) sexually violent rap lyrics, (c) both sexually violent rap music and lyrics, or (d) neither sexually violent rap music or lyrics. The results indicated that sole exposure to lyrics or lyrics with music did result in increased negative attitudes toward women. Participants exposed to both lyric conditions reported significantly more adversarial sexual beliefs (Wester et al., 1997). Additional inquiry related to the behavioral effects of exposure to lyrical music is needed given that the study focused primarily on the cognitive effects of exposure to violent music.

The most comprehensive examination of the effects of violent music that has been conducted to date investigated the effects of violent music on college students' aggressive thoughts and feelings in a series of five studies (Anderson, Carnagey, \& Eubanks, 2003). The first study examined participants' state hostility following exposure to a contemporary song selection. The results suggested that exposure to violent music yields higher levels of state hostility compared to nonviolent music exposure. In addition, higher levels of state hostility, or hostile feelings, were reported among females compared to males, which was believed to be attributed to dislike for hard rock music among the sampled females (Anderson, Carnagey, \& Eubanks, 2003).

The second study investigated the impact of exposure to either violent or non-violent music on college students' aggressive cognitions based on the assumption that exposure to violent music will increase the accessibility of aggressive thoughts in semantic memory. Participants were presented with (a) aggressive-aggressive word pairs, b) aggressive-ambiguous 
(having both aggressive and nonaggressive meanings) word pairs, and c) ambiguous-ambiguous word pairs and were asked to rate the degree of similarity of the words on a 7-point scale with 1 representing "not at all similar, associated or related" and 7 representing "extremely similar, associated or related." The aggressive-aggressive word pairs and ambiguous-ambiguous words were used as with-in subject controls. The results of experiment two indicated that exposure to a violent versus non-violent song leads to higher similarity ratings for aggressive-ambiguous word pairs among the sampled college students. Thus, exposure to violent music did indeed appear to increase aggressive thought accessibility among those sampled (Anderson, Carnagey, \& Eubanks, 2003).

In the third study, college students first completed a trait hostility inventory and then were at random either (a) exposed to one of eight songs (one of four violent songs or one of four nonviolent songs) or (b) were assigned to the non-exposure control condition. Participants' state hostility, perceived arousal, and accessibility of aggressive thoughts (using a reaction time test) were measured as well. The results of the experiment indicated that individuals who were first exposed to the violent song and then immediately following exposure had their state hostility assessed reported significantly higher state hostility. The findings also suggested that individuals who reported high trait hostility also tended to report higher levels of state hostility. In addition, the results indicated that aggressive words were more readily accessible following exposure to violent music (Anderson, Carnagey, \& Eubanks, 2003).

A follow-up study examined the impact of (a) exposure to violent, humorous music compared to (b) exposure to non-violent, humorous songs or (c) a non-exposure control condition on college students' aggressive cognitions and feelings using a word completion task. Following completion of a trait hostility measure, participants were randomly assigned to one of 
the three aforesaid conditions. Participants' state hostility and aggressive cognitions were measured following exposure to violent humorous, non-violent humorous, or no music. The findings suggested that exposure to humorous, non-violent music resulted in lower levels of state hostility than the average of the state hostility scores among the exposure to humorous, violent music and no exposure groups. Further, trait hostility was found to be positively related to participants' word completion. Also, exposure to humorous violent music resulted in the highest aggressive word completion mean, while exposure to non-humorous violent music was associated with the lowest aggressive word completion mean. In effect, the findings suggested that combining humorous with violent music content serves to negate the effects of violent content on state hostility. However, regarding cognitions, violent lyrics serve to influence aggressive affect and cognition for humorous as well as non-humorous songs (Anderson, Carnagey, \& Eubanks, 2003).

The final study examined level of trait hostility and the impact of exposure to (a) violent, humorous lyrics, (b) violent, non-humorous lyrics, (c) non-violent, humorous lyrics, (d) nonviolent, non-humorous lyrics, or (e) no song condition on college students' level of state hostility and aggressive thoughts. The same word completion task used in experiment four was utilized in this experiment to assess availability of aggressive cognitions. The results suggested that music condition and trait hostility affected level of state hostility among the participants. In effect, exposure to either one of the two violent song conditions, compared to exposure to either one of the two non-violent song conditions, contributed significantly to higher state hostility levels among the sampled participants. However, it is important to note that first order completion of the state hostility measure gave rise to higher reported levels of hostility, there again suggesting the potential for other tasks to interfere with participants' reported level of state hostility. In 
addition, participants exposed to humorous music conditions indicated lower levels of state hostility compared to those exposed to non-humorous music conditions. The lowest level of state hostility was reported by those exposed to a nonviolent humorous song (Anderson, Carnagey, \& Eubanks, 2003). Yet, the reported state hostility levels for the control group were more similar to the levels reported by participants exposed to the humorous, non-violent condition rather than to the humorous, violent song condition. These results were different then those attained in the fourth study.

The findings relating to the cognitive effects of exposure indicated that participants exposed to violent music had higher aggressive word completion scores compared to participants who listened to a non-violent song. However, participants who were assigned to the no-song control condition had word completion scores in between that of the violent and nonviolent conditions. No significant humor effect was found.

Previous studies that have investigated potential cognitive effects related to exposure to violent lyrical music have indicated that exposure to violent music can contribute to increased experiences of aggressive cognitions and negative attitudes (Anderson, Carnagey, \& Eubanks, 2003; St. Lawrence \& Jackson, 1991; Wester et al., 1997). More specifically, such studies indicate that listening to violent music can increase college students' tendency to interpret ambiguously aggressive words in an aggressive manner, can increase the speed in which individuals read aggressive words compared to non-aggressive words, and increase the number of aggressive word completions. Their findings indicate that exposure to violent music can increase individuals' state hostility. Additional inquiry to further investigate these constructs as well as to determine behavioral effects following exposure to violent music is needed given the 
evidenced cognitive and related affective effects with exposure to violent music (Anderson, Carnagey, \& Eubanks, 2003).

Summary of Literature Review

There have only been a limited number of studies that have examined other modes of media influence and their effects on behavior (e.g., Anderson, Carangey \& Eubanks, 2003; Cooper \& Mackie, 1986; Litman, 1997; Rustad, Small, \& Jobes, 2003; Smith, 1995; Waite, Hillbrand, \& Foster, 1992). In addition, the effects of exposure to violent music in audio form as compared to its music video counterpart has received significantly less attention in the literature. As a result, more attention has been given to the investigation of the potential negative effects of violent audio music exposure within the last decade. The available studies for review which have investigated the impact of exposure to aggressive or violent music on individuals', or more specifically college students', response patterns can be subdivided into two broad categories: (a) studies that have examined music preferences and their relationship to negative responses patterns involving such constructs as aggression, attitudes, self-esteem, sensation seeking, academic performance, and behavioral responses and (b) studies that have included an actual exposure component in which individuals are exposed to aggressive or violent music and subsequent to exposure various response patterns are measured. However, many questions remain due to the current paucity of literature that has addressed the effects of exposure to violent music in audio form. Additional attention should be given to further investigation of potential negative effects upon exposure to violent music.

Conclusion and Purpose of Study

Only a limited number of research investigations regarding the impact of exposure to violent audio music on college males' behavioral responses and other related responses have 
been conducted as shown in the previous literature review. The proposed study will explore potential negative effects on college males' aggressive behavioral action responses, state anger, anger and related feelings, affective (positive and negative), and physiological responses (heart rate and blood pressure) upon exposure to violent audio music. In addition, this study will investigate potential relationships between college males' level of trait anger and aggressive behavioral action responses, level of trait anger control and aggressive behavioral action responses, level of trait anger expression and aggressive behavioral action responses, overall anger expression index and aggressive behavioral action responses, reported number of hours spent listening to music daily and aggressive behavioral action responses, reported music preference and aggressive behavioral action responses, and reported prior music exposure and aggressive behavioral action responses. In effect, the proposed study will seek to establish the presence of negative effects on one's various responses with exposure to violent audio music among college males and, therefore, provide additional support for the need to give further research attention to the potential deleterious effects of exposure to violent audio music.

\section{Research Questions}

RQ1. Does exposure to violent lyrical music influence participants' anger and related feeling responses and aggressive behavioral action responses?

RQ1a. Does exposure to violent lyrical music influence participants' anger and related feelings as measured by the revised Aggressive Provocation Questionnaire (APQ; O’Connor, Archer, \& Wu, 2001)?

RQ1b. Does exposure to violent lyrical music influence participants' aggressive behavioral action responses as measured by the revised Aggressive Provocation Questionnaire (APQ; O'Connor, Archer, \& Wu, 2001)? 
RQ2. Does exposure to violent lyrical music impact participants' state anger responses as measured by the State Anger scale and related subscales of the State-Trait Anger Expression Inventory-2 (STAXI-2; Spielberger, 1999)?

RQ3. Does exposure to violent lyrical music negatively impact participants' affective responses as measured by the Positive and Negative Affect Schedule (PANAS; Watson, Clark, \& Tellegen, 1988)?

RQ4. What is the relationship between participants' level of trait anger and reported aggressive behavioral action responses following exposure to violent lyrical music? Specifically, what are the correlations between participants' scores on the Trait Anger scale and related subscales of the State-Trait Anger Expression Inventory-2 (Spielberger, 1999) and participants' aggressive behavioral action response scores on the revised Aggressive Provocation Questionnaire (O'Connor, Archer, \& Wu, 2001)?

RQ5. What is the relationship between participants' level of trait anger control and reported aggressive behavioral action responses following exposure to violent lyrical music? Specifically, what are the correlations between participants' individual scores on the Anger Control-In and Anger Control-Out scales of the State-Trait Anger Expression Inventory-2 (Spielberger, 1999) and participants' aggressive behavioral action response scores on the revised Aggressive Provocation Questionnaire (O’Connor, Archer, \& Wu, 2001)?

RQ6. What is the relationship between participants' level of trait anger expression and reported aggressive behavioral action responses following exposure to violent lyrical music? Specifically, what are the correlations between participants' 
individual scores on the Anger Expression-In and Anger Expression-Out scales of the State-Trait Anger Expression Inventory-2 (Spielberger, 1999).and participants' aggressive behavioral action response scores on the revised Aggressive Provocation Questionnaire (O'Connor, Archer, \& Wu, 2001)?

RQ7. What is the relationship between participants' overall anger expression index as measured by the Anger Expression Index of the State-Trait Anger Expression Inventory-2 (Spielberger, 1999) and participants' aggressive behavioral action responses following exposure to violent lyrical music as measured by the revised Aggressive Provocation Questionnaire (O’Connor, Archer, \& Wu, 2001)?

RQ8. What is the relationship between participants' reported number of hours spent listening to music daily as measured by the Demographics Questionnaire and participants' aggressive behavioral action responses following exposure to violent lyrical music as measured by the revised Aggressive Provocation Questionnaire (O’Connor, Archer, \& Wu, 2001)?

RQ9. What is the relationship between participants' reported music preference as measured by the Demographics Questionnaire and participants' aggressive behavioral action responses following exposure to violent lyrical music as measured by the revised Aggressive Provocation Questionnaire (O’Connor, Archer, \& Wu, 2001)?

RQ10. What is the relationship between participants' reported prior music exposure as measured by the Demographics Questionnaire and participants' aggressive behavioral action responses following exposure to violent lyrical music as 
measured by the revised Aggressive Provocation Questionnaire (O'Connor, Archer, \& Wu, 2001)?

RQ11. To what extent does exposure to violent lyrical music impact participants' physiological responses?

RQ11a. To what extent does exposure to violent lyrical music impact participants' heart rate as measured via three electrodes bilaterally placed on the shoulder and lower abdomen of each participant?

RQ11b. To what extent does exposure to violent lyrical music impact participants' systolic blood pressure and diastolic blood pressure as measured by an IBS (Industrial \& Biomedical Sensors Corporation, Waltham, MA) automated sphygmomanometer?

Operational Definitions. The variables under investigation in the proposed dissertation study are operationally defined as follows:

1. State Anger Response

State anger response will be measured via the State Anger scale and related subscales (e.g., Feeling Angry, Feeling Like Expressing Anger Verbally, and Feeling Like Expressing Anger Physically) of the State-Trait Anger Expression Inventory-2 (STAXI2; Spielberger, 1999).

2. Trait Anger Response

Trait anger response will be assessed via the Trait Anger scale and related subscales (e.g., Anger Temperament and Anger Reaction) of the STAXI-2 ( Speilberger, 1999).

3. Anger Expression-Out Response 
Anger expression-out response will be determined by scores on the Anger ExpressionOut scale of the STAXI-2 (Spielberger, 1999).

\section{Anger Expression-In Response}

Anger expression-in response will be determined by scores on the Anger Expression-In scale of the STAXI-2 (Spielberger, 1999).

\section{Anger Control-Out Response}

Anger control-out response will be assessed using the Anger Control-Out subscale of the STAXI-2 (Spielberger, 1999).

6. Anger Control-In Response

Anger control-in response will be measured via the Anger Control-In subscale of the STAXI-2 (Spielberger, 1999).

7. Anger Expression Index

Anger expression index will be determined by the overall score on the STAXI-2 (Spielberger, 1999).

8. Trait Hostility

Trait hostility will be measured via the total score on the Cook-Medley Hostility scale (Cook \& Medley, 1954).

9. Affective Responses

Affective responses will be assessed by the Positive and Negative Affect Schedule (PANAS; Watson, Clark, \& Tellegen, 1988).

10. Aggressive Behavioral Action Responses

Aggressive behavioral action responses will be measured by scores on the revised Aggressive Provocation Questionnaire (APQ; O’Connor, Archer, \& Wu, 2001). 
11. Physiological Responses

Physiological responses will be measurements of heart rate and blood pressure (systolic and diastolic) involving bilateral electrodes placed on the shoulder and lower abdomen of each participant and an IBS (Industrial \& Biomedical Sensors Corporation, Waltham, MA) automated sphygmomanometer, respectively. 


\section{CHAPTER 3}

Method

The proposed study explored the impact of exposure to violent music on undergraduate college males' physiological, affective, state anger, and aggressive behavioral action responses. This chapter discusses the methods involved in conducting the proposed study. The individual components addressed include the research design of the proposed study, participants and recruitment, study setting, data collection procedures, independent and dependent variables, research instruments, and statistical procedures for data analysis.

\section{Research Design}

A between subjects randomized mixed pre- and post-test with repeated measures control group experimental design was utilized in the current study. The experiment examined the effects of exposure to either a violent music, non-violent music, or no music condition on college males' physiological, affective, state anger, and aggressive behavioral action responses.

\section{Participants and Recruitment}

Upon receiving human subjects approval from the West Virginia University Institutional Review Board for the Protection of Human Research Participants, male, undergraduate college students currently enrolled in Introduction to Psychology courses at West Virginia University (WVU) were invited to volunteer to participate in the study. The invitation was made via a flyer posted in the Life Sciences building at WVU and verbal announcements made in the Introduction to Psychology classes. Participants were informed that they would receive extra credit points in the Introduction to Psychology course for their participation. They were also made aware that they would be asked to do the following: (a) not smoke an hour (b) not consume caffeine 5 to 6 hours, (c) not drink alcohol 5 to 6 hours, (d) not exercise an hour, and (e) not take any over-the- 
counter medication before coming in for their lab session. Participants were self-selected out of the study based upon their inability to follow these recommendations. In addition, participants were instructed to not sign-up for the study if they were currently taking prescribed medications. A copy of the flyer was provided in Appendix A.

A convenience sample of 132 undergraduate males enrolled in Introduction to Psychology were recruited for the current study. Of the 132 participants recruited, a total of 78 undergraduate males showed for their experimental session. Eleven participants' were discarded for analysis purposes related to ineligibility for participation, incomplete data and related to confederate withdrawal which would have contributed to inconsistency in confederate representation across the sample. The final sample consisted of 67 undergraduate males enrolled in Introduction to Psychology at West Virginia University.

\section{Study Setting}

The proposed study took place in the graduate student lab located on the second floor of the Life Sciences building on the downtown campus of WVU. The Life Sciences lab was the setting of choice because it offered the private setting, audio equipment accessibility for the compact disc player and two-way mirror necessary for the exposure component of the study. In addition, the Life Sciences lab housed the physiological equipment necessary for the appropriate measure of participants' heart rate and blood pressure, which also were among the foci of the current study.

\section{Procedures for Data Collection}

Prior to participation in the study, participants were contacted individually by telephone or email to confirm their participation and to remind them of the following: (a) no smoking one hour prior to the experimental session, 2) no caffeine 5 to 6 hours prior to the experimental 
session, 3) no alcohol consumption 5 to 6 hours prior to the experimental session, 4) no exercise 1 hour prior to experimental session, and 4) no over-the-counter medication prior to the experimental session. Upon arriving for the experimental session, participants were first introduced to the research investigator and confederate and then given an Informed Consent form that outlined the purposes of the study and any risks and benefits involved in participating in the study. They were then asked to sign the form if they agreed with its terms and to return it to the research investigator prior to participation in the experiment. A copy of the Informed Consent form was provided in Appendix B. Next, participants completed the pre-treatment questionnaire packet consisting of the following: (a) a Demographics Questionnaire, (b) the State-Trait Anger Expression Inventory-2 (STAXI-2; Spielberger, 1999), Positive and Negative Affect Schedule (PANAS; Watson, Clark, \& Tellegen, 1988), and Cook-Medley Hostility Scale (Cook \& Medley, 1954).

Participants were then randomly assigned via the taking of a condition paper slip from a cup having mixed together 60 paper slips (20 non-violent, 20 violent and 20 control-no music) to either the (a) violent music experimental condition, (b) non-violent music experimental condition or (c) no music control condition. Based upon the show rate and eligibility of participants, a total of 21 participants were included in each of the violent lyrical and no music (control) groups while 25 participants were included in the non-violent lyrical group.

First, all participants had their heart rate and blood pressure (systolic and diastolic) baseline established over a 6 minute time period with heart rate being measured each minute while blood pressure measurements were taken for minutes 1, 3 and 5. Second, prior to music exposure, head phones were placed on participants in the experimental groups and the volume was tested to determine a suitable loudness level and was preset for music exposure based upon 
previous study recommendations (e.g., Krumhansl, 1997). Experimental group participants were also instructed to pay attention to the lyrics of the song prior to music exposure. Next, participants assigned to the two experimental conditions were exposed to either a 4 minute violent or non-violent lyrical music audio clip (based on the same violent and non-violent music selections that were piloted and subsequently utilized in the Anderson, Carnagey, and Eubanks 2003 study). Their heart rate and blood pressure were measured simultaneously with heart rate being measured during minutes 1 through 4 while blood pressure was measured during minutes 1 and 3.

Following the establishment of their heart rate and blood pressure baselines across the 6 minute interval, participants in the control condition had their heart rate and blood pressure (systolic and diastolic) measured for 4 minutes without being exposed to an audio music clip. Upon the expiration of the 4 minute exposure time period, participants in both the experimental and control groups completed the state anger subscale of the STAXI-2 (Spielberger, 1999) and PANAS (Watson et al., 1988). Participants were encouraged to complete the questionnaires based on their experience during the past 4 minutes.

Following the four minute exposure period, participants in all three groups were then asked to complete a serial sevens mental arithmetic task adapted from Frazer, Larkin, and Goodie (2002) that was presented by a confederate positioned behind a one-way mirror. The procedures for the task involved participants being asked to subtract backwards by 7s for 3 base numbers that were presented to them over the course of a 3 minute time interval. During the task, a different number was used for each minute. The numbers that were used are as follows: 500 for minute one, 613 for minute two, and 518 for minute three. Participants were advised that their performance was being timed and that they must respond quickly and make as few response 
errors as possible. In addition, the confederate delivered the following prompts to participants: (a) After 20 seconds , "Do your best;" (b) after 60 seconds, "Try to be more accurate;" and (c) after 2 minutes 20 seconds, "Work more quickly and stop making so many mistakes." The accuracy of the participants' performance was also monitored for number of attempts and number correct for each of the three tasks. After the task, participants completed the PANAS (Watson et all., 1988) and the revised Aggressive Provocation Questionnaire (APQ; O’Connor, Archer, \& Wu, 2001). All participants were then debriefed and dismissed.

In addition, participants in the two experimental groups $(\mathrm{N}=46)$ were asked to complete a Debriefing Questionnaire consisting of two items that asked participants to (a) indicate whether or not they had heard the exposure music before and if so, to further explain and (b) rate how well they understood the lyrics of the music. Forty-four of the participants (95.7\%) indicated that they had not heard the exposure music before while two (4.3\%) reported that they had heard the music before. The results for the second question are as follows: (a) Two people (4.3\%) indicated "very slightly" understanding the lyrics, (b) Sixteen participants (34.8\%) indicated understanding the lyrics "a little,"(c) Twenty-three participants (50.0\%) indicated "moderately" understanding the lyrics, (d) Four participants $(8.7 \%)$ indicated understanding the lyrics "quite a bit," (e) and one participant (2.2\%) indicated understanding the lyrics "perfectly." Table 1 provides a procedural timeline for the current study.

Table 1

Procedural Timeline with Measures

\begin{tabular}{|c|c|c|}
\hline Step & Procedure & Time \\
\hline 1$)$ & $\begin{array}{r}\text { Pre-test Condition } \\
-\quad \text { Demographics } \\
\text { Questionnaire }\end{array}$ & 20 minutes \\
& - STAXI-2 & \\
\hline
\end{tabular}




\begin{tabular}{|c|c|c|}
\hline & $\begin{array}{ll}\text { - } & \text { PANAS } \\
\text { - } & \text { Cook-Medley }\end{array}$ & \\
\hline 2) & $\begin{array}{l}\text { Baseline Physiological } \\
\text { Measurements } \\
\text { - } \\
\text { - } \\
\text { Heart Rate (HR) }\end{array}$ & 6 minutes \\
\hline 3) & $\begin{array}{cl} & \text { Pressure (SBP) } \\
- & \text { Diastolic Blood } \\
& \text { Pressure (DBP) } \\
\text { Music/No Music Exposure } & \text { No } \\
- & \text { Heart Rate (HR) } \\
- & \text { Systolic Blood } \\
& \text { Pressure (SBP) }\end{array}$ & 4 minutes \\
\hline 4) & 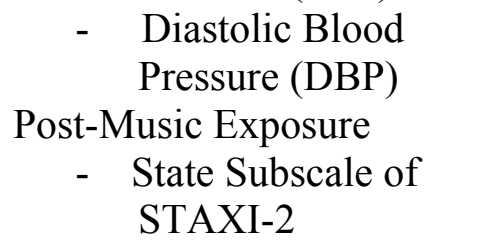 & 5 minutes \\
\hline 5) & $\begin{array}{l}\text { - } \quad \text { PANAS } \\
\text { Provocation } \\
\text { - } \\
\quad \text { Serial Sevens Mental } \\
\quad \text { Task }\end{array}$ & 3 minutes \\
\hline 6) & $\begin{array}{l}\text { Post-Task Measurements } \\
\text { - PANAS }\end{array}$ & 15 minutes \\
\hline 7) & $\begin{array}{l}-\mathrm{APQ} \\
\text { Debriefing }\end{array}$ & 5 minutes \\
\hline
\end{tabular}

Independent and Dependent Variables

The independent variable that was examined in the current study was level of exposure to audio music. There were 3 levels of exposure to audio music including (a) a violent lyrical music condition, (b) non-violent lyrical music condition, and (c) no music control condition.

Thirteen self-report dependent variables were investigated in this study. They are as follows: (a) post music state anger, (b) post music positive affect, (c) post task positive affect, (d) post music negative affect, (e) post task negative affect and (f) post music/post task APQ total anger, (g) post music/post task APQ total frustration, (h) post music/post task APQ total irritated, 
(i) post music/post task APQ aggressive behavioral action response, (j) post music/post task APQ assertive behavioral action response, $(\mathrm{k})$ post music/post task APQ avoidance behavioral action response, (1) post music/post task APQ no behavioral action response and (m) post music/post task APQ anger behavioral action response. These dependent variables were assessed by the State Anger scale of the STAXI-2 (Spielberger, 1999), the Positive and Negative Affect Schedule (Watson, Clark, \& Tellegen, 1988), and the revised Aggressive Provocation Questionnaire (O'Connor et al., 2001). In addition, six physiological dependent variables were examined, and they are as follows: (a) systolic blood pressure (SBP) during music condition, (b) SBP during task, (c) diastolic blood pressure (DBP) during music condition, (d) DBP during task, (e) heart rate (HR) during music condition and (f) HR during task. Heart rate was assessed using a Grass Model 7 Polygraph (Quincy, MA). Blood pressure was assessed using a blood pressure cuff and occluding cuff controlled by a microprocessor (Industrial and Biomedical Sensors, IBS 700A; Waltham, MA).

\section{Research Instruments}

The measures used to assess the impact of the independent variable on the dependent variables in the proposed study included one published instrument (STAXI-2; Spielberger, 1999) and two research instruments in the public domain (APQ; O'Connor et al., 2001, PANAS; Watson, Clark, \& Tellegen, 1988). The Cook-Medley Hostility Scale (Cook \& Medley, 1954) was also included to examine trait hostility as a pre-treatment control variable. In addition, a demographics questionnaire and debriefing questionnaire were specifically devised for the current study. Each of the aforesaid instruments will be discussed in detail in the sections that follow. In addition, the physiological devices for measurement of participants' heart rate and blood pressure (systolic and diastolic) will be further described as well. 
Demographic information. Participants were asked to complete a demographics questionnaire that requested the following information: age, sex, race/ethnicity, and college major. Three additional questions were included on the demographics questionnaire, which requested information pertaining to a) how many hours, on average, the participant listens to music each day, b) what type of music the participant prefers to listen to (i.e., favorite type of music), and c) whether or not the participant listened to music prior to attending the study session and if so, what type of music. Participants were also asked if they had been told about the nature of the current study and were asked to describe what they had been told. A copy of this measure was made available in Appendix C.

State-Trait Anger Expression Inventory-2. The State-Trait Anger Expression Inventory-2 (STAXI-2; Spielberger, 1999) is a 57-item revised version of the original 44 item State-Trait Anger Expression Inventory (STAXI; Spielberger, 1988). The STAXI-2 was designed to assess the experience, expression, and control of anger among adolescents and adults ranging in age from 16 to 63 years. In addition, separate norms are available for both females and males in groups: 16 to 19 years, 20 to 29 years, and 30 years and older. Additional norms were also provided to allow for the distinction between the normal adult, psychiatric population, age, adolescents, and college students based on their STAXI-2 scores.

The instrument is comprised of six individual scales (State Anger, Trait Anger, Anger Expression-Out, Anger Expression-In, Anger Control-Out, Anger Control-In), five separate subscales (State Anger/Feeling, State Anger/Verbal, State Anger/Physical, Trait Anger/Temperament, and Trait Anger/Reaction), and an Anger Expression Index. The State Anger scale was designed to measure the degree of intensity of one's current angry feelings and includes three subscales: Feeling Angry, Feeling Like Expressing Anger Verbally, and Feeling 
Like Expressing Anger Physically. The Trait Anger scale was designed to assess one's general disposition to experience anger and is comprised of two subscales: Anger Temperament (the disposition to experience anger without provocation) and Anger Reaction (the frequency that feelings of anger are experienced when one is provoked). The Anger Expression-Out scale was devised to measure the frequency that one's anger is expressed outwardly while the Anger Expression-In scale was developed to measure how often one experiences but does not express, or suppresses, anger. The Anger Control-Out scale was designed to assess the frequency of control exerted outwardly over one's anger while the Anger Control-In scale measured the frequency of individual attempts to control one's anger through methods including cooling off or calming oneself down. The Anger Expression Index provides an overall assessment of one's expression and control of his/her anger. Completion of the instrument in its entirety requires 12 to 15 minutes (Spielberger, 1999).

The STAXI-2 has be shown to have high internal consistency reliability as evidenced by reported alpha coefficients for the STAXI-2 ranging from .73 to .95 and from .73 to .93 for the subscales. However, the accompanying manual does not offer information regarding the testretest reliability of the STAXI-2. Regarding the demonstrated validity of the STAXI-2, the instrument has been shown to exhibit construct-related validity supported by the findings of a factor analysis, which evidenced factor loadings for the instrument's scales and subscales. In addition, there is demonstrated evidence of concurrent validity of the STAXI-2 with respect to the Minnesota Multiphasic Personality Inventory (Hostility and Overt Hostility scales), BussDurkee Hostility Inventory, and the Eysenck Personality Questionnaire (Psychoticism and Neuroticism) (Freeman, 2003). 
The State-Trait Anger Expression Inventory-2 (STAXI-2; Spielberger, 1999) was used to measure differences in experience, expression, and control of anger among participants exposed to either a violent audio music clip, non-violent audio music clip, or no music clip. In accordance with the STAXI-2 instructions, each participant was asked to indicate on a 4-point Likert scale ranging from 1 (not at all or almost never true of me) to 4 (very much so or almost always true of me) the following: How I feel right now (15 items), How I generally feel (10 items), and How I generally react when angry or furious (32 items) (Spielberger, 1999). A copy of this measure is provided in Appendix D.

Positive and Negative Affect Schedule. The Positive and Negative Affect Schedule (PANAS; Watson, Clark, \& Tellegen, 1988) is comprised of a 10-item positive affect scale, which includes a list of 10 positive descriptors (e.g., attentive, interested, alert, excited), and a 10-item negative affect scale, which includes a list of 10 negative descriptors (e.g., distressed, angry, fearful, guilty), for a total of 20 items. The normative sample for the instrument consisted primarily of college undergraduate students and for this reason was selected for the current study.

The authors have demonstrated that the PANAS scale has high internal consistency as evidenced by their reported .86 to .90 Cronbach coefficient alpha range for the Positive Affect scale and .84 to .87 Cronbach coefficient alpha range for the Negative Affect scale. In addition, the authors reported low intercorrelations between the Positive and Negative Affect scale ranging from -.12 to -.23 . The authors also provided evidence to support the test-retest reliability of the PANAS over an 8-week time span. Regarding the validity of the instrument, the authors demonstrated appropriate convergent validity of the PANAS relative to other positive and 
negative affect mood scales with the convergent correlations range reportedly being .76 to .92 (Watson, Clark, \& Tellegen, 1988).

The PANAS was used in the proposed study to measure differences in positive and negative affect among participants exposed to either a violent audio music clip, non-violent audio music clip, or no music clip. In addition, differences in positive and negative affect following the serial sevens mental task were measured as well using the PANAS. Participants were asked to indicate the extent of their agreement of how they feel "right now, that is, at the present moment" for each item on a 5-point Likert scale ranging from 1 (very slightly or not at all) to 5 (extremely). A copy of the PANAS is provided in Appendix E.

Cook-Medley Hostility Scale. The Cook-Medley Hostility Scale (Cook \& Medley, 1954) is an MMPI-based instrument that was designed to measure the personality, or trait, dimension of hostility. The scale consisted of 50 items having a True-False response format in which individuals were asked to indicate whether or not each item is true as applied to them or false as applied to them. The scale's directions also asked individuals to give their own opinion of themselves. Examples of items included the following: "I would certainly enjoy beating a crook at his own game," When someone does me wrong I feel I should pay him back if I can, just for the principle of the thing," and "I have often met people who were supposed to be an expert who were not better than I." The scale provided a Total Hostility score ranging from 0 to 50 . The measure has been shown by the authors to have high internal consistency as evidenced by their reported .86 Cronbach alpha coefficient. In addition, Kahler, Strong, Niaura, and Brown (2004) in their study reported an internal consistency coefficient of .84 for the Cook-Medley scale. Other studies have provided evidence to support the predictive validity of the Cook-Medley Hostility Scale (e.g., Hardy \& Smith, 1988). For the purposes of this study, the Cook-Medley 
Hostility scale was used to assess participants' pre-treatment level of trait hostility. A copy of the Cook-Medley Hostility scale is provided in Appendix F.

Aggressive Provocation Questionnaire. The revised Aggressive Provocation Questionnaire (APQ; O’Connor, Archer, \& Wu, 2001) was designed to measure the tendency among males to behave aggressively when faced with certain hypothetical provoking situations. The normative sample for the revised APQ consisted of males ranging in age from 17 to 54 who were blue-collar factory employees as well as members of the staff and students at the University of Manchester, Strathclyde University, and University of Liverpool.

The revised APQ consisted of twenty-one scenarios in which one is asked to imagine at that moment a) how he would feel in each situation (angry, frustrated, and irritated) on a 5-point Likert scale ranging from 0 (not at all) to 4 (extremely) and b) how he would respond to each scenario by selecting one of five action responses that is either avoidant in nature (e.g., "move to another seat"), includes no response (e.g., "try to ignore them."), angry in nature (e.g., "feel angry, and do nothing."), assertive behavior (e.g., "turn around and ask them to be quiet or to leave."), or direct aggressive behavior (e.g., "turn around and threaten to hit them if they do not keep quiet."). The revised APQ provided a score for each of the three feelings subscales (i.e., angry, frustrated, and irritated) based on the 4 point Likert scale and provided a total score for the frequency of aggressive and assertive behavioral action responses across the 21 scenarios. Regarding the statistical properties of the revised APQ, O'Connor, Archer, and Wu (2001) demonstrated that each subscale of the revised APQ exhibited internal consistency reliability as evidenced by the anger subscale Cronbach alpha coefficient of .92 , the frustrated scale Cronbach alpha coefficient of .92, and the irritated scale Cronbach coefficient of .93. The aggressive and assertive action scales were found to lack significant intercorrelations with one 
another $(\mathrm{r}=.18)$. Given that the aggression and assertive behavioral action response scales are categorical in nature, the authors were unable to perform reliability analyses for these scales. The authors also demonstrated the construct validity of the revised APQ. The aggressive action scale of the revised APQ was found to be significantly correlated with the physical aggression scale of the Aggression Questionnaire (AQ; Buss and Perry, 1992) ( $\mathrm{r}=.27$ ), a widely used measure of aggression. In addition, significant intercorrelations were demonstrated between the revised APQ subscales and those of the AQ (O’Connor, Archer, \& Wu, 2001).

The revised APQ was used to assess for differences in anger and related feelings and aggressive behavioral action responses among participants exposed to either a violent audio music clip, non-violent audio music clip, or no music clip. The use of such scenarios were included in the current study given that they provide a stand-in for a potential real-situation and, thus, can be viewed as being a valid substitute for a real life provocation situation (Van Goozen, Frijda, Kindt, \& van de Poll, 1994). Modification in terminology was made in order to adapt the measure for use with males in the United States. For example, the term "lad" was replaced with the Webster's $21^{\text {st }}$ Century Dictionary equivalent term "boy." A copy of the revised APQ is available in Appendix G.

Debriefing Questionnaire. The Debriefing Questionnaire was completed by participants in the violent lyrical and non-violent lyrical experimental groups after completion of the study. The questionnaire consisted of two items designed for the purposes of determining (a) if participants had heard the exposure music prior to participation in the study and if so, to determine the nature of the prior exposure and (b) how well participants understood the lyrics of the music using a Likert scale ranging from 1 (very slightly) to 3 (perfectly). A copy of the Debriefing Questionnaire is available in Appendix H. 
Physiological measurement devices. Participants' heart rate was measured using a Grass Model 7 Polygraph (Quincy, MA). Three silver- silver chloride disposable electrodes were placed on the upper shoulder and lower abdomen of each participant for the purpose of recording continuous measurements of heart rate. The first electrode was attached below each participant's right collarbone area while the second electrode was positioned on the participant's left side between ribs 2 and 3. The third electrode (ground) was attached to the right side of the upper torso of each participant. In preparation for the attachment of the electrodes, the areas were first sanitized with rubbing alcohol. The experimenter then attached electrical leads that ran from the electrodes to the polygraph. The leads were connected to an EKG pre-amplifier and driver amplifier before they were charted on the polygraph. Heart rate was measured each minute during the baseline period (approximately 6 minute time interval), each minute during the 4 minute exposure condition or control condition and each minute during the 3 minute mental task. A total average heart rate value was calculated for the baseline period, exposure period and mental task, respectively.

In order to measure participants' blood pressure (systolic and diastolic), a blood pressure cuff was positioned around the upper region of each participant's non-dominant arm. The blood pressure cuff included a microphone and an occluding cuff controlled by a microprocessor (Industrial and Biomedical Sensors, IBS 700A;Waltham, MA). The blood pressure inflation was set at least $30 \mathrm{~mm} \mathrm{Hg}$ above the participants' resting blood pressure and was deflated at a rate of $3 \mathrm{~mm} \mathrm{Hg} / \mathrm{sec}$. Participants' blood pressure was displayed in digital form and was recorded by the experimenter.

Systolic and diastolic blood pressure rates were recorded every other minute during the 6 minute baseline period (i.e., minutes 1, 3, and 5), every other minute during the 4 minute 
exposure period (i.e., minutes 1 and 3 ) and every other minute during the 3 minute mental task (i.e., minutes 1 and 3). The systolic and diastolic blood pressure rates were averaged to determine each participant's mean blood pressure rate for the baseline, exposure and mental task periods. Such physiological measures were used to reliably and validly measure changes in heart rate and blood pressure among participants exposed to either a violent audio music clip, nonviolent audio music clip, or no music clip. 


\section{CHAPTER 4}

Results

The analysis cohort for the current study was comprised of 67 undergraduate male students enrolled in Introduction to Psychology classes during the spring and summer semesters of 2005 at West Virginia University. Regarding ethnic/racial demographics of the sample, the majority of participants were White/Caucasian $(\mathrm{N}=64,95.5 \%)$ while three $(4.5 \%)$ were Asian American/Pacific Islander. The age distribution of the sample were as follows: (a) Fifty (74.6\%) were within the 18 to 19 age range, (b) twelve (17.9\%) were between the ages of 20 to 22 , (c) four $(6.0 \%)$ were within the 23 to 25 age range and (d) one (1.5\%) was between the ages of 26 to 30. The demographics of the sample are provided in Table 2 .

The amount in hours of daily music listening as reported by the participants is as follows: (a) $17.9 \%(\mathrm{~N}=12)$ reported less than 1 hours of daily music listening, (b) $56.7 \%(\mathrm{~N}=38)$ indicated 1 to 3 hours of daily music listening, (c) $20.9 \%(\mathrm{~N}=14)$ reported 4 to 6 hours of daily music listening, (d) $3.0 \%(\mathrm{~N}=2)$ indicated 7 to 9 hours of daily music listening and (e) $1.5 \%(\mathrm{~N}$ $=1$ ) reported 13 or more hours of daily music listening. The music preferences as reported by the participants are provided in Table 3. Thirty-five of the participants (52.2\%) indicated not listening to music while $32(47.8 \%)$ reported that they did listen to music the day of the study prior to participation in the study. Among those indicating prior music exposure on the day of the experiment, $14.9 \%$ indicated listening to rap/hip-hop, $11.9 \%$ reported listening to rock, $9.0 \%$ indicated listening to alternative, $4.5 \%$ indicated listening to country, $3.0 \%$ reported that they "don't know" to what type of prior music they listened while $1.5 \%$ indicated listening to classical, pop and soul/funk, respectively, prior to study participation. All but one of the participants (98.5\%) indicated that no one told them about their experiences in participating in 
the current study. However, the one participant did not report specifics but rather just that he was told of the other person's participation in the study.

\section{Data Analysis Overview}

Data obtained during the current study were analyzed using both descriptive and inferential statistics. Participants' scores on the pre-experimental self-report measures of state anger, trait anger, anger expression, anger control, affect (positive and negative) and trait hostility were first analyzed using univariate Analyses of Variance (ANOVAs) to determine the equivalence of the groups prior to random assignment to the exposure or control conditions. In addition, repeated measures Analyses of Variance (ANOVAs) were conducted for baseline systolic and diastolic blood pressure and baseline heart rate physiological measures in order to determine any systematic differences at pre-treatment.

When differences in pre-treatment variables were identified, these variables were included as covariates in subsequent analyses when appropriate. In such cases, analyses of covariance (ANCOVAs) were performed on the data to determine statistically significant mean differences within or between the violent, non-violent and no music exposure groups after adjusting for the covariate. However, when a significant covariate was not indicated, either univariate or repeated analyses of variance (ANOVAs) were utilized depending on the nature of the data to identify any within or between group differences. Also, a Multivariate Analysis of Variance (MANOVA) was initially conducted on the physiological parameters. Appropriate post-hoc tests were then conducted based on initial findings of analyses including the use of pairwise comparisons and univariate F-tests for simple main effects.

Pearson $\mathrm{r}$ correlation analyses were performed between the following variables for each group: (a) level of trait anger and aggressive behavioral action responses, (b) level of trait anger 
expression and aggressive behavioral action responses, (c) level of trait anger control and aggressive behavioral action responses, (d) overall anger expression index and aggressive behavioral action response, and (e) number of hours spent listening to music on a daily basis and aggressive behavioral action responses. In addition, point biserial correlation analyses were conducted for each group to examine relationships between participants' prior music exposure and aggressive behavioral action responses. Univariate analyses of variance (ANOVAs) were also conducted to examine the influence of participants' music preference on their aggressive behavioral action responses.

\section{Research Question 1}

RQ1. Does exposure to violent lyrical music influence participants' anger and related feeling responses and aggressive behavioral action responses?

RQ1a. Does exposure to violent lyrical music influence participants' anger and related feelings as measured by the revised Aggressive Provocation Questionnaire (APQ; O'Connor, Archer, \& Wu, 2001)? Univariate Analyses of Variance (ANOVAs) were conducted in order to assess for significant differences between participants' anger and related feelings (i.e., feeling frustrated and feeling irritated) scores across the violent music, non-violent, and no music groups.

RQ1b. Does exposure to violent lyrical music influence participants' aggressive behavioral action responses as measured by the revised Aggressive Provocation Questionnaire (APQ; O’Connor, Archer, \& Wu, 2001)? Univariate Analysis of Variance (ANOVA) was conducted in order to assess for significant differences between participants' aggressive behavioral action response score across the violent music, nonviolent, and no music groups. In addition, univariate Analyses of Variance (ANOVAs) 
were conducted for other possible behavioral action responses (i.e., avoidance, assertive, anger and no response) across groups.

\section{Research Question 2}

RQ2. Does exposure to violent lyrical music impact participants' state anger responses as measured by the State Anger scale and related subscales of the State-Trait Anger Expression Inventory-2 (STAXI-2; Spielberger, 1999)? A univariate Analysis of Variance (ANOVA) was conducted in order to assess for significant differences between participants' state anger response score across the violent music, non-violent, and no music groups.

\section{Research Question 3}

RQ3. Does exposure to violent lyrical music negatively impact participants' affective responses as measured by the Positive and Negative Affect Schedule (PANAS; Watson, Clark, \& Tellegen, 1988)? Univariate Analyses of Variance (ANOVAs) were conducted in order to assess for significant differences between participants' affective response (positive and negative) scores across the violent music, non-violent, and no music groups.

\section{Research Question 4}

RQ4. What is the relationship between participants' level of trait anger and reported aggressive behavioral action responses following exposure to violent lyrical music? Specifically, what are the correlations between participants' scores on the Trait Anger scale and related subscales of the State-Trait Anger Expression Inventory-2 (Spielberger, 1999) and participants' aggressive behavioral action response scores on the revised Aggressive Provocation Questionnaire (O’Connor, Archer, \& Wu, 2001)? For each group (violent lyrical, nonviolent lyrical and no music), pearson $\mathrm{r}$ correlation analyses were 
performed on the participants' trait anger and related subscales scores and participants' aggressive behavioral action response scores.

\section{Research Question 5}

RQ5. What is the relationship between participants' level of trait anger control and reported aggressive behavioral action responses following exposure to violent lyrical music? Specifically, what are the correlations between participants' individual scores on the Anger Control-In and Anger Control-Out scales of the State-Trait Anger Expression Inventory-2 (Spielberger, 1999) and participants' aggressive behavioral action responses scores on the revised Aggressive Provocation Questionnaire (O'Connor, Archer, \& Wu, 2001)? Pearson $r$ correlation analyses were performed on the participants' trait inward anger control and trait outward anger control and aggressive behavioral action response scores for each group (violent lyrical, nonviolent lyrical, no music).

\section{Research Question 6}

RQ6. What is the relationship between participants' level of trait anger expression and reported aggressive behavioral action responses following exposure to violent lyrical music? Specifically, what are the correlations between participants' individual scores on the Anger Expression-In and Anger Expression-Out scales of the State-Trait Anger Expression Inventory-2 (Spielberger, 1999) and participants' aggressive behavioral action responses scores on the revised Aggressive Provocation Questionnaire (O'Connor, Archer, \& Wu, 2001)? Pearson $\mathrm{r}$ correlation analyses were performed on the participants' trait inward anger expression and trait outward anger expression and aggressive behavioral action response scores for each group (violent lyrical music, nonviolent lyrical and no music). 


\section{Research Question 7}

RQ7. What is the relationship between participants' overall anger expression index as measured by the Anger Expression Index of the State-Trait Anger Expression Inventory2 (Spielberger, 1999) and participants' aggressive behavioral action responses following exposure to violent lyrical music as measured by the revised Aggressive Provocation Questionnaire (O'Connor, Archer, \& Wu, 2001)? Pearson r correlation analyses were conducted on participants' overall anger expression index and aggressive behavioral action response scores for each group (violent lyrical, non-violent lyrical, and no music).

\section{Research Question 8}

RQ8. What is the relationship between participants' reported number of hours spent listening to music daily as measured by the Demographics Questionnaire and participants' aggressive behavioral action responses following exposure to violent lyrical music as measured by the revised Aggressive Provocation Questionnaire (O'Connor, Archer, \& Wu, 2001)? Pearson r correlation analyses were conducted on participants' reported number of hours spent listening to music daily and aggressive behavioral action response scores for each group (violent lyrical, non-violent lyrical or no music).

\section{Research Question 9}

RQ 9. What is the impact of participants' reported music preference as measured by the Demographics Questionnaire on their aggressive behavioral action responses following exposure to violent lyrical music as measured by the revised Aggressive Provocation Questionnaire (O'Connor, Archer, \& Wu, 2001)? A univariate analysis of variance (ANOVA) was conducted on participants' reported music preference and aggressive behavioral action response scores with music preference as the between subjects factor. 


\section{Research Question 10}

RQ10. What is the relationship between participants' reported prior music exposure as measured by the Demographics Questionnaire and participants' aggressive behavioral action responses following exposure to violent lyrical music as measured by the revised Aggressive Provocation Questionnaire (O'Connor, Archer, \& Wu, 2001)? Point biserial correlation analyses were conducted on participants' reported prior music exposure and aggressive behavioral action response scores for each group (violent lyrical, non-violent lyrical or no music).

\section{Research Question 11}

RQ11. To what extent does exposure to violent lyrical music impact participants' physiological responses?

RQ11a. To what extent does exposure to violent lyrical music impact participants' heart rate as measured via three electrodes bilaterally placed on the shoulder and lower abdomen of each participant? Multivariate Analysis of Variance (MANOVA) was initially conducted in order to assess for significant differences between participants' heart rate across the violent music, non-violent, and no music groups. Post hoc analyses were then conducted as appropriate.

RQ4b. To what extent does exposure to violent lyrical music impact participants' systolic blood pressure and diastolic blood pressure as measured by an IBS (Industrial \& Biomedical Sensors Corporation, Waltham, MA) automated sphygmomanometer? Multivariate Analysis of Variance (MANOVA) was initially conducted in order to assess for significant differences between participants' blood pressure rate across the violent 
music, non-violent, and no music groups. Post hoc analyses were then conducted as appropriate.

Additional analyses were conducted as appropriate. For example, analyses were conducted to determine whether any differences related to confederate assignment existed for post-task positive and negative affect; post-task systolic blood pressure, diastolic blood pressure and heart rate; APQ measures and number of mental task attempts and number correct. In addition, the relationship between music preferences, trait hostility as well lyrical understanding and other variables under investigation as well as analyses of number of mental task attempts and number correct across groups were analyzed.

A supplemental analysis was also conducted to determine the impact of the 18 participants who indicated their level of understanding of the musical lyrics as being either "very slightly" or "a little." The purpose of the analysis was to determine if lack of lyrical understanding affected participants' post-music exposure state anger, positive and negative affect, aggressive behavioral action or physiological responses.

Internal Consistency, Self-Report and Physiological Preliminary Analyses

\section{Internal Consistency}

In an effort to ensure that the items of subscales and overall scales of measurement used in the current study did indeed measure their intended constructs, analyses of the internal consistency of the items for each pretest scale and its respective subscale(s), when applicable, as well as for the overall instrument were conducted using Cronbach's alpha as the internal consistency estimate. In addition, the internal consistency estimates for the APQ post-test measure were also examined using Cronbach's alpha. Cronbach's alpha ranges from zero indicating that the items are "totally inconsistent" to 1.0 , which indicates the items correlate 
"perfectly" with one another (Vogt, 2007, p. 115). According to Vogt (2007), an alpha equal to or higher than .70 is deemed to be "satisfactory for most purposes."

The internal consistency estimates for the subscales and scales of the STAXI-2 (Spielberger, 1999) were as follows: (a) Cronbach's alpha $=.745$ for the State Anger Scale, (b) Cronbach's alpha $=.687$ for State Anger-Feeling Angry Subscale, $(\mathrm{c})$ Cronbach's alpha $=.746$ for State Anger-Verbal Subscale, (d) Cronbach's alpha $=.550$ for the State Anger-Physical Subscale, (e) Cronbach's alpha $=.834$ for Trait Anger Scale, (f) Cronbach's alpha $=.825$ for the Trait Anger-Angry Temperament Subscale, (h) Cronbach's alpha $=.695$ for Trait Anger-Angry Reaction Subscale, (i) Cronbach's alpha = .666 for Anger Expression-Out Scale, (j) Cronbach's alpha $=.804$ for Anger Expression-In Scale, $(\mathrm{k})$ Cronbach's alpha $=.897$ for Anger Control-In Scale, (1) Cronbach's alpha $=.851$ for Anger Control-Out Scale, and (1) Cronbach's alpha $=.707$ for the total instrument.

The internal consistency estimates for the PANAS (Watson, Clark, \& Tellegen, 1988) ranged from .697 to .832 for the individual negative and positive affect scales, respectively, while the internal consistency coefficient for the overall instrument was .832 . The internal consistency estimate for the Cook-Medley Hostility Scale (Cook \& Medley, 1954) was found to be .773. The internal consistency findings for the feeling scales of the Aggressive Provocation Questionnaire (APQ; O'Connor, Archer, \& Wu, 2001) were as follows: (a) Cronbach's alpha= .934 for the Feeling Angry items, (b) Cronbach's alpha $=.917$ for the Feeling Frustrated items and $(\mathrm{c})$ Cronbach's alpha $=.914$ for the Feeling Irritated items. However, it is important to note that the internal consistency estimates for the APQ Feeling Angry, Irritated and Frustrated items were missing data resulting in only 43 available cases for analysis. The missing data for the APQ was related to the authors of the instrument initially sending a copy of the measure having 
an incorrect sample, which instructed participants to circle one likert response for only one of the scales (Feeling Angry, Irritated, or Frustrated). In addition, given that the behavioral action response scales are categorical in nature, reliability analyses for these scales are unavailable for the current study.

\section{Self-report Preliminary Analyses}

In order to determine whether any pre-treatment differences existed across groups (violent lyrical, non-violent lyrical, no music), individual univariate one-way analyses of variance (ANOVAs) were initially conducted for each of the following self-report measures: (a) state anger scale, (a) state anger feeling angry subscale, (b) state anger verbal subscale, (c) state anger physical subscale, (d) trait anger scale score, (e) trait anger temperament subscale, (f) trait anger reaction subscale, (g) anger expression-out scale, (h) anger expression-in scale, (i) anger control-out scale, (j) anger control-in scale, (k) positive affect, (1) negative affect and (m) hostility scores. Anger expression-out scale was the only pre-treatment measure that was found to differ significantly across groups, $F(2,64)=3.88, p<.05$. Mean anger expression-out for the violent lyrical group $(M=15.5, S D=3.5)$ was significantly lower compared to mean anger expression-out for the no music (control) group $(M=18.1, S D=3.1)$. Given this finding, anger expression-out was included as a covariate in subsequent post-treatment analyses when appropriate. For two of the pre-treatment measures (i.e., pre-state anger and pre-negative affect), heterogeneity of variances as measured by the Levene's test was significant $(p<.001, p<.05$, respectively). Therefore, nonparametric Kruskal-Wallis tests were used to confirm the lack of significance for these measures (all $p>.05$ ).

Pearson $r$ correlation analyses (all two-tailed tests) were conducted to determine for which post-treatment analyses anger expression-out needed to be included as a covariate. The 
results revealed the following: (a) a significant negative correlation between anger expressionout and post-mental task positive affect $(r=-.28, p<.05)$, (b) a significant positive correlation between anger expression-out and APQ total frustration $(r=+.39, N=44, p<.05)$, (c) a significant positive correlation between anger expression-out and APQ total irritated $(r=+.51$, $N=44, p<.01),(\mathrm{d})$ a significant positive correlation between anger expression-out and APQ total aggressive action response $(r=+.27, p<.05)$ and (e) a significant negative correlation between anger expression-out and APQ total no action response $(r=-.27, p<.05)$. No significant correlations were observed between anger expression-out and post-music state anger $(r=.15, p>.05)$, post-music positive affect $(r=-.05, p>.05)$, post-music negative affect $(r=$ $.14, p>.05)$, post-task negative affect $(r=.15, p>.05)$, mental task attempts for minute $1(r=$ $.07, p>.05)$, mental task attempts for minute $2(r=.06, p>.05)$, mental task attempts for minute $3(r=.05, p>.05)$, mental task correct for minute $1(r=.05, p>.05)$, mental task correct for minute $2(r=.11, p>.05)$, mental task correct for minute $3(r=.03, p>.05)$, APQ total anger $(r=.16, p>.05)$, APQ total assertive action response $(r=.08, p>.05)$, APQ total avoidance action response $(r=-.20, p>.05)$ and APQ total anger action response $(r=-.00, p>$ .05). Given these findings, subsequent analyses involving post-mental task positive affect, APQ total frustration, APQ total irritated, APQ total aggressive action response, and APQ total no action response included anger expression-out as a covariate. It is important to note that the results for APQ total anger, frustration and irritated are missing data and, therefore, the findings are based upon the available complete data for these measures.

Analyses of variance (ANOVAs) also were conducted to determine whether any significant differences existed related to confederate assignment for mental task number of attempts across minutes 1,2 and 3, mental task number correct across minutes 1,2 and 3, mental 
task post-mental task positive affect, post-mental task negative affect, APQ total anger score, APQ total frustration score, APQ total irritated score, APQ total aggressive action response score, APQ total assertive action response score, APQ total avoidance action response score, APQ total no action response score and APQ total anger response score. The results of these analyses revealed no significant confederate main effects for each measure: mental task attempts across minutes 1,2 and $3, \mathrm{~F}(1,65)=.27$, mental task correct across minutes 1,2 and $3, F(1,65)$ $=.64$; post-mental task positive affect, $F(1,65)=.72$; post-mental task negative affect, $F(1,65)$ $=.10 ; \mathrm{APQ}$ total anger score, $F(1,42)=.17, N=44$; APQ total frustration score, $F(1,42)=.33$, $N=44$; APQ total irritated score, $F(1,42)=.04, N=44$; APQ total aggressive action response score, $F(1,65)=.65$; APQ total assertive response score, $F(1,65)=.02$; APQ total avoidance action response score, $F(1,65)=.24$; APQ total no action response score, $F(1,65)=.02$ and APQ total anger response score, $F(1,65)=.85$ (all $p>.05)$. While APQ total frustration score was not initially found to differ significantly across confederates, the test for heterogeneity of variance was significant for this measure $(\operatorname{Levene}(1,42)=9.98, p<.01)$. A nonparametric Kruskal-Wallis test was conducted and verified nonsignificant differences in APQ total frustration across confederates, $\chi^{2}(1)=.03, p>.05$. It is important to note that the results for APQ total anger, frustration and irritated are missing data, and, therefore, the findings are based upon the available complete data for these measures.

Physiological Measures Preliminary Analyses

The participants' heart rate and blood pressure (systolic and diastolic) measurements were first screened to determine which measurements would be included for analysis. Heart rates below 50 that were not consistent were excluded. Only one participant's heart rate measurement was excluded, though it was based upon an equipment malfunction that occurred during the 
mental task portion of the study. The data screening process for systolic and diastolic blood pressure was based upon Marler, Javob, Lehoczky and Shapiro’s (1988) criteria for exclusion: (a) systolic blood pressures (SBP) below 70 or above 250 , (b) diastolic blood pressure (DBP) below 45 or above 150 and (c) SBP/DBP below $1.0625+.00125 \times$ DBP or above 3.0. When a single measure that met Marler et al.'s criteria was identified it was discarded for analysis purposes.

In order to determine whether any systematic differences existed across minutes for each physiological parameter during baseline, individual repeated-measures analyses of variance (ANOVAs) were conducted for each of the following physiological measures: (a) baseline systolic blood pressure (minutes 1,3 and 5); (b) baseline diastolic blood pressure (minutes 1,3 and 5) and (c) baseline heart rate (minutes 1 through 6). Results indicated significant withinsubject differences across baseline heart rates, $F(4,245)=5.09, p<.05$. Baseline HR during the third minute of the baseline period $(M=70.1, S D=9.2 \mathrm{bpm})$ was significantly lower than baseline HRs during minutes $4(M=71.4, S D=10.4 \mathrm{bpm}), 5(M=71.7, S D=10.5 \mathrm{bpm})$, and 6 $(M=72.0, \mathrm{SD}=10.7 \mathrm{bpm} ; p s<.05)$. These findings suggest that participants may have experienced increased tension or frustration with the extended baseline beyond minute 3 . Based upon these findings, a second repeated-measures ANOVA was conducted across baseline heart rates for minutes 1,2 and 3 . The results of this analysis revealed no significant difference within subjects across minutes 1,2 and $3(p>.05)$. In addition, a repeated-measures analysis of variance was conducted to determine if there was a significant difference between mean baseline heart rate averaged for minutes 1 to 3 and mean baseline HR averaged using minutes 1 through 6. The results of this analysis indicated a significant difference between the two ways of calculating baseline HR, F $(1,66)=9.29, p<.05$; mean baseline HR using minutes 1,2 and $3(M$ 
$=70.6, S D=9.6 \mathrm{bpm}$ ) was significantly lower than mean baseline HR using minutes 1 through 6 $(M=71.1, S D=9.9 \mathrm{bpm})$. Therefore, the value calculated based upon minutes 1 to 3 was chosen as the measure of baseline heart rate used in this study and was included in subsequent analyses. In addition, three separate one-way analyses of variance (ANOVAs) were computed in order to identify any potential significant pre-treatment differences for average baseline systolic blood pressure, average baseline diastolic blood pressure and average baseline heart rate across the three experimental groups (violent lyrical music, non-violent lyrical music and no music). The results of the analyses indicated no significant differences across groups for average baseline systolic blood pressure, $\mathrm{F}(2,64)=.82, p>.05$ or for average baseline heart rate, $\mathrm{F}(2,64)=.16$, $p>.05$. However, average baseline diastolic blood pressure was significantly different among the three groups, $\mathrm{F}(2,64)=4.31, p<.05$. Baseline DBP for the no-music control group $(M=$ $62.5, S D=10.4 \mathrm{~mm} \mathrm{Hg}$ ) was significantly lower than baseline DBPs for the violent lyrical music $(M=69.1, S D=12.3 \mathrm{~mm} \mathrm{Hg})$ and non-violent lyrical music $(M=71.3, S D=8.6 \mathrm{~mm} \mathrm{Hg})$ groups. Given these findings, average baseline diastolic blood pressure was included as a covariate in subsequent analyses of DBP when appropriate.

Three separate 2 x 3 [Confederate (number 1, number 2) x Phase (baseline, music/no music condition, mental task)] mixed factors analyses of variance (ANOVAs) were also conducted to determine whether any significant differences existed related to confederate assignment for each physiological parameter during baseline, music condition and mental task phases. The results of these analyses revealed no significant main effects for confederate assignment for SBP, F $(1.65)=1.81$, DBP, $\mathrm{F}(1,65)=1.28$, or HR at baseline, during music/no music condition and mental task, $\mathrm{F}(1,64)=.01$ (all $p>.05)$. In addition, no significant 
Confederate x Phase interactions were observed for SBP, F $(1.4,93.6)=.38$, DBP, F $(1.6,106.4)$ $=.16$, or HR, F $(1.2,79.6)=1.58($ all $p>.05)$.

\section{Self-Report Data Analyses}

\section{Research Question 1}

In order to examine whether or not exposure to violent lyrical music influences (a) participants' anger and related feelings and (b) aggressive behavioral action responses as measured by the revised Aggressive Provocation Questionnaire (APQ; O'Connor, Archer, \& $\mathrm{Wu}, 2001$ ), univariate analyses of variance (ANOVAs) were conducted for each of the following APQ variables: (a) APQ total anger, (b) APQ total assertive action response, (c) APQ total avoidance action response and (d) APQ total anger action response. No significant group (violent lyrical music, non-violent lyrical music and no music) differences were observed for each of these variables. However, given that the test for heterogeneity of variance was significant for APQ total anger, a Kruskal-Wallis test was conducted and confirmed nonsignificance for APQ total anger, $\chi^{2}(2)=2.53, p>.05$. In addition, univariate analyses of covariance (ANCOVAs) were conducted for APQ total frustration, APQ total irritated, APQ total aggressive action response, and APQ total no action response with group (violent lyrical music, non-violent lyrical music and no music) as the between subjects factor and anger expression-out entered as the covariate. The results of the ANCOVAs for each of these APQ variables indicated anger expression-out as being a significant covariate (all $p<.05)$. After adjustment by the covariate, the only significant finding observed was a significant group main effect for APQ total aggressive action response, $F(2,63)=3.88, p<.05$, partial $\eta^{2}=.11$. Mean number of APQ total aggressive action responses for the violent lyrical music group ( $M=2.9$, $S D=3.3)$ was significantly higher compared to the no music (control) group $(M=1.4, S D=1.8)$, 
though it did not significantly differ from the non-violent lyrical music group $(M=2.2, S D=$ 2.4). It is important to note that the results for APQ total anger, frustration and irritated are missing data related to these participants responding to an incorrect example as provided by the authors of the APQ, and, therefore, the findings are based upon the available correct complete data for these measures (all $N=44$ ). Significant findings for Research Question 1 are provided in Table 4. Means and standard deviations for Research Question 1 are shown in Table 5.

\section{Research Question 2}

In order to investigate whether or not exposure to violent lyrical music impacts participants' level of state anger as measured by the State Anger and related subscales of the State-Trait Anger Expression Inventory-2 (STAXI-2; Spielberger, 1999), a univariate one-way analysis of variance (ANOVA) was conducted on post-music state anger with group (violent lyrical, non-violent lyrical, no music) as the between subjects factor. Results revealed no significant main effects for group, $\mathrm{F}(2,64)=1.91, p>.05$. However, because the test for heterogeneity of variance was significant for post-music state anger (Levene $(2,64)=4.97, p<$ .05), a Kruskal-Wallis test was conducted and confirmed nonsignificance for post-music state anger across groups, $\chi^{2}(2)=2.04, p>.05$. Mean post-music state anger for the violent music group $(M=18.9, S D=4.9)$ was not significantly different compared to the non-violent music $(M$ $=17.2, S D=2.8)$ and the no music (control) $(M=16.9, S D=2.7)$ groups (see Table 6$)$.

In addition, a 3 x 2 [Group (violent lyrical music, non-violent lyrical music, no music) x Phase (baseline and music/no music condition)] repeated measures analysis of variance (ANOVA) was conducted to ascertain whether or not there were differences in participants' post-music exposure state anger relative to their baseline state anger level. The results revealed an interaction between phase and condition, $\mathrm{F}(2,64)=3.94, p<.05$, partial $\eta^{2}=.11$ (see Figure 
1). No significant between group differences for state anger response relative to phase were found, $\mathrm{F}(2,64)=.92, p>.05$.

\section{Research Question 3}

The question of whether exposure to violent lyrical music has an impact on participants' affective responses as measured by the Positive and Negative Affect Schedule (PANAS; Watson, Clark \& Tellegen, 1998) compared to non-violent lyrical music and no music was examined via univariate analyses of variance (ANOVAs) for (a) post-music positive affect and (b) post-music negative affect. Results indicated no significant differences in post-music positive affect, $F$ (2, $64)=2.27, p>.05$, and post-music negative affect, $F(2,64)=.82, p>.05$, across groups. Mean post-music positive affect was not significantly different for the violent lyrical group ( $M=27.0$, $S D=8.9)$ compared to the non-violent lyrical group $(M=28.7, S D=7.9)$ and no music group $(M$ $=23.2, S D=9.3)$. In addition, post-music negative affect for the violent lyrical group $(M=13.9$, $S D=4.2)$ was not significantly different relative to the non-violent lyrical $(M=13.4, S D=2.7)$ and no music $(M=14.7, S D=3.8)$ groups (see Table 7).

Two separate 3 x 3 [Group (violent lyrical music, non-violent lyrical music, no music) x Phase (baseline, music/no music condition, mental task)] repeated measures analysis of variance (ANOVAs) were conducted to explore whether or not there were differences in participants' post-music positive and negative affect compared to their baseline and mental task positive and negative affect responses. The results revealed a Phase effect for positive affect among participants across all groups, $\mathrm{F}(2,126)=20.34, p<.001$. Using partial $\eta^{2}$ as the measure of effect size, phase accounted for $24 \%$ of the total variability in participants' positive affect responses. Mean post-music positive affect $(M=26.3, S D=8.8)$ and post-task positive affect ( $M$ $=24.4, S D=9.0)$ were significantly lower compared to baseline positive affect $(M=29.2, S D=$ 
7.8) while post-task positive affect was significantly lower than post-music positive affect for all participants. The interaction between phase and condition was not significant, $\mathrm{F}(4,126)=1.67$, $p>.05$. In addition, no significant between group differences for positive affect relative to phase were found, $F(2,63)=1.03, p>.05$. Similar to the findings for positive affect, the ANOVA for negative affect indicated no significant between group differences relative to phase, $\mathrm{F}(2,63)=$ $.09, p>.05$. However, unlike for positive affect, the results for negative affect suggested an interaction effect between phase and condition, $\mathrm{F}(4,126)=3.42, p<.05$, partial $\eta^{2}=.10$ (see Figure 2).

In addition, a univariate analysis of covariance (ANCOVA) for post-task positive affect with anger expression-out as the covariate and (b) a univariate one-way analysis of variance (ANOVA) for post-task negative affect were conducted to investigate for differences in affect across groups (violent lyrical, non-violent lyrical and no music) following mental task completion. The results of the ANCOVA for post-task positive affect indicated anger expressionout as being a significant covariate, $F(1,63)=4.23, p<.05$. After adjustment by the covariate, no significant group differences for post-task positive affect were evidenced, $F(2,63)=.36, p>$ .05. The ANOVA for post-task negative affect also revealed no significant group differences, $F$ $(2,64)=1.14, p>.05$

\section{Research Question 4}

In order to examine the relationship between participants' level of trait anger and related trait-angry temperament and trait-angry reaction and number of reported aggressive behavioral action responses following exposure to violent lyrical music versus non-violent lyrical music or no music exposure, Pearson $r$ correlation analyses (all two-tailed tests) were conducted for each group. For the violent lyrical group, a significant positive correlation between total number of 
aggressive behavioral action responses and (a) total trait anger score $\left(r=+.61, p<.01, r^{2}=.37\right)$, (b) trait- angry temperament $\left(r=+.44, p<.05, r^{2}=.19\right)$ and (c) trait-angry reaction $(r=+.65, p$ $<.01, r^{2}=.42$ ) were revealed. However, for the non-violent lyrical and no music groups, no significant correlations between these variables were indicated (all $p>.05$ ). The means, standard deviations, and results of the correlational analyses by group (violent lyrical, non-violent lyrical and no music) for Research Question 4 are provided in Tables 8, 9 and 10, respectively.

\section{Research Question 5}

An investigation of the relationship between participants' level of trait anger control-in and trait anger control-out and number of reported aggressive behavioral action responses following exposure to violent lyrical versus non-violent lyrical or no music exposure was conducted using Pearson $r$ correlation analyses (all two-tailed tests) for each group. The only significant correlation observed was a negative correlation between anger control-out and total number of aggressive action responses for the violent lyrical group $\left(r=-.50, p<.05, r^{2}=.25\right)$. The means, standard deviations, and results of the correlational analyses by group (violent lyrical, non-violent lyrical and no music) for Research Question 5 are provided in Tables 8, 9 and 10 , respectively.

\section{Research Question 6}

An examination of the relationship between participants' level of trait anger expressionin and trait anger expression-out and number of reported aggressive behavioral action responses following exposure to violent lyrical versus non-violent lyrical or no music exposure was conducted using Pearson $r$ correlation analyses (all two-tailed tests) for each group. For the violent lyrical group, a significant positive correlation between trait anger expression-out and total number of aggressive behavioral action responses was observed $\left(r=+.65, p<.01, r^{2}=.42\right)$. 
For the nonviolent lyrical group, a significant negative correlation between trait anger expression-in and aggressive action response was revealed $\left(r=-.41, p<.05, r^{2}=.17\right)$. No significant correlations were indicated for the no music group. The means, standard deviations, and results of the correlational analyses by group (violent lyrical, non-violent lyrical and no music) for Research Question 6 are provided in Tables 8, 9 and 10, respectively.

\section{Research Question 7}

In order to investigate the relationship between participants' overall anger expression index and number of reported aggressive behavioral action responses following exposure to violent lyrical versus non-violent lyrical or no music exposure, Pearson $r$ correlation analyses (all two-tailed tests) were conducted for each group. A significant positive correlation between overall anger expression index and aggressive behavioral action response for the violent lyrical group was the only significant correlation observed, $r=+.49, p<.05, r^{2}=.24$. The means,

standard deviations, and results of the correlational analyses by group (violent lyrical, nonviolent lyrical and no music) for Research Question 7 are provided in Tables 8, 9 and 10, respectively.

\section{Research Question 8}

In order to examine the relationship between participants' reported amount of daily music listening and number of aggressive behavioral action responses following exposure to violent lyrical versus non-violent lyrical or no music exposure, Pearson $r$ correlation analyses (all twotailed) were conducted for each group. No significant relationships between amount of daily music listening and total number of aggressive action responses were observed for each group (all $p>.05$ ). The means, standard deviations, and results of the correlational analyses by group 
(violent lyrical, non-violent lyrical and no music) for Research Question 8 are provided in Tables 8,9 and 10, respectively.

Research Question 9

An investigation of the influence of participants' reported music preference on their number of aggressive behavioral action responses following exposure to either violent lyrical, non-violent lyrical and no music was conducted using a univariate analysis of variance (ANOVA) with music preference as the between subjects factor. Given the lack of appropriate sample sizes for all music preference options, the four predominant music preference groupings based upon participants self-report (alternative, country, rap/hip-hop and rock) were used for analysis purposes. No significant differences in participants' aggressive behavioral action responses based upon their reported music preferences were indicated $(p>.05)$. Given that heterogeneity of variances as measured by Levene's test was significant, nonparametric Kruskall-Wallis tests was used to confirm the lack of significance for participants' aggressive behavioral action responses relative to music preference $(p>.05)$. Means and standard deviations for Research Question 9 are provided in Table 11.

\section{Research Question 10}

An examination of the relationship between participants' reported prior music exposure and number of aggressive behavioral action responses following exposure to either violent lyrical, non-violent lyrical or no music was conducted using Point Biserial correlation analyses for each group. No significant relationships were observed (all $p>.05$ ). The results of the correlational analyses by group (violent lyrical, non-violent lyrical and no music) for Research Question 10 are provided in Tables 8, 9 and 10, respectively. 


\section{Cardiovascular Data Analysis}

\section{Research Question 11}

In order to examine the extent to which violent lyrical, non-violent lyrical and no music exposure impacts participants' physiological responses (systolic and diastolic blood pressures and heart rate), a 3 x 3 [Group (violent lyrical music, non-violent lyrical music, no music) $\mathrm{x}$ Phase (baseline, music/no music condition, mental task)] multivariate mixed factors analysis of variance (MANOVA) (with Group as the between subjects factor and Phase as the repeated measures factor) was conducted using all three cardiovascular dependent variables (systolic blood pressure, diastolic blood pressure and heart rate). Results indicated a significant main effect for Phase, $\mathrm{F}(6,58)=41.90, p<.05$. In addition, a significant Group x Phase interaction, $\mathrm{F}$ $(12,116)=2.47, p<.05$, was observed. A summary of the results of the MANOVA are provided in Table I1 of Appendix I.

Based upon this significant interaction at the multivariate level, follow-up 3 x 3 [Group (violent lyrical music, non-violent lyrical music, no music) x Phase (baseline, music/no music condition, mental task) univariate mixed factors analyses of variance (ANOVAs) were conducted on SBP and HR. Given that preliminary analyses indicated significant differences in DBP at baseline, a 3 × 2 [Group (violent lyrical music, non-violent lyrical music, no music) x Phase (music/no music condition, mental task) univariate mixed factors analysis of covariance (ANCOVA) was conducted on DBP covarying baseline DBP.

\section{Systolic Blood Pressure (SBP)}

Results of the univariate ANOVA on SBP revealed a main effect for Phase, F $(1.4,90.3)$ $=113.48, p<.001$, partial $\eta^{2}=.64$. Mean baseline SBP $(M=117.3, S D=9.8 \mathrm{~mm} \mathrm{Hg})$ was significantly lower than mean music condition SBP $(M=119.3, S D=10.3 \mathrm{~mm} \mathrm{Hg})$ and mean 
mental task SBP $(M=131.9, S D=12.1 \mathrm{~mm} \mathrm{Hg})$. In addition, mean music condition SBP was significantly lower than mean mental task SBP. A significant Group x Phase interaction, F (2.8, $90.3)=2.94 . p<.05$, was also observed. This interaction was further analyzed using F-tests for simple main effects. No significant differences were observed across groups for average baseline $\operatorname{SBP}, \mathrm{F}(2,64)=.82$, average music condition $\operatorname{SBP}, \mathrm{F}(2,64)=.29$ and for average mental task SBP, F $(2,64)=2.06$ (all $p>.05)$. In contrast, significant main effects for Phase were observed for the violent music, $\mathrm{F}(1.3,26.6)=25.89, p<.001$, partial $\eta^{2}=.56$, the non-violent music, $\mathrm{F}(1.2,29.8)=40.71, p<.001$, partial $\eta^{2}=.63$, and no music (control) groups, $\mathrm{F}(2,40)$ $=56.44, p<.001$, partial $\eta^{2}=.74$. Participants in the violent music group exhibited lower average baseline SBP $(M=115.5, S D=9.6 \mathrm{~mm} \mathrm{Hg})$ relative to their average music condition SBP $(M=119.4, S D=11.1 \mathrm{~mm} \mathrm{Hg})$ and average mental task SBP $(M=127.6, S D=9.2 \mathrm{~mm}$ $\mathrm{Hg}$ ); their average music condition SBP was also significantly lower than their average mental task SBP. Participants in the non-violent music group also evidenced an average baseline SBP $(M=117.1, S D=7.1 \mathrm{~mm} \mathrm{Hg})$ that was significantly lower than their average music condition SBP $(M=120.3, S D=7.9 \mathrm{~mm} \mathrm{Hg})$ and mental task average SBP $(M=133.3, S D=11.8 \mathrm{~mm}$ $\mathrm{Hg}$ ). Their average music condition SBP was also significantly lower than average mental task SBP. Participants in the no music (control) group exhibited an average baseline SBP $(M=119.3$, $S D=12.4 \mathrm{~mm} \mathrm{Hg})$ that was significantly lower compared to their average mental task SBP $(M=$ 134.6, $S D=14.3 \mathrm{~mm} \mathrm{Hg})$. Although their average music condition $\mathrm{SBP}(M=118.0, S D=12.2$ $\mathrm{mm} \mathrm{Hg}$ ) was significantly lower than their average mental task SBP, it was not significantly different than their baseline SBP. Analyses for SBP are summarized in Table I2 of Appendix I. In addition, see Figure 3 for a summary of the SBP means for each group.

Diastolic Blood Pressure (DBP) 
Results of the ANCOVA revealed a main effect for Phase, $\mathrm{F}(1,63)=4.71, p<.05$, partial $\eta^{2}=.07$. Mean music condition DBP $(M=70.2, S D=11.5 \mathrm{~mm} \mathrm{Hg})$ was significantly lower than mean mental task DBP $(M=80.0, S D=12.1 \mathrm{~mm} \mathrm{Hg})$. The Group x Phase interaction approached significance, $\mathrm{F}(2,63)=3.11, p<.06$. Although not significant, this interaction was further analyzed using F-tests for simple main effects to determine whether differential patterns of DBP response would be observed across groups. No significant main effects for Phase were observed for the violent music, $\mathrm{F}(1,19)=.52$, or the non-violent music, F $(1,23)=.04$, groups (all $p>.05)$. However, a significant main effect for Phase was revealed for the no music (control) group, $\mathrm{F}(1,19)=7.17, p<.05$, partial $\eta^{2}=.27$. Participants in the no music (control) condition exhibited an average music condition DBP $(M=63.7, S D=11.5 \mathrm{~mm}$ $\mathrm{Hg})$ that was significantly lower than their average mental task DBP $(M=78.6, S D=12.4)$. A summary of the analyses for DBP are available in Table I3 of Appendix I. In addition, see Figure 4 for a summary of the DBP means for each group.

Heart Rate (HR)

Results of the univariate ANOVA on HR revealed a main effect for Phase, F $(1.2,78.6)=$ $89.89, p<.001$, partial $\eta^{2}=.59$. Mean baseline $\operatorname{HR}(M=70.5, S D=9.7 \mathrm{bpm})$ was significantly lower compared to mean music condition $\operatorname{HR}(M=71.9, S D=9.2 \mathrm{bpm})$ and mean mental task HR $(M=81.2, S D=11.9 \mathrm{bpm})$. In addition, mean music condition HR was significantly lower than mean mental task HR. The Group x Phase interaction approached significance, F $(2.5,78.6)$ $=2.77, p<.06$. Although not significant, this interaction was further analyzed using F-tests for simple main effects to determine whether differential patterns of HR response would be observed across groups. No significant differences were observed across groups for average baseline HR, $\mathrm{F}(2,64)=.16$, average music condition HR, $\mathrm{F}(2,64)=.10$, or for average mental task HR, F $(2$, 
$63)=2.01($ all $p>.05)$. In contrast, significant main effects for Phase were observed for the violent music, $\mathrm{F}(2,40)=37.70$, partial $\eta^{2}=.65$, non-violent music, $\mathrm{F}(1.3,29.3)=51.37$, partial $\eta^{2}=.69$, and no music (control) conditions, $\mathrm{F}(1.1,21.5)=23.27$, partial $\eta^{2}=.54$ (all $\left.p<.001\right)$. Participants in the violent music condition exhibited a significantly lower average baseline HR $(M=69.8, S D=9.9 \mathrm{bpm})$ compared to their average mental task $\mathrm{HR}(M=77.5, S D=8.8 \mathrm{bpm})$ their average music condition $\operatorname{HR}(M=71.9, S D=9.5 \mathrm{bpm})$ was also significantly lower than their mental task HR. Participants in the non-violent music condition also evidenced an average baseline $\mathrm{HR}(M=70.3, S D=9.9 \mathrm{bpm})$ that was significantly lower than their average mental task HR $(M=81.5, S D=10.8 \mathrm{bpm})$. Their average music condition HR $(M=71.2, S D=8.8$ bpm) was also significantly lower than their average mental task HR. Participants in the no music (control) condition exhibited an average baseline HR $(M=71.5, S D=9.7 \mathrm{bpm})$ that was significantly lower relative to their average mental task $\operatorname{HR}(M=84.7, S D=15.0 \mathrm{bpm})$. Their average music condition $\mathrm{HR}(M=72.8, S D=9.7 \mathrm{bpm})$ was also significantly lower than their mental task HR. A summary of the analyses for HR are provided in Table I4 of Appendix I. In addition, see Figure 5 for a summary of the HR means for each group.

\section{Additional Analyses}

\section{Music Preference Relationships}

Based upon the four main reported music preference groupings (alternative, country, rap/hip-hop and rock), an examination of the potential influence of participants' reported music preferences on their state anger, positive and negative affect, heart rate and blood pressure (systolic and diastolic) responses following exposure to either violent lyrical, non-violent lyrical or no music (control) was conducted using univariate analyses of variance (ANOVAs). No 
significant differences in these variables based upon participants' music preferences were observed (all $p>.05)$.

\section{Trait Hostility Relationships}

An investigation of potential relationships between trait hostility and post-music selfreport measures (i.e., post-music state anger, APQ total anger, APQ total frustration, APQ total irritated, and APQ aggressive behavioral action responses) was conducted using Pearson $r$ correlation analyses. Significant positive correlations between trait hostility and (a) APQ total anger $\left(r=+.34, N=44, p<.05, \mathrm{r}^{2}=.12\right)$ and (b) APQ total aggressive behavioral action response $\left(r=.33, p<.05, \mathrm{r}^{2}=.11\right)$ were observed. It is important to note that APQ total anger, frustration and irritated scores were missing data and that analyses are based upon available complete data; therefore, findings related to these variables should be interpreted with caution. Means and standard deviations for trait hostility relationships across all groups are provided in Table 12.

\section{Understanding of Lyrics}

For participants assigned to either the violent lyrical or non-violent lyrical music groups, they were asked to indicate their degree of understanding of the lyrics on a Likert scale ranging from 1 (very slightly) to 5 (perfectly). In order to examine the relationship between participants' understanding of the lyrics and number of reported aggressive behavioral action responses, point biserial correlation analyses were conducted. In combining both groups, a significant positive relationship between rating of understanding of lyrics and number of reported behavioral action responses was observed $\left(r=+.34, p<.05, \mathrm{r}^{2}=.12\right)$. However, subsequent analyses of each group individually indicated a significant positive relationship between understanding of lyrics and APQ aggressive behavioral action responses for the violent lyrical music group $(r=+.55, p$ 
$\left.<.05, \mathrm{r}^{2}=.30\right)$ but not for the non-violent lyrical group $(p>.05)$. Means, standard deviations and results for these correlational analyses across all groups are provided in Table 13.

\section{Mental Task Attempts and Number Correct}

A $3 \times 3$ [Group (violent lyrical music, non-violent lyrical music, no music) x Attempts (number of mental task attempts for minute 1, attempts for minute 2, and attempts for minute 3)] univariate mixed factors analysis of variance (ANOVA) was conducted to examine the impact of violent lyrical versus non-violent and no music exposure on participants' total number of attempts for each mental task. Results indicated significant within group differences for number of attempts across each minute task, $F(2,128)=34.07, p<.01$, partial $\eta^{2}=.35$. The mean number of mental task attempts for minute $1(M=14.0, S D=8.8)$ was significantly higher than the mean number of attempts for minute $2(M=10.4, S D=7.3)$ and minute $3(M=11.8, S D=$ 8.8). In addition, the mean number of attempts for minute 3 was significantly higher compared to the number of attempts for minute 2. No significant findings of a main effect for group, $F$ (2. $64)=.02, p>.05$, or a significant Group $\mathrm{x}$ Attempt interaction, $F(4,128)=5.28, p>.05$, were observed.

A $3 \times 3$ [Group (violent lyrical music, non-violent lyrical music, no music) x Correct (number of mental task correct for minute 1, correct for minute 2, and correct for minute 3)] univariate mixed factors analysis of variance (ANOVA) was also conducted to examine the impact of violent lyrical versus non-violent and no music exposure on participants' total number correct for each mental task. The analysis also revealed within group differences for number correct across each minute task, $F(2,128)=10.17, p<.01$, partial $\eta^{2}=.14$. The mean number correct for the minute 1 mental task $(M=10.2, S D=9.4)$ was significantly higher than the mean number correct for the minute 2 mental task $(M=6.6, S D=5.4)$. In addition, the mean number 
correct for the minute 3 mental task $(M=8.8, S D=9.0)$ was significantly higher than the mean correct for minute 2 mental task. No significant findings of a main effect for group, $F(2.64)=$ $.13, p>.05$, or a significant Group $\mathrm{x}$ Correct interaction, $F(4,128)=1.80, p>.05$, were observed.

\section{Supplemental Analysis}

A Crosstabs analysis was conducted between music condition (violent lyrical music and non-violent lyrical music) and level of understanding of lyrics for the 18 participants who indicated their lyrical understanding as being either "a little" or "very slightly" in order to determine if lyrical understanding may have influenced the study's outcome results. The results revealed that level of understanding was evenly distributed between the two music conditions. Given this finding, no further follow-up analyses are warranted because it appears this variable was randomly distributed across the conditions and, therefore, would have no discernable impact on the post-music outcome variables including state anger, positive and negative affect, aggressive behavioral action as well as on physiological responses (see Table 14).

Table 14

Level of Lyrical Understanding and Representation

Condition Did Not Understand Did Understand

\begin{tabular}{lcc}
\hline Violent Lyrical Music & 8 & 13 \\
$\begin{array}{l}\text { Non-Violent Lyrical } \\
\text { Music }\end{array}$ & 10 & 15 \\
\hline
\end{tabular}


Table 2

Demographics of Participants $(N=67)$

Variable

Frequency

Percent

Ethnicity/Race

White/Caucasian

Asian American / Pacific Island

64

95.5

3

4.5

$\underline{\text { Age }}$

$$
\begin{aligned}
& 18-19 \\
& 20-22 \\
& 23-25 \\
& 26-30
\end{aligned}
$$

Major

Accounting

Athletic coaching ed

Athletic training

Business and economics

Biology

Biometrics

Broadcast journalism

Business and marketing

Business administration

Business and financing

Business

Business and management

Communications

Computer science

Education

Exercise physiology

History

Journalism

MDS

Mech/Aero engineering

Medical technology

Physical education

Political science

Pre-Athletic training

Pre-Business and economics

Pre-Biology
4.5

1.5

3.0

4.5

4.5

1.5

1.5

1.5

1.5

1.5

14.9

4.5

1.5

1.5

4.5

1.5

1.5

1.5

1.5

3.0

1.5

1.5

3.0

1.5

4.5

1.5 
Variable

$\underline{\text { Major }}$

Pre-Business

Pre-History

Pre-Physical education

Psychology

Secondary education

Spanish

Sports management

Sports psychology

Undecided
Frequency Percent

3

4.5

$1 \quad 1.5$

$1 \quad 1.5$

$1 \quad 1.5$

$1 \quad 1.5$

$2 \quad 3.0$

$2 \quad 3.0$

$1 \quad 1.5$

$1 \quad 1.5$


Table 3

Music Preferences of Participants $(N=67)$

\begin{tabular}{lrr}
\hline & Frequency & Percent \\
\hline & & \\
\hline Alternative & 13 & 19.4 \\
Country & 8 & 11.9 \\
Electronica/Dance & 1 & 1.5 \\
Heavy Metal & 1 & 1.5 \\
Rap/Hip-Hop & 25 & 37.3 \\
Jazz & 1 & 1.5 \\
Pop & 1 & 1.5 \\
Rock & 12 & 17.9 \\
Soul/Funk & 1 & 1.5 \\
Sound Tracks & 2 & 3.0 \\
Other* & 2 & 3.0 \\
\hline
\end{tabular}

Note. Other preferences included Psy-Trance and Bluegrass. 
Table 4

Research Question 1: Summary of Significant Findings

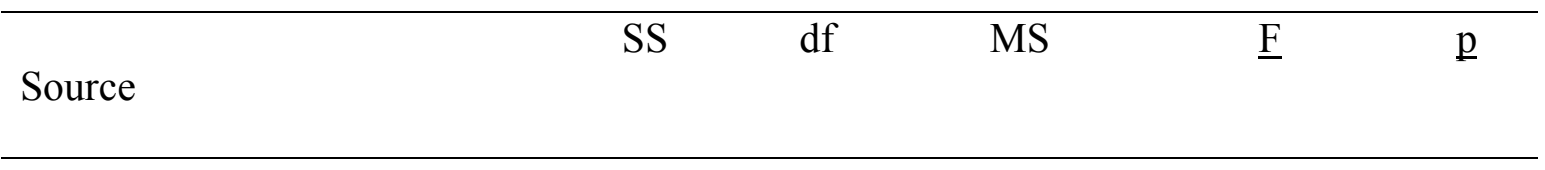

ANCOVA of APQ Total

Aggressive Action Response

Covariate

55.00

Group

$45.43 \quad 2$

55.00

9.40

$.003 *$

Error

$368.71 \quad 63$

22.72

$3.88 \quad .026^{*}$

$$
\begin{aligned}
& \mathrm{N}=67 \\
& * p<.05
\end{aligned}
$$


Table 5

Means and Standard Deviations for Research Question 1

\begin{tabular}{|c|c|c|c|}
\hline Variable & Violent Lyrical & Non-Violent Lyrical & No Music \\
\hline $\begin{array}{l}\text { APQ Total Anger } \\
(\mathrm{N}=44)\end{array}$ & $52.0(7.3)$ & $55.2(16.0)$ & $46.1(16.8)$ \\
\hline $\begin{array}{l}\text { APQ Total Irritated } \\
(\mathrm{N}=44)\end{array}$ & $56.6(11.8)$ & $62.5(14.1)$ & $58.9(11.9)$ \\
\hline $\begin{array}{l}\text { APQ Total Frustration } \\
(\mathrm{N}=44)\end{array}$ & $52.7(11.0)$ & $52.2(18.0)$ & $50.0(14.6)$ \\
\hline $\begin{array}{l}\text { APQ Total } \\
\text { Aggressive Action } \\
(\mathrm{N}=67)\end{array}$ & $2.9(3.3)$ & $2.2(2.4)$ & $1.4(1.8)$ \\
\hline $\begin{array}{l}\text { APQ Total Anger } \\
\text { Action } \\
(\mathrm{N}=67)\end{array}$ & $1.9(1.7)$ & $1.6(1.8)$ & $1.6(1.5)$ \\
\hline $\begin{array}{l}\text { APQ Total Assertive } \\
\text { Action } \\
(\mathrm{N}=67)\end{array}$ & $9.8(3.5)$ & $11.2(3.5)$ & $11.0(3.9)$ \\
\hline $\begin{array}{l}\text { APQ Total Avoidance } \\
\text { Action } \\
(\mathrm{N}=67)\end{array}$ & $2.9(1.5)$ & $3.0(2.1)$ & $3.0(1.6)$ \\
\hline $\begin{array}{l}\text { APQ Total No Action } \\
(\mathrm{N}=67)\end{array}$ & $3.5(2.8)$ & $3.0(2.6)$ & $4.0(1.8)$ \\
\hline
\end{tabular}

Note. The means and standard deviations for APQ Total Anger, APQ Total Irritated, and APQ Total Frustration reflect missing data and are based upon available accurate data. 
Table 6

Means and Standard Deviations for Research Question 2

\begin{tabular}{lccc}
\hline Variable & Violent Lyrical & Non-Violent Lyrical & No Music \\
\hline $\begin{array}{l}\text { Post-Music State } \\
\text { Anger }(\mathrm{N}=67)\end{array}$ & $18.9(4.9)$ & $17.2(2.8)$ & $16.9(2.7)$ \\
\hline
\end{tabular}


Table 7

Means and Standard Deviations for Research Question 3

\begin{tabular}{lccc}
\hline Variable & Violent Lyrical & Non-Violent Lyrical & No Music \\
\hline $\begin{array}{l}\text { Post-Music Positive } \\
\text { Affect }(\mathrm{N}=67)\end{array}$ & $27.0(8.9)$ & $28.7(7.9)$ & $23.2(9.3)$ \\
$\begin{array}{l}\text { Post-Music Negative } \\
\text { Affect }(\mathrm{N}=67)\end{array}$ & $13.9(4.2)$ & $13.4(2.7)$ & $14.7(3.8)$ \\
\hline
\end{tabular}


Table 8

Means, Standard Deviations and Summary of Correlational Analyses for the Violent Lyrical Group

\begin{tabular}{clllllrrrrrr}
\hline & 1. & 2. & 3. & 4. & 5. & 6. & 7. & 8. & 9. & 10. & 11. \\
& $\begin{array}{l}\text { APQ } \\
\text { AgAR }\end{array}$ & TA & TA-T & TA-R & $\begin{array}{l}\text { TA- } \\
\text { TI }\end{array}$ & $\begin{array}{l}\text { TA- } \\
\text { CO }\end{array}$ & $\begin{array}{l}\text { TA- } \\
\text { EI }\end{array}$ & $\begin{array}{l}\text { TA- } \\
\text { EO }\end{array}$ & AX-I & DML & PME \\
\hline 1.APQ & 1.00 & $.61^{* *}$ & $.44^{*}$ & $.65^{* *}$ & -.35 & $-.50^{*}$ & .03 & $.65^{* *}$ & $.49^{*}$ & .22 & .10 \\
AgAR & & & & & & & & & & & \\
M & 2.9 & 17.7 & 6.2 & 7.8 & 21.6 & 24.0 & 15.4 & 15.4 & 33.4 & 1.9 & .47 \\
SD & 3.3 & 6.3 & 2.9 & 3.0 & 5.3 & 4.8 & 5.1 & 3.5 & 13.7 & .74 & .51 \\
\hline
\end{tabular}

Note. APQ AgAR = Aggressive Action Response; TA = Trait Anger; TA-T = Trait Angry

Temperament; TA-R = Trait Angry Reaction; TA-CI = Trait Anger Control In; TA-CO = Trait Anger Control Out; TA-EI = Trait Anger Expression In; TA-EO = Trait Anger Expression Out; AX-I = Anger Expression Index; DML = Daily Music Listening Amount; PME = Prior Music Exposure.

$\mathrm{N}=21$ for each correlation.

${ }^{*} p<.05, * * p<.01$ 
Table 9

Summary of Correlational Analyses for the Non-Violent Lyrical Group

\begin{tabular}{|c|c|c|c|c|c|c|c|c|c|c|c|}
\hline & $\begin{array}{l}1 . \\
\text { APQ } \\
\text { AgAR }\end{array}$ & $\begin{array}{l}2 . \\
\text { TA }\end{array}$ & $\begin{array}{l}3 . \\
\text { TA- } \\
\mathrm{T}\end{array}$ & $\begin{array}{l}4 . \\
\text { TA- } \\
\text { R }\end{array}$ & $\begin{array}{l}5 . \\
\text { TA- } \\
\text { CI }\end{array}$ & $\begin{array}{l}6 . \\
\mathrm{TA}- \\
\mathrm{CO}\end{array}$ & $\begin{array}{l}7 . \\
\text { TA- } \\
\text { EI }\end{array}$ & $\begin{array}{l}8 . \\
\text { TA- } \\
\text { EO }\end{array}$ & 9. & $\begin{array}{l}10 . \\
\text { DML }\end{array}$ & $\begin{array}{l}11 . \\
\text { PME }\end{array}$ \\
\hline $\begin{array}{l}\text { 1.APQ } \\
\text { AgAR }\end{array}$ & 1.00 & .00 & .10 & -.04 & .09 & .02 & $-.41^{*}$ & .15 & -.15 & -.05 & .12 \\
\hline M & 2.2 & 18.0 & 6.2 & 8.5 & 21.2 & 24.0 & 17.2 & 15.8 & 35.9 & 2.4 & .36 \\
\hline $\mathrm{SD}$ & 2.4 & 4.4 & 2.2 & 2.1 & 6.1 & 4.2 & 4.6 & 3.2 & 13.7 & 1.0 & .49 \\
\hline
\end{tabular}

Note. APQ AgAR = Aggressive Action Response; TA = Trait Anger; TA-T = Trait Angry Temperament; TA-R = Trait Angry Reaction; TA-CI = Trait Anger Control In; TA-CO = Trait Anger Control Out; TA-EI = Trait Anger Expression In; TA-EO = Trait Anger Expression Out; AX-I = Anger Expression Index; DML = Daily Music Listening Amount; PME = Prior Music Exposure.

$\mathrm{N}=25$ for each correlation.

$* p<.05, * * p<.01$ 
Table 10

Summary of Correlational Analyses for the No Music Group

\begin{tabular}{|c|c|c|c|c|c|c|c|c|c|c|c|}
\hline & $\begin{array}{l}1 . \\
\text { APQ } \\
\text { AgAR }\end{array}$ & $\begin{array}{l}2 . \\
\text { TA }\end{array}$ & $\begin{array}{l}3 . \\
\text { TA- } \\
\mathrm{T}\end{array}$ & $\begin{array}{l}4 . \\
\text { TA- } \\
\text { R }\end{array}$ & $\begin{array}{l}5 . \\
\text { TA- } \\
\text { CI }\end{array}$ & $\begin{array}{l}6 . \\
\text { TA- } \\
\mathrm{CO}\end{array}$ & $\begin{array}{l}7 . \\
\text { TA- } \\
\text { EI }\end{array}$ & $\begin{array}{l}8 . \\
\text { TA- } \\
\text { EO }\end{array}$ & $\begin{array}{l}9 . \\
\text { AX-I }\end{array}$ & $\begin{array}{c}10 . \\
\text { DML }\end{array}$ & $\begin{array}{c}11 . \\
\text { PME }\end{array}$ \\
\hline $\begin{array}{l}\text { 1.APQ } \\
\text { AgAR }\end{array}$ & 1.00 & .33 & .28 & .29 & -.35 & -.35 & -.38 & .14 & .27 & -.07 & .24 \\
\hline $\mathrm{M}$ & 1.4 & 18.9 & 6.6 & 8.7 & 20.0 & 21.9 & 17.0 & 18.1 & 41.2 & 2.1 & .62 \\
\hline SD & 1.8 & 4.0 & 2.2 & 1.6 & 5.2 & 5.5 & 3.9 & 3.1 & 10.2 & .77 & .50 \\
\hline
\end{tabular}

Note. APQ AgAR = Aggressive Action Response; TA = Trait Anger; TA-T = Trait Angry

Temperament; TA-R = Trait Angry Reaction; TA-CI = Trait Anger Control In; TA-CO = Trait Anger Control Out; TA-EI = Trait Anger Expression In; TA-EO = Trait Anger Expression Out; AX-I = Anger Expression Index; DML = Daily Music Listening Amount; PME = Prior Music Exposure.

$\mathrm{N}=21$ for each correlation.

${ }^{*} p<.05, * * p<.01$. 
Table 11

Means and Standard Deviations for Research Question 9

\begin{tabular}{lllll}
\hline & $\begin{array}{l}\text { Alternative } \\
\text { Music Preference }\end{array}$ & $\begin{array}{l}\text { Country } \\
\text { Music Preference }\end{array}$ & $\begin{array}{l}\text { Rap/Hip-hop } \\
\text { Music Preference }\end{array}$ & $\begin{array}{l}\text { Rock } \\
\text { Music Preference }\end{array}$ \\
\hline $\begin{array}{l}\text { APQ Aggressive } \\
\text { Action }\end{array}$ & $3.3(3.9)$ & $1.9(2.0)$ & $2.2(2.2)$ & $1.5(2.6)$ \\
$\begin{array}{l}\text { Responses }(\mathrm{N}= \\
67)\end{array}$ & & & & \\
\hline
\end{tabular}


Table 12

Means, Standard Deviations and Correlational Analyses for Trait Hostility Relationships

\begin{tabular}{|c|c|c|c|c|c|c|}
\hline & $\begin{array}{l}1 . \\
\text { Trait } \\
\text { Hostility }\end{array}$ & $\begin{array}{l}2 . \\
\text { APQ } \\
\text { AgAR }\end{array}$ & $\begin{array}{l}3 . \\
\text { Post-Music } \\
\text { SA }\end{array}$ & $\begin{array}{l}4 . \\
\text { Total APQ } \\
\text { Anger }\end{array}$ & $\begin{array}{l}5 . \\
\text { Total APQ } \\
\text { Irritated }\end{array}$ & $\begin{array}{l}6 . \\
\text { Total APQ } \\
\text { Frustration } \\
\end{array}$ \\
\hline $\begin{array}{l}\text { 1. Trait } \\
\text { Hostility }\end{array}$ & 1.00 & $.33 * *$ & .10 & $.34^{*}$ & .24 & .24 \\
\hline \multicolumn{7}{|c|}{ Note. APQ AgAR = Aggressive Action Response; Post-Music SA = Post-Music State Anger. } \\
\hline
\end{tabular}


Table 13

Means, Standard Deviations and Correlational Analyses for Lyrical Understanding

\begin{tabular}{|l|c|c|}
\hline & $\begin{array}{c}\text { 1. Degree of Lyrical } \\
\text { Understanding }\end{array}$ & 2. APQ AgAR \\
\hline $\begin{array}{l}\text { 1. Degree of Lyrical } \\
\text { Understanding } \\
\text { M }\end{array}$ & 1.00 & $.34 *$ \\
SD & 2.70 & 2.16 \\
\hline
\end{tabular}

Note. APQAgAR = Aggressive Action Response.

$\mathrm{N}=46$ for correlation given that only violent lyrical and non-violent lyrical group participants evaluated their level of lyrical understanding.

${ }^{*} p<.05$. 

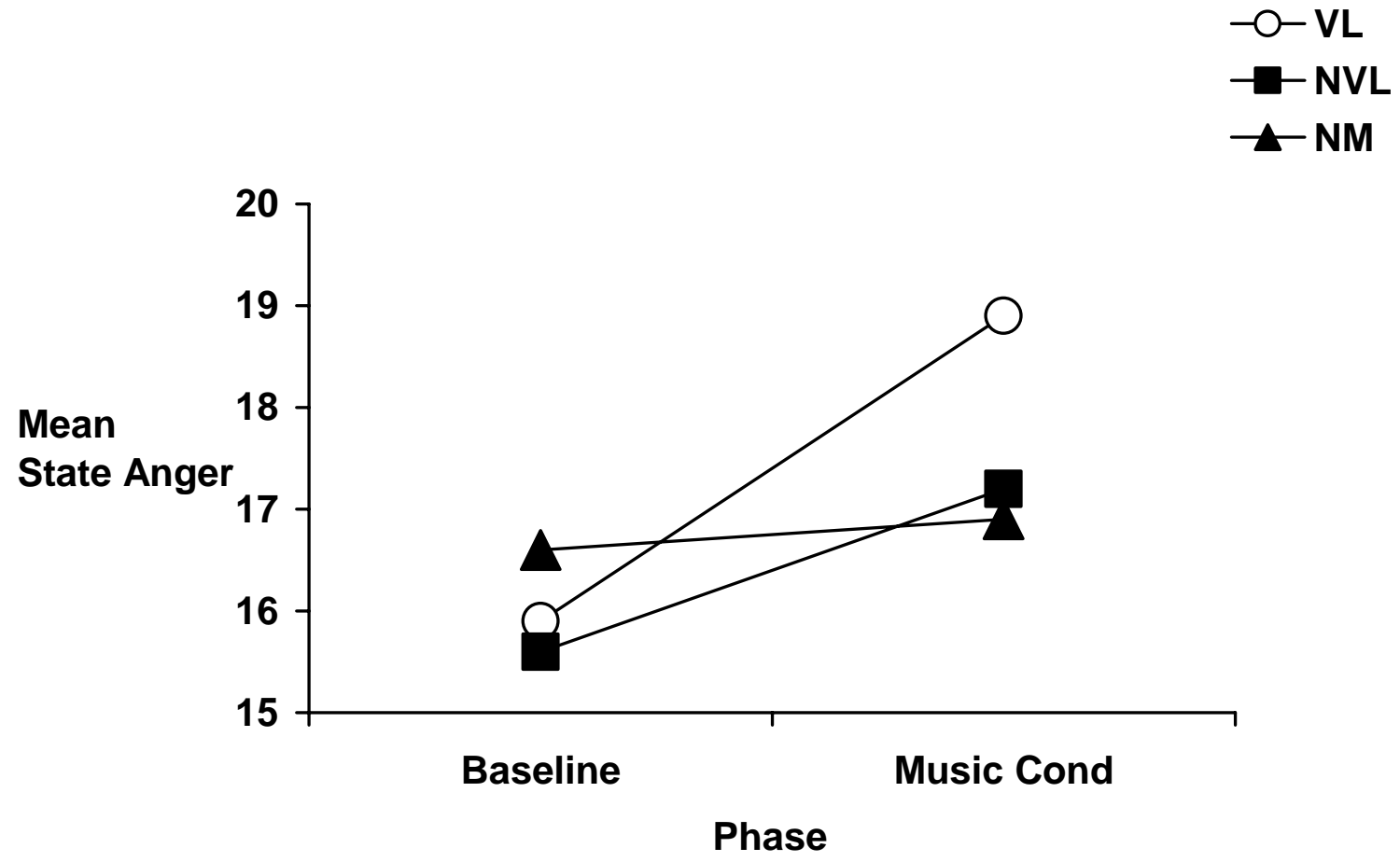

Figure 1. Mean state anger for each phase (baseline and music/no music condition) across all groups (violent lyrical, non-violent lyrical and no music) $(\mathrm{N}=67)$. 


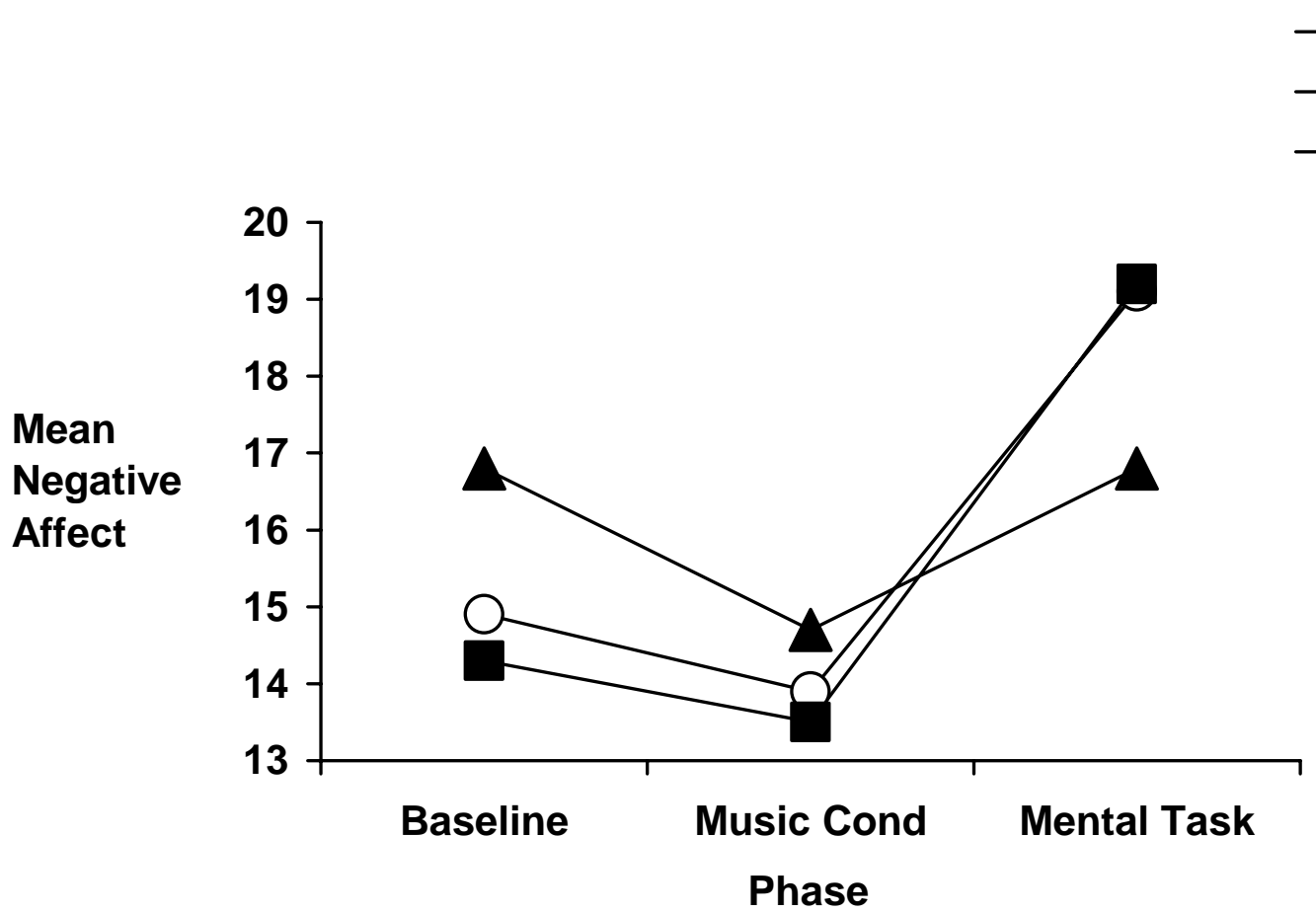

Figure 2. Mean negative affect for each phase (baseline and music/no music condition) across all groups (violent lyrical, non-violent lyrical and no music) $(\mathrm{N}=67)$. 

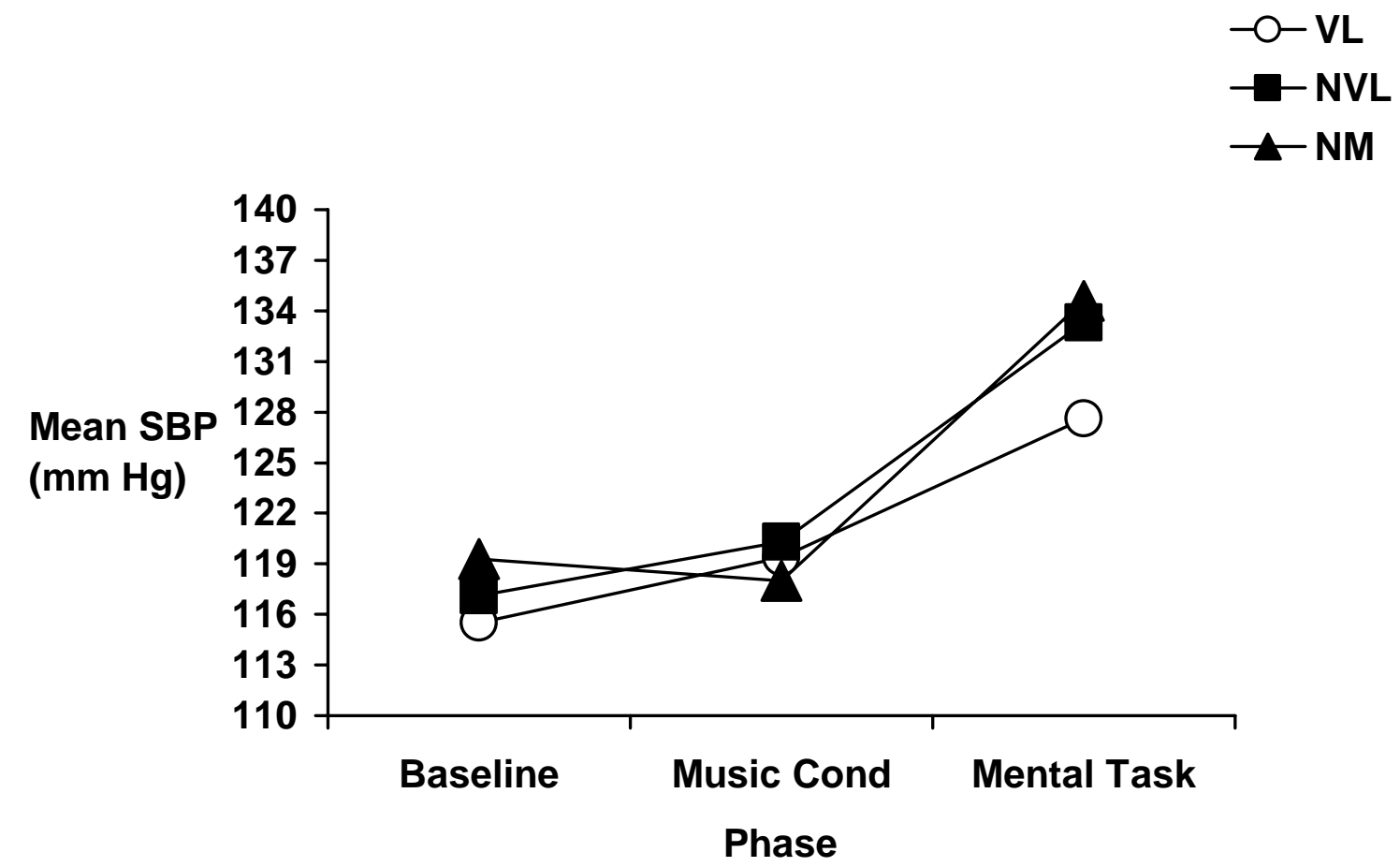

Figure 3. Mean systolic blood pressure (SBP) for each phase (baseline, music/no music condition and mental task) across all groups (violent lyrical, non-violent lyrical and no music) ( $\mathrm{N}$ $=67$ ). 

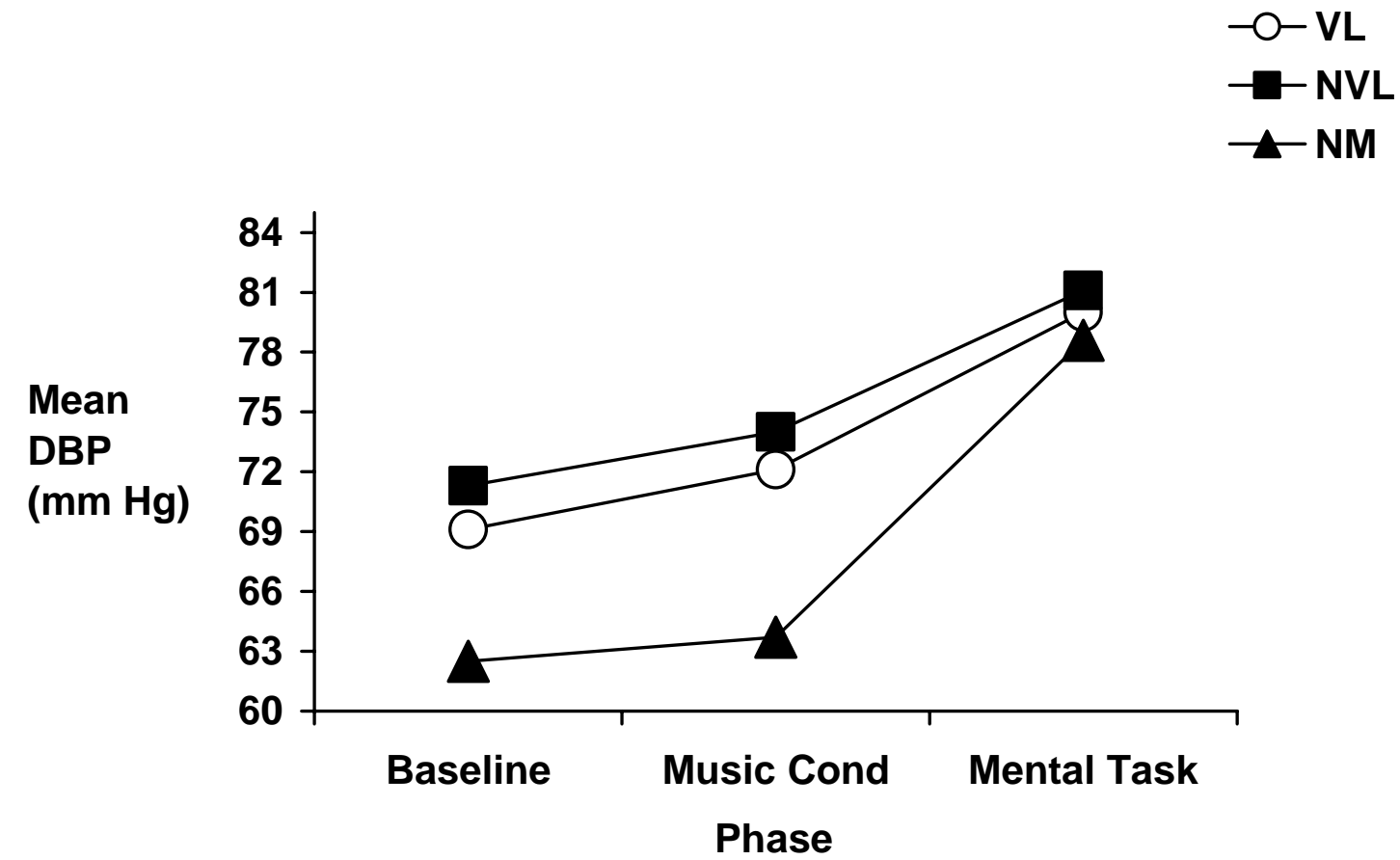

Figure 4. Mean diastolic blood pressure (DBP) for each phase (baseline, music/no music condition and mental task) across all groups (violent lyrical, non-violent lyrical and no music) ( $\mathrm{N}$ $=67)$. 

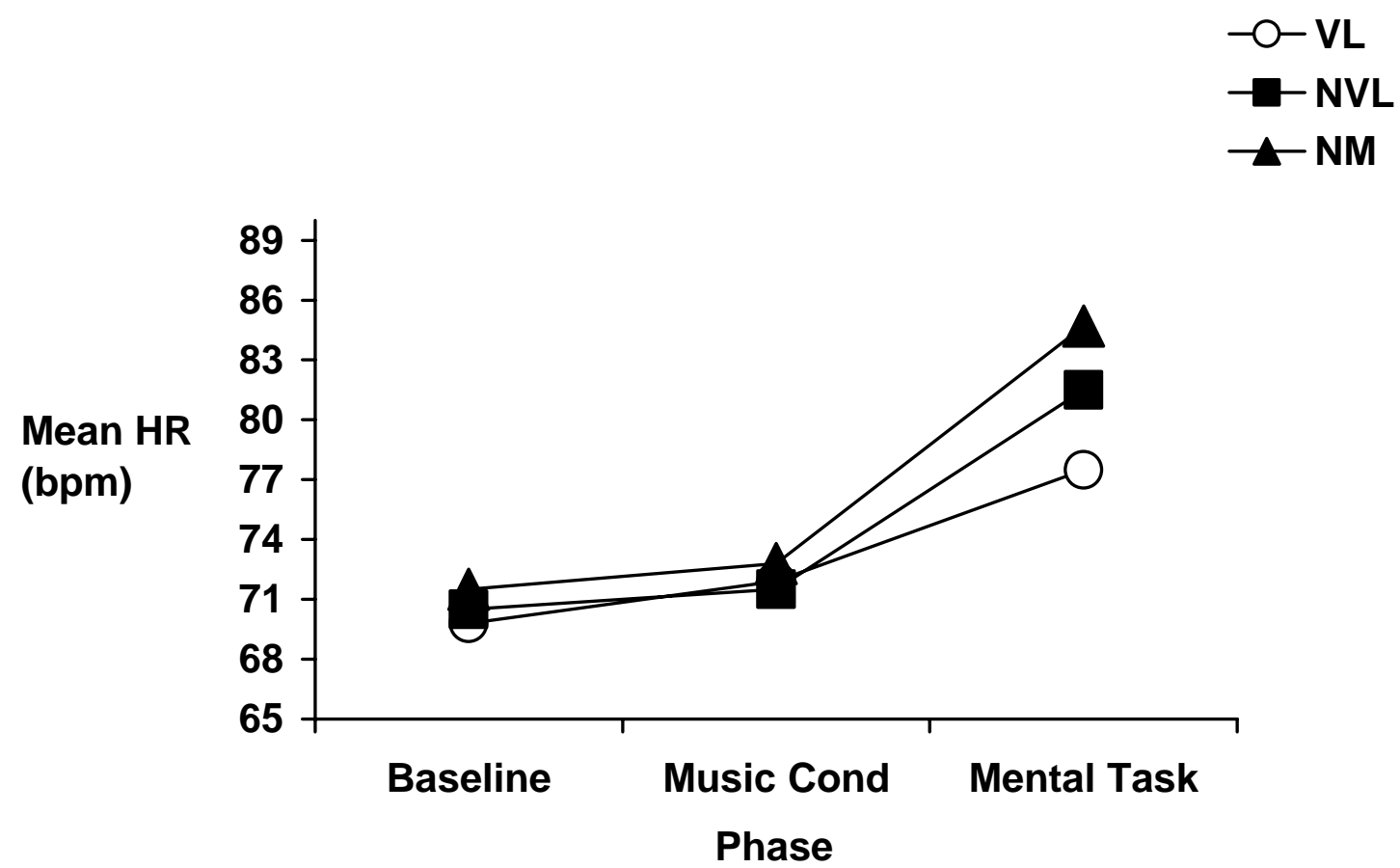

Figure 5. Mean heart rate (HR) for each phase (baseline, music/no music condition and mental task) across all groups (violent lyrical, non-violent lyrical and no music) $(\mathrm{N}=67)$. 


\section{Figure Captions}

Figure 1. Mean state anger for each phase (baseline and music/no music condition) across all groups (violent lyrical, non-violent lyrical and no music) $(\mathrm{N}=67)$.

Figure 2. Mean negative affect for each phase (baseline and music/no music condition) across all groups (violent lyrical, non-violent lyrical and no music) $(\mathrm{N}=67)$.

Figure 3. Mean systolic blood pressure (SBP) for each phase (baseline, music/no music condition and mental task) across all groups (violent lyrical, non-violent lyrical and no music) (N $=67)$.

Figure 4. Mean diastolic blood pressure (DBP) for each phase (baseline, music/no music condition and mental task) across all groups (violent lyrical, non-violent lyrical and no music) (N $=67)$.

Figure 5. Mean heart rate (HR) for each phase (baseline, music/no music condition and mental task) across all groups (violent lyrical, non-violent lyrical and no music) $(\mathrm{N}=67)$. 


\section{CHAPTER 5}

\section{Discussion}

The results of this study provide information on the impact exposure to violent lyrical music has on undergraduate college males' aggressive behavioral action responses. The study expands to include the effect of exposure to violent lyrical music on their state anger, anger and related feelings, affective (positive and negative), and physiological (heart rate and blood pressure) responses. While there is variability in the findings, they serve to further support previous research and offer new considerations for future study.

\section{Violent Lyrical Music and Aggressive Behavior}

Exposure to violent lyrical music does not appear to influence this population's report of anger and related feelings when responding to provocation scenarios. The findings reveal no significant differences in participants' APQ total anger, APQ total frustration, and APQ total irritated scores following exposure to either violent lyrical, non-violent lyrical or no music conditions. The interpretation is made with caution due to the size of the collected data $(\mathrm{N}=44)$ once cases with missing data were expunged.

The findings do show that those exposed to violent lyrical music and when provoked during a serial sevens mental task report more aggressive behavioral action responses compared to no music (control) participants, though there are no significant differences between the violent lyrical and non-violent lyrical groups. However, it is important to note that the increase in aggressive behavioral responses is only slightly higher for the violent lyrical group compared to the no music group.

These results are similar to those found in previous research studies. For instance, a review of Litman's (1997) work shows (1) a minimal effect on short-term aggressive behavioral 
responses following exposure to rap music alone, and (2) higher rates of nonverbal aggressive behavior following exposure to both rap music and lyrics in combination. This study expands Litman's findings to include the population of college males in addition to $3^{\text {rd }}$ and $5^{\text {th }}$ grade males. Another type of music and a differing measure of aggressive behavioral responses was used in an effort to enhance previous research given that the behavioral effects of violent lyrical music have not been investigated in detail in currently available psychological literature.

Barongan and Hall (1995) report exposure to misogynous rap music with lyrics reflecting cognitively distorted attitudes toward women may increase sexually aggressive behavior among exposed males. The type of music used in the study under discussion was different but did include negative lyrics and did affect college males' aggressive behavioral responses in other provocative situations in addition to those that are sexual in nature. Thus, this adds to their finding and also supports other research which suggests a relationship exists between listening to violent music and verbal aggression among adolescents (Akin et al., 2002).

In addition, the increase in behavioral action responses following exposure to violent lyrical music alone serves to expand upon Smith's (1995) observations of an increase in aggressive responses following exposure to violent music in combination with alcohol. That is, the current study reveals an increase in aggressive behavioral responses with violent lyrical music exposure even without the additional variable of the use of alcohol. The finding of no difference in aggressive behavioral action responses between the violent and non-violent lyrical groups is somewhat of a surprise; yet, this is likely attributed to similarity in the type of music in both songs. It is also important to note that participants' endorsements of avoidance, assertive, anger or no behavioral action responses do not differ significantly across the violent lyrical, nonviolent lyrical or no music groups. 


\section{Violent Lyrics and State Anger}

Exposure to violent lyrical as well as to non-violent lyrical and no music does not appear to impact one's level of state anger. The college males' exposure to violent lyrical music does not correspond to a higher level of state anger. This finding deviates from previous research, which suggests violent music yields higher levels of state hostility (Anderson, Carnagey \& Eubanks, 2003). The use of heavy metal music clips may serve to explain the non-significant findings for state anger. One study tells us undergraduate males exposed to rap music exhibit more angry responses than those exposed to heavy metal music (Ballard \& Coates, 1995). Small sample sizes and homogeneous ethnic representation of the groups may also explain the contradiction. Therefore, the current study's findings are to be interpreted with caution.

\section{Violent Lyrics and Affect}

Upon examination, exposure to violent lyrical music did not have a significant impact on college males' positive and negative affect responses relative to non-violent lyrical or no music exposure. Rather, regardless of exposure condition, participants' level of positive affect declined with post-task positive affect showing the most significant decline relative to baseline positive affect. In addition, participants' level of negative affect increased with both music/no music exposure and provocation, though there were no unique group differences. These findings differ from previous reports which say specific exposure to happy, sad or fearful music contributes to like emotional experiences among participants (Krumhansl, 1997). In addition, music is indicated as being the stimulus that most often causes intense emotional responses with sad music more often being associated with such responses (Goldstein, 1980; Pansepp, 1995; Stratton \& Zalanowski, 1994). While it may be believed other types of music may yield similar findings, the affective reactions of these study participants to violent lyrical music alone do not 
lend support to this belief. Further research would help to distinguish if type of music influences individual affective reactions. The small sample size may influence outcomes so the research must be done on larger groups.

\section{Violent Lyrics and Trait Anger}

The results of this study show a significant positive correlation between total number of aggressive behavioral action responses and (a) total trait anger, (b) trait-angry temperament, and (c) trait-angry reaction for the violent lyrical group. The violent lyrical group participants show an increase in their total trait, trait-angry temperament and trait-angry reaction scores as well as their number of aggressive behavioral action endorsements. More specifically, 37 percent of the variance in aggressive behavioral action responses can be associated with the variance in trait anger while 19 percent of the variance is associated with trait-angry temperament with 42 percent of the variance being related to trait-angry reaction. These findings are consistent with the known likelihood that one's predisposition for anger serves to inform one's subsequent responses to anger provoking situations (Spielberger, 1999). Yet, this relationship is only indicated for the violent lyrical group, which suggests listening to violent lyrical music when combined with one's trait anger disposition influences subsequent aggressive action responses. These findings offer new information for the field. The current study also uses behavioral action response measures that have not been previously studied with respect to trait anger dispositions. More research with diverse samples will be needed to verify and/or expand the study's current findings.

There is a significant inverse relationship between level of trait anger control-out and number of reported aggressive behavioral action responses to provocation scenarios after exposure to violent lyrical music. As level of trait anger control-out increases, the number of 
aggressive behavioral action responses appears to decrease. Trait anger-control out appears to account for 25 percent of the variance in aggressive behavioral action responses. This effect does not seem to occur after exposure to non-violent lyrical or no music. This finding could be anticipated as it is expected that one's degree of effort to control angry feelings by preventing outward expressions of anger (anger control-out) could affect one's aggressive behavioral responses. Yet, according to the study's findings, the same relationship is not true of one's efforts to control suppressed anger by calming oneself, or anger control-in, and one's level of subsequent aggressive behavioral actions upon being exposed to violent lyrical music. In addition, degree of anger control-out and anger control-in does not appear to influence those exposed to non-violent lyrical or no music in a like manner. This suggests a unique correlation between violent lyrical music exposure, level of control-out, and subsequent level of aggressive behavioral action responses. More research in this area is needed to determine generalizability of the study's findings to larger and more diverse groups.

There is a relationship between undergraduate college males' level of trait anger expression-in and trait anger expression-out and number of aggressive behavioral action responses to provocation scenarios following exposure to either violent lyrical, non-violent lyrical or no music. Exposure to violent lyrical music and trait anger expression-out positively influences aggressive behavioral responses with trait anger expression-out accounting for 42 percent of the variance in number of aggressive behavioral responses among violent lyrical participants. As level of trait anger expression-out increases, number of aggressive behavioral responses increases as well. This finding could be expected given that trait anger expression-out measures how often one expresses anger outwardly (Spielberger, 1999). However, for those listening to non-violent lyrical music, the degree of anger expression-in is negatively correlated 
with their subsequent report of aggressive behavioral action responses with anger expression-in accounting for 17 percent of the variance among non-violent lyrical males. The report of aggressive behavioral responses decreases as the degree of suppression of anger experiences increases. One can anticipate anger suppression may reduce people's level of outward anger expression (Spielberger, 1999). Yet, additional research is needed to determine generalizability of these findings to larger and more diverse samples.

Undergraduate college males' overall anger expression and control tendencies also influence their aggressive behavioral action responses after listening to violent lyrical music. The same significant differences are not found for those who listened to non-violent lyrical or no music. One's overall anger expression index is a composite of anger expression (in and out) and anger control (in and out) tendencies (Spielberger, 1999). Previously discussed findings indicate that among college males' anger control-out and anger expression-out tendencies influence subsequent aggressive behavioral action responses when exposed to violent lyrical music. Therefore, this finding for overall anger expression and control tendencies reinforces the previous discussions of the findings for these individual scales among violent lyrical participants.

\section{Music Preference and Prior Music Exposure}

The amount of music this population listens to in a day is not associated with members' aggressive behavioral action responses, whether they are provoked toward that action after listening to music with or without violent lyrics or no music at all. Therefore, amount of daily music listening does not appear to impact level of aggressive behavioral action responses. Again, it is important to note that the current study's samples are small and generalizability of these findings requires larger samples. 
Upon considering the predominant music preference groupings for this group of undergraduate college males (alternative, country, rap/hip-hop and rock), it is suggested that music preference also does not appear to impact level of aggressive behavioral action responses among this population. This finding does not support previous research reports which suggest college students and adolescents with certain music preferences (e.g., heavy metal) will respond negatively with higher levels of aggressive attitudes, less regard for women, and behavioral problems (Ballard, Took, \& Weiss, 1994; Rubin, West, \& Mitchell, 2001). Given the distribution of reported music preferences relative to the small sample size of the current study, there is not enough data available across the music preference categories to accurately determine the presence of any relationships. Additional research with a larger sample is needed in order to further understand the influence of individual music preference on subsequent behavioral responses.

According to the study's findings, another factor that does not influence aggressive behavioral action responses is recent repetitive music exposure. The results of the study show listening to music during the day before the experiment did not influence undergraduate college males' subsequent aggressive behavioral action responses. This finding indicates that previous music exposure, regardless of type, does not appear to confound their subsequent responses. Research using larger samples is suggested to further examine relationships between repetitive exposure to certain music types and subsequent behavioral response patterns.

\section{Music Exposure and Cardiovascular Responses}

Comparisons in undergraduate college males' heart rate and blood pressure (systolic and diastolic) responses are reported in this study across baseline, music or no music exposure and serial sevens mental task phases. Among all participants, significant within phase differences in 
their physiological responses are indicated for all three cardiovascular measures regardless of type of music exposure or lack thereof. This suggests that baseline systolic blood pressure (SBP) is lower compared to music exposure SBP and mental task SBP . In addition, music exposure SBP is significantly lower than mental task SBP among all participants. Upon examining diastolic blood pressure (DBP) among all participants, baseline DBP differs across groups and is indicated as a covariate to be included when conducting other DBP analyses. Results of these analyses indicate that for all participants music condition DBP is significantly lower than their mental task DBP. Regarding heart rate (HR), the current study's findings indicate that for all participants baseline HR is significantly lower than heart rate during music exposure and mental task phases. When considering all participants, music exposure HR is also significantly lower than mental task HR. These findings suggest that undergraduate college males' blood pressure (systolic and diastolic) and heart rate responses differ during baseline, music/no music exposure and task completion regardless of their experimental condition group assignment.

Interaction effects between baseline, music exposure and mental task phases and group assignment (violent lyrical, non-violent lyrical or no music) are observed for systolic blood pressure (SBP). While no significant differences in SBP across groups are revealed, there are indications of within group differences in SBP across phases. Participants in the violent lyrical music group evidence lower baseline SBP relative to their SBP measures for the music exposure and mental task conditions. The non-violent lyrical music group exhibits this same trend. Average baseline SBP is also found to be significantly lower than mental task SBP among those who listened to no music. In addition, their average music exposure SBP is significantly lower than their average mental task SBP. Yet, their average no music exposure SBP is not significantly different than their baseline SBP. This could be expected given that they were not 
exposed to music. While within group differences among their baseline and music exposure SBP are evidenced for the violent lyrical group participants, between group differences are not revealed as was anticipated prior to the start of the study.

Upon further examination of interaction effects between phase (baseline, music exposure, mental task) and group assignment (violent lyrical, non-violent lyrical, no music), there appears to be no significant interactions for diastolic blood pressure (DBP). Yet, the results do approach significance and warrant further study with larger, more diverse groups. However, upon considering each group individually, a phase effect is indicated for the no music group participants. These participants exhibited the most variance in their mental task responses following condition exposure indicating that the violent lyrical and non-violent lyrical participants were less reactive relative to no music participants.

An investigation for potential interactions for heart rate between baseline, music exposure and mental task phases and group assignment also approached significance, though no significant interactions are indicated for participants' heart rate measures. Yet, these findings warrant further research attention with larger, more diverse groups. Additional analyses also suggest no significant group differences for participants' baseline, music exposure and mental task HR measures. However, within group differences are again indicated for violent lyrical exposure. These participants exhibit lower baseline HR relative to mental task HR. Their music exposure HR is also lower than their mental task HR. The same trends are observed within the non-violent lyrical and no music groups. Although anticipated, there does not appear to be between or within group differences for participants' baseline HR and music exposure HR.

As we consider these findings for the physiological measures under investigation, it is important that we review the previous research in this area. One study suggests that type of 
music exposure influences heart rate and blood pressure responses with sad music being found to contribute to a decrease in heart rate and increase in systolic and diastolic blood pressures (Krumhans1, 1997). Yet, other research findings indicate that music exposure contributes to decreases in heart rate (e.g., Guzetta, 1989). Still other studies have suggested mixed findings with some observing increases in heart rate with exposure to various types of music (e.g., excitative or sedative music types) or no changes in HR upon exposure (DeJong, Van Mourick, \& Schellekens, 1973; Ellis \& Brighouse, 1952; Iwanaga \& Moroki, 1999; Landreth \& Landreth, 1974; Vanderark and Ely, 1994; Zimny \& Weidenfeller, 1963). Similar mixed findings are indicated for blood pressure. One study indicates more pronounced increases in blood pressure with excitative versus sedative music (Iwanaga \& Moroki, 1999) while other studies suggest no significant increases in blood pressure with exposure to these or other types of music (Bassagaoglu, Kalkan \& Sari, 2004; Vanderark \& Ely, 1994).

A number of the current findings support previous research reports, which find no increase in heart rate or diastolic blood pressure with music exposure. However, one outstanding variable appears, there is an increase in SBP with exposure to violent lyrical as well as nonviolent lyrical music. This differs from the DBP and heart rate findings. Therefore, overall, this study serves to support the current mixed findings reported in the literature regarding music exposure and its effects on individual's cardiovascular measures. It adds to the literature with its investigation of the effects of other music types (violent lyrical and non-violent lyrical) on heart and blood pressure measures. In addition, it expands previous research by focusing on undergraduate college males' physiological responses to music exposure. Yet, additional research using more heterogeneous groups is warranted in an effort to further understand the 
impact of exposure to violent lyrical versus non-violent lyrical music on this population's physiological responses.

Music preferences do not appear to play a role in post-music anger, affective or physiological responses. This discovery is contrary to Ballard, Took and Weiss's (1994) reports that rap and heavy-metal music preferences are associated with various negative responses among adolescents. Future research in this area is warranted to further understand the role that music preferences play in individual's subsequent response patterns.

The results of an examination of relationships between trait hostility and post-music selfreport measures (i.e., post-music state anger, APQ total anger, APQ total frustration, APQ total irritated, and APQ aggressive behavioral action responses) are also provided in the current study. Level of trait hostility serves to positively influence APQ total anger and APQ total aggressive behavioral action responses and accounts for 12 percent and 11 percent of the variance in total anger and total aggressive behavioral action responses, respectively. As level of trait hostility increases so does reports of anger and aggressive behavioral response to provocation scenarios. However, the same trend is not indicated for the other variables. While Anderson et al. (2003) reveals a relationship between trait hostility and state hostility responses, the current study does not indicate a significant relationship between trait hostility and the state measure of anger post music exposure. Regarding the other findings, it is important to note that analyses for APQ total anger, frustration and irritated scores could only be performed on available complete data, lessening the total number $(\mathrm{N}=44)$, and should be interpreted with caution.

The results of the experiment show a positive relationship between lyrical understanding and number of aggressive behavioral responses among the violent lyrical and non-violent lyrical groups when considered together with degree of lyrical understanding accounting for 12 percent 
of the variance in aggressive behavioral action responses among participants in both groups. However, this relationship is only found for the violent lyrical group when the groups are analyzed separately. Among violent lyrical participants, degree of lyrical understanding accounted for 30 percent of the variance in aggressive behavioral action responses. It appears this group accounts for the previous significant relationship found when considering all groups as a combined unit. Lyrical understanding may be of special significance for individuals exposed to violent lyrical music. Given these findings, consideration of the impact of the reports of those participants who indicated their lyrical understanding as being either "very slightly" or "a little" on the study's findings is explored and indicates that these participants were evenly distributed across the violent lyrical and non-violent lyrical groups and therefore the above findings are accurate representations free of this potential bias. Such findings support the hypothesis that the impact of music lyrics warrants attention and better understanding in the psychology literature.

No significant findings were discovered in the analysis of the degree to which exposure to violent lyrical versus non-violent lyrical or no music impacts number of mental task attempts and number correct results. In effect, the type of music exposure, or lack thereof, does not appear to impact mental task responses and degree of correctness. While Anderson et al. (2003) indicates cognitive effects occur from exposure to violent lyrical versus non-violent lyrical music, the current study does not suggest mental task cognitive efforts are impacted by the exposure music. However, it is also important to note that Anderson and colleagues investigated cognitive effects using different measures. This may serve to explain the lack of significant findings in the current study for the serial sevens mental task measure. Therefore, additional research to further investigate the impact of music on undergraduate college males' cognitive task performance is likely to be beneficial in delineating the essential variables involved. 


\section{Conclusions/Implications}

The current study suggests that exposure to violent lyrical music and subsequent provocation may contribute to increased aggressive behavioral action responses among undergraduate college males. Such findings provide further support for previous research suggesting that media depictions of violence in their various forms may serve to influence behavior among adolescents including their degree of participation in at-risk and violent behavior (e.g., Hoberman, 1990; Strasburger, 1995). More specifically, there is a need for more attention to the lyrical content of audio music given its potential to have a negative influence on future behavioral responses of this age group. Additional research involving other behavioral measures would allow for further elucidation of potential deleterious effects of violent music exposure. Given that violent lyrical participants' level of trait anger, trait anger control-out, trait anger expression-out and overall anger expression may be related to their level of behavioral aggressive responses, these appear to be important individual variables that are worthwhile to consider in evaluating the potential risks from violent music exposure.

The study's outcomes also have clinical relevance. They provide information to consider when working with individuals or, more specifically, with adolescents who exhibit aggressive behavioral patterns and related anger management difficulties. For example, the nature of the music these individuals are listening to may serve as a potential trigger factor for aggressive action and should be considered for intervention. We suggest that there is a potential need for monitoring of one's music exposure. Yet, the study's findings also indicate that violent lyrical music whose degree of lyrical understanding is lacking may not be associated with negative behavioral action responses. Additional research to further clarify the relationship between lyrical understanding and aggressive behavioral responses is warranted. In addition, one's 
predisposition for anger appears to be a significant factor to consider given its relationship with subsequent aggressive behavioral responses as indicated in the current study.

State anger and affective responses do not appear to be impacted following exposure to violent lyrical music. In addition, neither music preferences nor pre-study music exposure appear to impact subsequent reported aggressive behavioral responses, state anger, affective or physiological responses following exposure to violent lyrical music. Such findings suggest that violent lyrical music exposure does not negatively influence college males' anger and affective responses. In addition, one's music preference does not appear to have negative implications as might be anticipated. Yet, given the small sample sizes under study, these findings must be considered preliminary in nature and therefore, warrant further investigation in future research.

Undergraduate college males' physiological responses (heart rate and systolic and diastolic blood pressure) do not appear to be significantly impacted with exposure to violent lyrical music relative to non-violent and no music exposure. While no between group differences are indicated for each cardiovascular parameter, violent lyrical as well as non-violent lyrical exposure do appear to be associated with increases in systolic blood pressure. Such findings add to the mixed findings of current research. Longitudinal research may assist in determining if this slight rise in systolic blood pressure will increase significantly and/or cause harm if the practice continues.

To listen or not to listen to violent lyrical music still remains a question to be explored, though the current study serves to uncover additional information regarding the impact of violent lyrical music exposure even if in a tentative way. Yet, additional research is needed in order to better understand the implications of violent lyrical music exposure. The study's limitations and recommendations for future research will be further explored in subsequent sections. 


\section{Limitations of Study}

In making interpretations regarding the current study's findings, the study's limitations should first be considered. Among the potential limitations of the proposed study regards the use of a convenience sample and its representativeness of the actual population. A related limitation is the degree of generalizability to the actual population under investigation. Another limitation relates to the use of an all male undergraduate sample for investigation. This limits the generalizability of the study's findings beyond the undergraduate college male population. The study's sample is also homogeneous in terms of racial/ethnic representation again limiting the study's findings to the Caucasian male undergraduate sector. Apart from the demographic limitations of the study's sample, the sample sizes of the groups understudy are minimal in number.

An additional limitation is the use of self-report instruments and the related issue of the accuracy of the participants' reports related to the variables under investigation (Cohen \& Swerdlik, 1999). Related to this is the issue of social desirability and the associated question of whether or not participants' responses were accurate representations or rather were indicative of efforts to present themselves in a positive, or socially appropriate, manner. Other limitations relate to data analysis procedures including the issue of missing data for the APQ feelings scales, which thereby impacted the nature of the study's findings with regards to the scales' constructs. In addition, the use of correlational analyses to examine a number of the study's research questions provide indications of relationships among the variables being studied though preclude identification of causality. 


\section{Future Research Recommendations}

Given the current study's findings, the following directions for future research are suggested: (a) Future research should be facilitated using a larger, more heterogeneous sample in terms of gender and race/ethnicity of participants in an effort to confirm, disconfirm and/or expand the current study's significant findings upon replication with another more diverse sample. (b) Also, given that one of the primary instruments used in the study (i.e., the APQ) is relatively new and has not been used previously to study the constructs investigated in this study, additional research is needed to further validate the utility of the instrument for research purposes. (c) In addition, future research that includes other behavioral measures to assess for individual impact of exposure to violent lyrical music may likely be beneficial. (d) The inclusion of a social desirability measure in subsequent research is recommended in order to control for this potential confounding variable. (e) Further exploration of the specific elements of a music piece (e.g., lyrics or the music itself) involved in subsequent aggressive behavioral responses warrants further attention as well in order to better understand what factors contribute to and/or are associated with such responses. 


\section{References}

Anderson, C. A., \& Bushman, B. J. (2001). Effects of violent video games on aggressive behavior, aggressive cognition, aggressive affect, physiological arousal, and prosocial behavior: A meta-analytic review of the scientific literature. Psychological Science, 12(5), 353-359.

Anderson, C. A., Carnagey, N. L., \& Eubanks, J. (2003). Exposure to violent media: The effects of songs with violent lyrics on aggressive thoughts and feelings. Journal of Personality \& Social Psychology, 83(5), 960-971.

Atkin, C. K., Smith, S. W., \& Roberto, A. J. (2002). Correlates of verbally aggressive communication in adolescents. Journal of Applied Communication Research, 30(3), 251-268.

Ballard, M. E. (1999). Resting arousal, sensation seeking, and music preference. Genetic, Social, \& General Psychology Monographs, 125(3), 229-250.

Ballard, M. E., \& Coates, S. (1995). The immediate effects of homicidal, suicidal, and nonviolent heavy metal and rap songs on the moods of college students. Youth and Society, 27(2), 148-168.

Ballard, M. E., \& Wiest, J. R. (1996). Mortal Kombat: The effects of violent videogame play on males' hostility and cardiovascular responding. Journal of Applied social Psychology, 26, 717-730.

Barongan, C., \& Hall, G. C. N. ( 1995). The influence of misogynous rap music on sexual aggression against women. Psychology of Women Quarterly, 19(2), 195-207.

Bassagaoglu, I. B., Kalkan, M. T., \& Sari, N. (2004). The physiological and 
psychological effects of classical music and pop music on female high school students. Yeni Symposium, 42(2), 82-90.

Benjamin, A. J. (1999). The influence of locus of control and aggressiveness of rock music videos on aggression: A reanalysis and methodological critique of Wann and Wilson (1996). Journal of Social Behavior and Personality, 14(4), 491-498.

Bushman, B. J. (1996). Individual differences in the extent and development of aggressive cognitive-associative networks. Personality and Social Psychology Bulletin, 22, 811-819.

Buss, A. H., \& Perry, M. (1992). The aggression questionnaire. Journal of Personality and Social Psychology, 63, 452-459.

Cohen, R. J., \& Swerdlik, M. E. (1999). Psychological testing and assessment ( $4^{\text {th }}$ ed.). Mountain View, CA: Mayfield Publishing Company.

Cook, W. W., \& Medley, D. M. (1954). Proposed hostility and pharisaic-virtue scales for the MMPI. Journal of Applied Psychology, 38, 414-418.

Cooper, J., \& Mackie, D. (1986). Video games and aggression in children. Journal of Applied Social Psychology, 16, 726-744.

Cooperative Institutional Research Program. (1999). Cooperative Institutional Research Program survey results. Ames, IA: Office of Institutional Research.

Cortina, J. M. (1993). What is coefficient alpha?: An examination of theory and applications. Journal of Applied Social Psychology, 78, 98-104.

Davis, W. B., \& Thaut, M. H. (1989). The influence of preferred relaxing music 
on measures of state anxiety, relaxation, and physiological responses. Journal of Music Therapy, 26, 168-187.

Drabman, R. S., \& Thomas, M. H. (1974). Does media violence increase children's toleration of real-life aggression? Developmental Psychology, 10, 418-421.

Frazer, N. L., Larkin, K. T., \& Goodie, J. L. (2002). Do behavioral responses mediate or moderate the relation between cardiovascular reactivity to stress and parental history of hypertension? Health Psychology, 21 (3), 244-253.

Freeman, S. J. (2003). [Review of the State-Trait Anger Expression Inventory-2.] In B. S. Plake, J. C. Impara \& R. A. Spies (Eds.), The fifteenth mental measurements yearbook (pp. 875 - 876). Lincoln, NE: Buros Institute of Mental Measurements.

Frost, R., \& Stauffer, J. (1987). The effects of social class, gender, and personality on physiological responses to filmed violence. Journal of Communication, 37(2), 29-45.

Funk, J. A. (1993). Reevaluating the impact of video games. Clinical Pediatrics, 32, 86-90.

Gerbner, G., \& Signorelli, N. (1990). Violence profile, 1967 through 1988-1989: Enduring patterns. Unpublished manuscript, Annenberg School of Communication, University of Pennsylvania.

Goldstein, A. (1980). Thrills in response to music and other stimuli. Physiological Psychology, 8, 126-129.

Goldstein, A. P. (1994). The ecology of aggression. New York: Plenum.

Guzzetta, C. E. (1989). Effects of relaxation and music therapy on patients in a 
coronary care unit with presumptive acute myocardial infarction. Heart \& Lung, 18, 609618.

Hansen, C. H., \& Hansen, R. D. (1990). Rock music videos and antisocial behavior. Basic and Applied Social Psychology, 11, 357-369.

Hardy, J. D., \& Smith, T. W. (1988). Cynical hostility and vulnerability to disease: Social support, life stress, and physiological response to conflict. Health Psychology, 7(5), 447-459.

Hoberman, H. M. (1990). Study group report on the impact of television violence on adolescents. Journal of Adolescent Health Care, 11(1), 45-49.

Huesmann, L. R., \& Eron, L. D. (1986). Television and the aggressive child: A cross-national comparison. Hillsdale, NJ: Erlbaum.

Huesmann, L. R., Moise, J. F., \& Podolski, C. L. (1997). The effects of media violence on the development of antisocial behavior. In D. M. Stoff, \& J. Breiling (Eds.), Handbook of antisocial behavior (pp. 181-193). New York, NY: John Wiley \& Sons, Inc.

Huston, A. C., Donnerstein, E., Fairchild, H., Feshbach, N. D., Katz, P. A., Murray, J. P., Rubinstein, E. A., Wilcoz, B. L., \& Zuckerman, D. (1992). Big world, small screen: The role of television in American society. Lincoln: University of Nebraska Press.

Iwanaga, M., Ikeda, M., \& Iwaki, T. (1996). The effects of repetitive exposure to music on subjective and physiological responses. Journal of Music Therapy, 33(3), 219230.

Iwanaga, M., \& Moroki, Y. (1999). Subjective and physiological responses to 
music stimuli controlled over activity and preference. Journal of Music Therapy, 36(1), 26-38.

Johnson, J. D., Adams, M. S., Ashburn, L., \& Reed, W. (1995). Differential gender effects of exposure to rap music on African American adolescents' acceptance of teen dating violence. Sex Roles, 33(7-8), 597-605.

Johnson, J. D., Jackson, L. A., \& Gatto, L. (1995). Violent attitudes and deferred academic aspirations: Deleterious effects of exposure to rap music. Basic and applied Social Psychology, 16(1-2), 27-41.

Josephson, W. (1987). Television violence and children's aggression: Testing the priming, social script, and disinhibition predictions. Journal of Personality and Social Psychology, 53, 882-890.

Kahler, C. W., Strong, D. R., Niaura, R., \& Brown, R. A. (2004). Hostility in smokers with past major depressive disorder: Relation to smoking patterns, reasons for quitting, and cessation outcomes. Nicotine \& Tobacco Research, 6(5), 809-818.

Krumhansl, C. L. (1997). An exploratory study of musical emotions and psychophysiology. Canadian Journal of Experimental Psychology, 51(4), 336-352.

Landreth, J. E., \& Landreth, H. F. (1974). Effects of music on physiological responses. Journal of Research in Music Education, 22(1), 4-12.

Litman, C. S. (1997). Effects of rap music on verbal and nonverbal aggressive and disruptive behavior in boys' social interactions. Dissertation Abstracts International: Section B: The Sciences and Engineering, 57(10-B), 6741.

Marler, M. R., Jacob, R. G., Lehoczky, J. P., \& Shapiro, A. P. (1988). The statistical analysis of 
treatment effects in 24-hour ambulatory blood pressure recordings. Statistics in Medicine, 7, 697-716.

Mediascope. (1996). National television violence study: Executive summary 19941995. Studio City, CA: Author.

Molitor, F., \& Hirsch, K. W. (1994). Children's toleration of real-life aggression after exposure to media violence: a replication of the Drabman and Thomas studies. Child Study Journal, 24(3), 191-207.

O’Connor, D. B., Arhcer, J., \& Wu, F. W. C. (2001). Measuring Aggression: Self-reports, partner reports, and responses to provoking scenarios. Aggressive Behavior, 27, 79-101.

Pansepp, J. (1995). The emotional source of "chills" induced by music. Music Perception, 13, 171-207.

Rentfrow, P. J., \& Gosling, S. D. (2003). The Do Re Mi's of everyday life: The structure and personality correlates of music preferences. Journal of Personality and Social Psychology, 84(6), 1-27.

Rubin, A. M., West, D. V.., \& Mitchell, W. W. (2001). Differences in aggression, attitudes toward women, and distrust as reflected in popular music preferences. Media Psychology, 3(1), 25-42.

Rustad, R. A., Small, J. E., \& Jobes, D. A. (2003). The impact of rock videos and music with suicidal content on thoughts and attitudes about suicide. Suicide \& Life Threatening Behavior, 33(2), 120-131.

Silvern, S. B., \& Williamson, P. A. (1987). The effects of video game play on 
young children's aggression, fantasy, and pro-social behavior. Journal of Applied Developmental Psychology, 8, 453-462.

Sloboda, J. A. (1991). Musical structure and emotional response: Some empirical findings. Psychology of Music, 19, 110-120.

Smith, B. A. (1995). The effects of exposure to violent lyric music and consumption of alcohol on aggressiveness. Dissertation Abstracts International: Section B: The Science and Engineering, 56(6-B), 3487.

Sousou, S. D. (1997). Effects of melody and lyrics on mood and memory. Perceptual \& Motor Skills, 85(1), 31-40.

Spielberger, C. D. (1999). State-trait anger expression inventory-2. Odessa: Psychological Assessment Resources.

St. Lawrence, J. S. (1991). The effects of sexually violent rock music on males' acceptance of violence against women. Psychology of Women Quarterly, 15(1), 49-63.

Strasburger, V. C. (1995). Adolescents and the media: Medical and psychological impact. Developmental Clinical Psychology and Psychiatry, 33, 130-135.

Stratton, V. N., \& Zalanowski, A. H. (1994). Affective impact of music vs. lyrics. Empirical Studies of the Arts, 12(2), 173-184.

Strouse, J. S., Buerkel-Rothfuss, N., \& Long, E. C. J. (1995). Gender and family as moderators of the relationship between music video exposure and adolescent sexual permissiveness. Adolescence, 30, 505-521.

Toohey, J. V. (1982). Popular music and social values. Journal of School Health, 52(10), 582-585.

Took, K. J., \& Weiss, D. S. (1994). The relationship between heavy metal and rap 
music and adolescent turmoil: Real or abstract? Adolescence, 29(115), 613-623.

Vanderark, S. D. \& Ely, D. (1994). University biology and music majors’ emotional ratings of musical stimuli and their physiological correlates of heart rate, finger temperature, and blood pressure. Perceptual \& Motor Skills, 79 (3, Pt. 1), 1391-1397.

Van Goozen, S. H. M., Frijda, N. H., Kindt, M., van de Poll, N. E. (1994). Anger proneness in women: Development and validation of the anger situation questionnaire. Aggressive Behavior, 20, 79-100.

Vogt, W. P. (2007). Quantitative research methods for professionals. Boston, MA: Allyn and Bacon.

Waite, B. M., Hillbrand, M., \& Foster, H. G. (1992). Reduction of aggressive behavior after removal of Music Television. Hospital and Community Psychiatry, 43(2), $173-175$.

Watson, D., Clark, L. A., \& Tellegen, A. (1988). The Positive and Negative Affect Schedule. Journal of Personality and Social Psychology, 54(6), 1063-1070.

Wester, S. R., Crown, C. L., Quatman, G. L., \& Heesacker, M. (1997). The influence of sexually violent rap music on attitudes of men with little prior exposure. Psychology of Women Quarterly, 21(4), 497-508.

Worchel, S., Cooper, J., Goethals, G. R., \& Olson, J. M. (2000). Social psychology. Belmont, CA: Wadsworth/Thomson Learning.

Zimny, G. H., \& Weidenfeller, E. W. (1963). Effects of music upon GSR and 
heart-rate. American Journal of Psychology, 76(2), 311-314. 
Appendices 
Appendix A

Recruitment Flyer 


\section{Psychological Research Project}

If you are an undergraduate male currently enrolled in Introduction to Psychology and at least 18 years of age, I would like to invite you to participate in my doctoral dissertation study. The purpose of the study is to investigate college males' reactions to cognitive tasks.

The study will only require an hour of your time and will take place in the graduate student lab on the $2^{\text {nd }}$ floor of the Life Sciences Building.

You will receive extra credit points for your participation.

Note: You will be asked to 1) not smoke an hour before coming into the lab, 2) not consume caffeine for 5-6 hours before coming into the lab, 3) not drink alcohol for 5-6 hours before coming into the lab, 4) not exercise an hour before coming into the lab, and to 5) not take any overthe-counter medication prior to coming to the lab. If any of the above will be a problem for you, it is recommended that you not participate in this study. In addition, if you are currently taking prescribed medications, you will be ineligible for participation in the study.

If you are interested, please, contact me at the number provided below for further information and to sign up.

Thank you for your help!

Kristee H. Treadwell, M.S.

Doctoral Candidate in Counseling Psychology

West Virginia University

(304) 292-5747 
Appendix B

Informed Consent 


\section{CONSENT and INFORMATION FORM}

\section{STUDY OF REACTIONS TO COGNITIVE TASKS}

Introduction. I, , have been invited to participate in the current research study, which has been explained to me by Kristee H. Treadwell, M.S or her research assistant. I understand that Kristee $\mathrm{H}$. Treadwell is conducting the study in an effort to fulfill requirements for her doctoral dissertation and that Margaret K. Glenn, Ed.D. will be supervising the research project.

Purposes of the Study. The purpose of the study is to explore and understand undergraduate college males' individual reactions to cognitive tasks.

Description of Procedures. I understand that a minimum of 60 participants will be involved in the current study and that the experimental session will be no more than an hour in length. I have been told that I can see a copy of each questionnaire prior to giving consent if so desired and that I do not have to answer all the questions if I decide to participate. I also understand that the study session will be videotaped. In addition, I am aware that I will be asked to do the following as part of my participation in the current study: I will be required to initially complete 4 questionnaires. Next, I will have my heart rate and blood pressure measured twice via three silver-silver chloride disposable electrodes that will be placed on my upper shoulder and lower abdomen and via a blood pressure cuff respectively. In addition, I will be asked to listen to music, to complete cognitive tasks requiring me to count backwards and to respond to related questionnaires pertaining to my thoughts and feelings. I will then be debriefed during which time I will be given the opportunity to ask and have questions answered that I may have regarding my participation in the study. I will then be dismissed.

Risks and Discomforts. I understand that it is possible that I may experience some discomfort related to completion of questionnaires, music exposure and/or to having my heart rate and blood pressure measured during my participation in the study. However, I am aware that if I do experience such discomfort that the degree of discomfort is likely to be minimal. I am also aware that referral resources will be available, if needed, to assist in any psychological discomfort that may be experienced as a result of participation in the study. In addition, I understand that I may discontinue the study during this time or at any time without any penalty for doing so.

Version date March 8, $2005 \quad$ Page 1 of 3

$\overline{\text { Initials }} \quad$ Date 


\section{STUDY OF REACTIONS TO COGNITIVE TASKS}

Alternatives. I understand that I will receive extra credit points in Introduction to Psychology for participating in the study. I also understand that there are other opportunities available for earning the same extra credit. I understand that I am not required to participate in the study and that I can stop participation at any time during the process. I understand that should I decide to withdraw from the study at any time related to the experience of discomfort that I will still earn extra credit points.

Benefits. I understand that I will receive extra credit points in Introduction to Psychology for my participation in the current study. However, I also understand that while the study itself is not designed to benefit me directly others may serve to benefit from what is learned from the findings of the study.

Contact Persons. For more information about the study, I understand that I can contact Kristee H. Treadwell, M.S. or Margaret K. Glenn, Ed.D. at (304) 293-3807. For more information regarding my rights as a research participant, I am aware that I may contact the Executive Secretary of the Institutional Review Board at (304) 293-7073.

Confidentiality. I understand that any information that is obtained as part of my participation in the current study will be kept as confidential as legally possible. I also understand that videotapes of study sessions will be kept in a locked filing cabinet in the graduate student lab located on the $2^{\text {nd }}$ floor of the Life Sciences Building on the downtown campus of West Virginia University until the videotapes are coded. Once the videotapes are coded, they will be erased. I am also aware that my research records, like my hospital records, may be subpoenaed by court order or may be inspected by the sponsor, federal regulatory authorities, or the IRB without my additional consent. In addition, I understand that in any publications or presentations that may follow from this research, neither my name nor any other identifying information will be published or presented without my consent.

Voluntary Participation. Participation in this study is strictly voluntary. I understand that I am in no way required to participate in the study and that I may withdraw at any time if I choose to do so. I am also aware that there will be no penalty or loss of benefit for me should I decide to refuse to participate or withdraw from the study. I have been given the opportunity to ask questions about the research, and I have received answers concerning areas I did not understand.

Version date March 8, 2005

Page 2 of 3

$\overline{\text { Initials }} \quad \overline{\text { Date }}$ 


\section{STUDY OF REACTIONS TO COGNITIVE TASKS}

In addition, in the event new information becomes available that may affect my willingness to participate in this study, this information will be given to me so that I can make an informed decision whether or not to continue my participation.

Upon signing this form, I will receive a copy.

I willingly consent to participate in this research study.

Signature of Participant

$\overline{\text { Signature of Investigator or Investigator's Representative }} \overline{\text { Date }}$
Date

$$
\text { Date }
$$

Time

Time
Initials
Date 
Appendix C

Demographics Questionnaire 


\section{Demographics Questionnaire}

Please note that all responses to this questionnaire and other questionnaires that are part of the current study will remain anonymous and confidential. No efforts will be made to determine the identity of participants completing this and other questionnaires.

1) Age (Please, check):

$18-19$
$20-22$
$23-25$
$26-30$
$30+$

2) Ethnicity: (Please, check) White/Caucasian Black/African

American Asian American/

Pacific Islander Native American/ American Indian Hispanic/Latino Other (specify):

3) Major:

4) a) How many hours do you generally listen to music each day? (Please, check) less than 1

\begin{tabular}{l}
$-1-3$ \\
$-\quad 4-6$ \\
$-7-9$ \\
$-10-12$ \\
\hline
\end{tabular}

b) If you listen to 0 hours of music each day, please check here.

5) *What type of music do you prefer to listen to (i.e., what is your favorite type of music?)? Please check only 1.

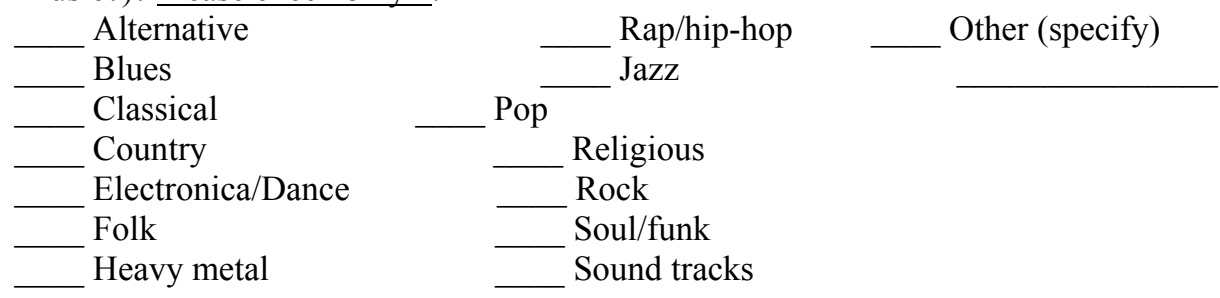

*Music preferences are based on the Short Test of Music Preferences (STOMP; Rentfrow \& Gosling, 2003).

6) Did you listen to music prior to coming to the lab for this session?(Please, check) Yes No

If yes, a) what type of music (see above) and b) what specific song did you listen to prior to coming to the lab?

7) Did anyone tell you about their experiences in participating in the current study?

$$
\text { Yes }
$$
No

If you indicate yes, please explain: 


\section{Appendix D}

State-Trait Anger Expression Inventory-2 


\section{Appendix E}

Positive and Negative Affect Schedule 
Appendix F

Cook-Medley Hostility Scale 
Appendix G

Aggressive Provocation Questionnaire (Modified) 


\section{Appendix $\mathrm{H}$}

Debriefing Questionnaire 


\section{Debriefing Questionnaire}

1) Have you heard the music that you were exposed to before?

Yes

If yes, please, explain.

2) Please, rate how well you could understand the lyrics of the music using the following scale: (Please, circle)

very slightly

1 a little

2 moderately

3 quite a bit

4 perfectly 5 
Appendix I

Summary Tables for Physiological Analyses 
Table I1

Summary Table for MANOVA of Cardiovascular Measures

\begin{tabular}{lcccc}
\hline Source & WL & $\mathrm{df}$ & $\underline{\mathrm{F}}$ & $\underline{\mathrm{p}}$ \\
\hline Group & & & & \\
Phase & .86 & 6,122 & 1.59 & .16 \\
Group x Phase & .19 & 6,58 & 41.90 & $.00^{* *}$ \\
& .63 & 12,116 & 2.47 & $.01^{*}$ \\
\hline
\end{tabular}

$* p<.05, * * p<.01$ 
Table I2

Summary Tables for Analyses of Systolic Blood Pressure (SBP)

\begin{tabular}{llllll}
\hline Source & SS & df & MS & F & $p$
\end{tabular}

\section{ANOVA of SBP}

Group

Error Term

Phase

Group x Phase

Error Term

$\begin{array}{rr}378.17 & 2 \\ 17530.05 & 64 \\ 8250.97 & 1.4\end{array}$

$427.49 \quad 2.8$

$4653.35 \quad 90.3$
189.09

273.91

5847.34

151.48

51.53 p

ANOVA of Baseline SBP

Group

$\begin{array}{rrrr}156.18 & 2 & 78.09 & .82 \\ 6119.15 & 64 & 95.61 & \\ 28515.33 & 67 & & \end{array}$

31.43

.29

.75

Error Term

$62.86 \quad 2$

108.47

113.48

2.94

$.000 * *$

$.04 *$

Total

$960319.00 \quad 67$

ANOVA of Mental Task SBP

\begin{tabular}{lrr}
\hline Group & 586.63 & 2 \\
Error Term & 9122.49 & 64 \\
Total & 1175401.75 & 67
\end{tabular}

ANOVA of SBP for Violent Music Condition

\begin{tabular}{lccccc}
\hline Phase & 1601.50 & 1.3 & 1204.32 & 25.89 & $.000 * *$ \\
Error Term & 1237.24 & 26.6 & 46.5 & &
\end{tabular}

ANOVA of SBP for Non-Violent Music Condition

\begin{tabular}{lrrrrr}
\hline Phase & 3652.63 & 2 & 1826.32 & 40.71 & $.000 * *$ \\
Error Term & 2153.55 & 48 & 44.87 & &
\end{tabular}

ANOVA of SBP for No Music (Control) Condition

\begin{tabular}{lrrrrr}
\hline Phase & 3563.02 & 2 & 1781.51 & 56.44 & $.000^{* *}$ \\
Error Term & 1262.55 & 40 & 31.56 & &
\end{tabular}

$* p<.05, * * p<.001$ 
Table I3

Summary Tables for Analyses of Diastolic Blood Pressure (DBP)

\begin{tabular}{|c|c|c|c|c|c|}
\hline Source & SS & $\mathrm{f}$ & MS & $\underline{F}$ & $\mathrm{p}$ \\
\hline \multicolumn{6}{|l|}{$\underline{\text { ANCOVA of DBP }}$} \\
\hline Covariate & 8219.37 & 1 & 8219.37 & 89.69 & $.000 * *$ \\
\hline Group & 2.34 & 2 & 1.17 & .01 & .99 \\
\hline Error term & 5773.75 & 63 & 91.65 & & \\
\hline Phase & 212.74 & 1 & 212.74 & 4.71 & $.03 *$ \\
\hline Phase $\mathrm{x}$ Covariate & 36.72 & 1 & 36.72 & .81 & .37 \\
\hline Group x Phase & 280.87 & 2 & 140.44 & 3.11 & .051 \\
\hline Error Term & 2843.61 & 63 & 45.14 & & \\
\hline \multicolumn{6}{|c|}{ ANCOVA of DBP for Violent Music Condition } \\
\hline Phase & 34.07 & 1 & 34.07 & .52 & .48 \\
\hline Error Term & 1256.56 & 19 & 66.14 & & \\
\hline \multicolumn{6}{|c|}{ ANCOVA of DBP for Non-Violent Music Condition } \\
\hline Phase & .90 & 2 & .90 & .04 & .85 \\
\hline Error Term & 583.21 & 23 & 25.36 & & \\
\hline \multicolumn{6}{|c|}{ ANCOVA of DBP for No Music (Control) Condition } \\
\hline Phase & 344.44 & 1 & 344.44 & 7.17 & $.02 *$ \\
\hline Error Term & 913.44 & 19 & 48.06 & & \\
\hline
\end{tabular}

${ }^{*} p<.05,{ }^{* *} p<.001$ 
Table I4

Summary Tables for Analyses of Heart Rate (HR)

Source

SS df

MS

$\underline{F}$

p

ANOVA of HR

Group

Error Term

Phase

340.55
17153.81

170.27

.63

.54

Group x Phase

$4445.99 \quad 1.25$

$273.54 \quad 2.50$

272.28

3564.30

89.89

$109.65 \quad 2.77$

$.000 *$

Error Term

$3115.91 \quad 78.6$

39.65

ANOVA of Baseline HR

Group

$29.84 \quad 2$

14.92

.16

.86

Error Term

$6110.62 \quad 64$

95.48

Total

$339970.22 \quad 67$

ANOVA of Music Condition HR

Group

Error Term

Total

$17.16 \quad 2$

$5529.75 \quad 64$

$353235.00 \quad 67$

ANOVA of Mental Task HR

Group

Error Term

Total

$557.08 \quad 2$

$8714.77 \quad 63$

$444947.89 \quad 66$

ANOVA of HR for Violent Music Condition

Phase

Error Term

663.24

351.82

2

40

ANOVA of HR for Non-Violent Music Condition

Phase $1845.82 \quad 1.3$

Error Term

$826.43 \quad 29.3$

ANOVA of HR for No Music (Control) Condition

\begin{tabular}{lrr}
\hline Phase & 2254.55 & 1.1 \\
Error Term & 1937.67 & 21.5
\end{tabular}

$$
8.58
$$

.10

86.40

$278.54 \quad 2.01$

.14

138.33

331.62

37.70

$.000 *$

8.80

$1449.67 \quad 51.37$

$.000 *$

$* p<.001$ 